\title{
AN INVESTIGATION OF PRELIMINARY ENGINEERING FUNDING VARIABILITY AND A MODEL TO FORECAST PROJECT LEVEL PRELIMINARY ENGINEERING EXPENDITURES
}

\section{TABLE OF CONTENTS}

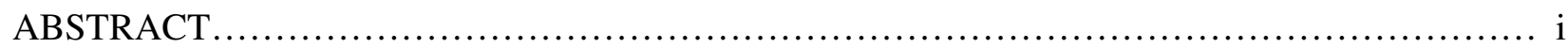

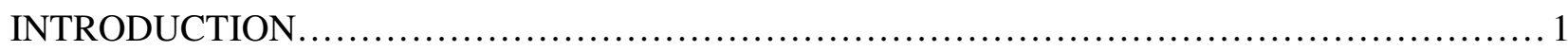

Program Level Versus Project Level Analyses.......................................

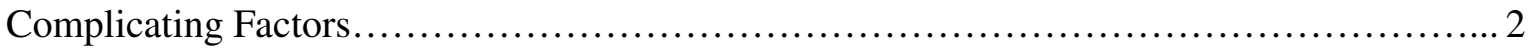

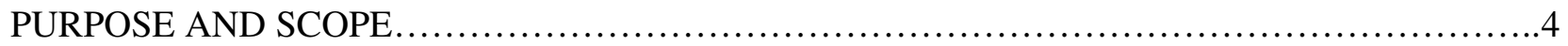

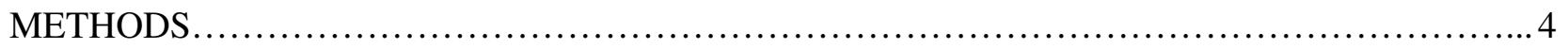

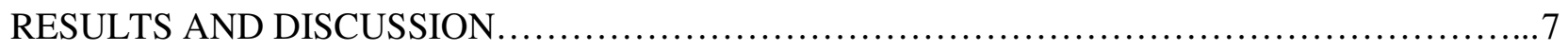

PART 1: Definition of Preliminary Engineering..................................... 7

Definition of Preliminary Engineering Based on the Literature $\ldots \ldots \ldots \ldots \ldots \ldots \ldots \ldots . .7$

Definition of Preliminary Engineering Based on VDOT District Interviews........... 11

PART 2: Availability and VDOT Staff Review of PE Data............................. 14

Availability and Quality of PE Financial Information............................ 15

Availability and Quality of Project Characteristic Information...................... 21

Staff Review of Project Level and Program Level PE Expenditures.................. 21

PART 3: A Model to Forecast PE Costs at the Project Level................................24

Literature Review of Methods for Forecasting PE Costs at the Project Level...........24

Identification of Candidate Project Characteristics................................ 28

Establishment of Training and Testing Data Sets................................ 31

Investigation of Models Based on Construction Cost Alone.......................... 32

Development of Models with Additional Variables............................... 34

Verification of Assumptions............................................... 43

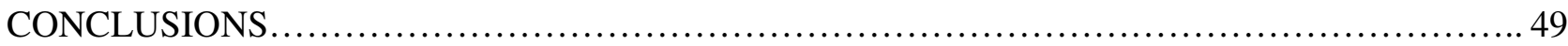

RECOMMENDATIONS .............................................................5

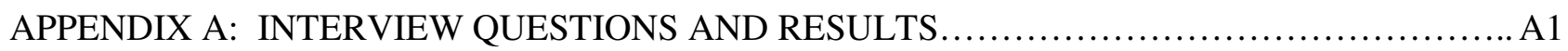

APPENDIX B: DETAILS OF THE DATA COLLECTION METHODOLOGY ...................... 


\begin{abstract}
For the Virginia Department of Transportation (VDOT), preliminary engineering (PE) includes most activities that occur prior to construction such as scoping, detailed design, environmental review, and advertisement. Because this definition is broader than that used by other organizations, their methodologies for forecasting PE costs are not necessarily transferrable to Virginia. This project takes a deeper look at VDOT project development and outlines the definition of PE, addresses availability issues locating PE expenditure data and develops a model to better forecast the PE cost of a construction project.

Currently, VDOT forecasts PE costs based solely on the construction estimate, and the percentage of total project costs devoted to PE is inversely proportional to this estimate. Accordingly, forecasting PE costs for smaller projects, i.e., under \$5 million, merits attention.

Based on 124 projects reviewed by the researchers and DOT experts, this research develops an approach for forecasting PE costs as a function of statistically significant characteristics typically known at the project's inception: length, duration, level of required environmental review, locally administered status and Right-Of-Way (RW). Twenty-seven projects were used to test the model and the new approach reduced the mean absolute error from about $\$ 200,000$ to $\$ 110,000$. This error reduction was evaluated as statistically significant $(\mathrm{p}=$ 0.02). Additionally, compared to the original approach, the new approach nominally reduced the mean percentage error from $135 \%$ to $47 \%$. Although an immediate benefit is more accurate PE forecasts, these results also demonstrate the importance of providing forecasts as a range based on a statistical or empirical confidence interval rather than solely as a point estimate.
\end{abstract}




\section{INTRODUCTION}

Preliminary engineering (PE) is loosely described as detailed physical planning and design conducted during project development, after which a project's scope, cost estimate, and financial plan should not be changed (Smith, 2009; FTA, 2007). In Virginia, PE is also a phase in the project development process that is differentiated from the right of way (RW) and construction $(\mathrm{CN})$ phases in terms of expenditures.

This research topic originated in the VDOT Transportation Planning Research Advisory Committee (TPRAC), where one asked, is VDOT spending too much or too little on PE? Although this question initiated the study, it quickly became clear that the question wasn't if VDOT was spending too much or too little, but rather what exactly is VDOT spending on PE and is anyone reviewing this data?

In an effort to break up this task, this thesis is divided into three parts (1) Definition of Preliminary Engineering (2) Availability of PE data and VDOT Review and (3) A Model to Forecast PE Expenditures at the Project Level. Part 1 examines the variability in PE expenditures at both the program (Transportation Planning Research Advisory Committee [TPRAC], 2011) and project level (A. Hammadi, personal communication, September 25, 2012), two very different scopes. Part 2 addresses the availability of the PE expenditure data and various limitations that arise using multiple sources. Part 3 uses the data collected in both Part 1 and Part 2 to develop a model using project characteristics to better estimate the $\mathrm{PE}$ cost of a $\mathrm{CN}$ project.

Further analysis of Virginia's PE compared to other states is evaluated in the full VDOT report "Determinants of Preliminary Engineering Funding Variability," however will not be discussed in this thesis.

\section{Program Level Versus Project Level Analyses}

At the program level, for Virginia's Six Year Improvement Program (SYIP), the allocation of PE funds in a given fiscal year to a particular set of projects serves two conflicting goals: (1) ensure sufficient funds are spent on PE in the current year in order to prepare enough projects for $\mathrm{CN}$ spending in future years; yet (2) constrain total spending on PE in the current year in order to ensure that enough money is spent on $\mathrm{CN}$ in current year. For example, in one recent year, more than half of SYIP dollars for one construction district was spent on PE and right of way, leaving less than half of the funds available for construction. Based on that anecdote, a concern is whether the second goal, ensure adequate funds are placed in $\mathrm{CN}$, is met.

Literature discussing the relative amounts of funds that should be, or are, spent on PE at the program level was not found, apart from two exceptions,. One exception was Virginia, which discusses the funds that should be programmed: the VDOT 2013-2014 Business Plan (2011) identifies a goal of programming between $10 \%$ and $15 \%$ of the annual construction program for new PE work annually. The other exception was in North Carolina which highlights funds that are programmed: Liu et al. (2011) report that the State Auditor (Merritt, 2008) reviewed PE, $\mathrm{RW}$, and CN expenditures for 292 NCDOT highway projects constructed between April 1, 2004 and March 31, 2007. With PE, RW, and CN expenditures of $\$ 117, \$ 149$, and $\$ 1,020 \mathrm{M}$ for these projects, PE accounted for approximately $9 \%$ of total project costs.

At the project level, staff from one VDOT construction district suggested that the forecast of PE costs helps balance two goals: (1) making each aspect of the project (e.g., drainage, 
structures) as good as it can be yet (2) completing the design as quickly and as cheaply as possible. VDOT staff currently use the Project Cost Estimation Tool (PCES) to forecast the PE costs relative to construction. Construction costs do not explain all the variation in PE costs, therefore an individual estimating costs must use their experience to adjust the PE estimate (Holley, personal communication, November 30, 2012). For such a project-level analysis, district staff questioned how various project characteristics, such as wetland mitigation required, project delivery method, type of drainage, and other factors influence overall PE costs. An answer to this question can help project managers develop a better forecast of what PE costs should be expected for a given project, and may help such managers strike the aforementioned balance between achieving the best design and achieving a relatively quick and/or inexpensive design. (A potential ancillary benefit is that other stakeholders, such as localities or advocacy groups, who wish to influence the planning or project development processes may better understand the project development cycle.)

While both the program level and project level analyses entail an assessment of PE expenditures, the audience for each type of analysis differs. At the program level, the audience ultimately reflects those charged with making investment decisions, such as MPO or VDOT staff supporting decision makers who decide the emphasis of a transportation program. Accordingly, these staff are interested in allocations - that is, allotments of funds to future projects. At the project level, the audience is likely project managers, who are charged with delivering specific projects from inception to construction. Accordingly, these staff are interested in forecasting expenditures - that is, the monies spent on specific projects.

\section{Complicating Factors}

There are at least five potential complicating factors for assessing PE percentages.

- The term "preliminary engineering" may not necessarily be defined in the same manner for all projects. Differences in the definition result because of different perspectives on project management and the diverse nature of construction projects. For example, the ability to reliably forecast the cost estimate for buried utility relocation should differ depending on whether the project is a major highway investment (which will require substantial earthwork), an ITS investment (which may require some foundation work), and a transit investment (which, if it focused on rolling stock only, could arguably not require any foundation work unless the surface needed to be strengthened to accommodate heavy vehicles.)

- The categorizations of costs may not be uniform throughout agency databases. For example, there are a variety of ways in which PE costs can be handled depending on whether the project is classified as maintenance or construction. Because there are some projects for which the distinction between maintenance and construction may not always be clear (e.g., a bridge deck reconstruction), the cost categorizations may affect some types of projects more than others. Hammadi (2012) notes in particular that delays can cause the PE portion of total costs to be higher than otherwise would be the case for three reasons: (1) geometric design standards change during the intervening years 
(necessitating a more expensive design); (2) the project scope changes such that PE must be performed anew for what is really a fundamentally different project but with the same UPC; or (3) extensive studies such as interchange justification reports or other environmental documents may be required and thus increase the cost. Further, PE and right of way need to be analyzed separately as different factors may drive each of these sets of expenditures.

- Programming practices evolve in response to specific conditions. For example, for the period 2009 through 2011, a drop in revenues and an emphasis on "shovel-ready" projects led to a focus on funding those projects that are underway or scheduled to be soon underway in order to ensure that all federal funds are obligated, including those based on 2009 American Recovery and Reinvestment Act (ARRA) funds (also known as "stimulus" projects). As another example, Saunders (2012) notes that more than $70 \%$ of projects that are advertised do not have any PE funding, thus, a substantial portion of PErelated labor expenditures are placed under an administrative category rather than an explicit PE funding category.

- Programming practices vary by region. In Northern Virginia, for many years more than half of SYIP dollars have been spent on RW because RW (in urban areas) is quite expensive. Further, any comparisons of Virginia practices to those of other states may not be useful unless either (1) the other states have transportation responsibilities comparable to Virginia or (2) the data are controlled such that comparable projects are compared. Virginia also has some specific requirements: for example, Cherry, Bekaert \& Holland (2010) note that FHWA approval is required before each phase can be initiated, and that VDOT has a policy of not authorizing PE for a project until funding for the $\mathrm{CN}$ phase was available.

- Long, multi-year horizons are associated with construction projects. As an illustration, the FY 2012 Hampton Roads SYIP contained 303 UPCs for which expenditure data were available. Table 1 indicates whether monies were spent on the same UPCs for previous fiscal years. For example, 248 of these UPCs had some type of expenditure in FY 2011 and 39 had some type of expenditure as early as 2000 . 
Table 1. Previous Years' Expenditures for the Projects from the FY 2012 SYIP for Hampton Roads

\begin{tabular}{|c|c|c|}
\hline Fiscal Year & Total Amount & No. of projects with expenditures $>\$ 0$ \\
\hline 2011 & $\$ 206,003,948$ & 248 \\
\hline 2010 & $\$ 127,405,950$ & 164 \\
\hline 2009 & $\$ 101,014,170$ & 127 \\
\hline 2008 & $\$ 90,626,126$ & 106 \\
\hline 2007 & $\$ 52,676,949$ & 89 \\
\hline 2006 & $\$ 29,745,949$ & 71 \\
\hline 2005 & $\$ 29,830,681$ & 56 \\
\hline 2000 & $\$ 13,071,368$ & 39 \\
\hline 1995 & $\$ 888,258$ & 14 \\
\hline 1990 & $\$ 361,906$ & 4 \\
\hline 1985 & $\$ 4,317$ & 1 \\
\hline 1981 & $\$ 720$ & 1 \\
\hline
\end{tabular}

Because of these complications, prior to analyzing the determinants of variability in PE expenditures, this research sought to define preliminary engineering as used in VDOT construction districts and to determine the extent to which expenditure and project characteristic data are available.

\section{PURPOSE AND SCOPE}

The purpose of this research effort is to analyze the variability in PE at the program level and at the project level within the constraints of available data. The scope of this research is defined as answering these three questions:

- What is preliminary engineering, both in the literature and as practiced by VDOT?

- Are the data available to determine the percentage of funds spent on PE by district or project, and are these data reviewed by VDOT staff?

- At the project level, which characteristics have a statistically significant impact on PE costs?

\section{METHODS}

Three tasks guided this research effort.

1. Define preliminary engineering based on a review of the literature and interviews with VDOT districts.

A literature search was conducted using the Transportation Research and Development (TRID) database as well as the Google Internet search engine using keywords such as 
"preliminary engineering." Three types of literature were sought: descriptions of the activities that are included in preliminary engineering, reports citing the percentage of funds spent on preliminary engineering at the program level, and quantitative approaches for forecasting PE expenditures at the project level. Additionally, project managers and/or planning and investment managers were interviewed from the nine VDOT construction districts and the Central Office as shown in Table 2. Interviewees were visited in person (with one exception, by both Dr. John Miller and Bethany Turner or two instances by just Dr. John Miller). Following the interview, interviewees were given an opportunity to make changes to the authors' notes from the interview. The data collected in the interviews (Appendix A) is also used in the VDOT Report "Determinants of Preliminary Engineering Funding Variability."

Table 2. Interview Schedule ${ }^{\text {ab }}$

\begin{tabular}{|c|c|c|c|}
\hline $\begin{array}{l}\text { Interview } \\
\text { No. }\end{array}$ & District & Staff (expertise represented) & $\begin{array}{l}\text { Interview } \\
\text { Date }\end{array}$ \\
\hline I1 & Fredericksburg & $\begin{array}{l}\text { Abdul Hammadi (PM), Kevin Northridge (PM), and Jason } \\
\text { Williams (PM) }\end{array}$ & Sept. 25, 2012 \\
\hline $\mathrm{I} 2$ & Bristol & Chase Buchanan (PM) [conducted by telephone] & Nov. 2, 2012 \\
\hline $\mathrm{I} 3$ & Culpeper & $\begin{array}{l}\text { John Giometti (PM), Brent Sprinkel (PIM), and Wendy Thomas } \\
\text { (PIM) }\end{array}$ & January 4, 2013 \\
\hline I4 & Salem & $\begin{array}{l}\text { Tommy DiGiulian (PIM), Jane-Ellen Hess (PM), and Alex Price } \\
\text { (PM) }\end{array}$ & $\begin{array}{l}\text { January 28, } \\
2013\end{array}$ \\
\hline I5 & Central Office & $\begin{array}{l}\text { Bob Carver (Fiscal Division), Margit Ray (Programming } \\
\text { Division), and Rob Walters (Programming Division) }\end{array}$ & $\begin{array}{l}\text { January 30, } \\
2013\end{array}$ \\
\hline I6 & Lynchburg & $\begin{array}{l}\text { Jay Brown (Programming Division), Brian Casto (PM), Jeff } \\
\text { Kessler (Area Land Use Engineer), Randy Hamilton (ACE), and } \\
\text { Zack Weddle (ACE) }\end{array}$ & March 5, 2013 \\
\hline I7 & $\begin{array}{l}\text { Hampton } \\
\text { Roads }\end{array}$ & Bruce Duvall (PM) and Steve Rowan (PIM) & March 29, 2013 \\
\hline I8 & Staunton & $\begin{array}{l}\text { Mike Fulcher (PIM), Matt Dana (PM), and Terry Short (district } \\
\text { planner) }\end{array}$ & May 9, 2013 \\
\hline I9 & $\begin{array}{l}\text { Northern } \\
\text { Virginia }\end{array}$ & $\begin{array}{l}\text { Dic Burke (PM), Claudia Llana (PM), Bud Siegel (PM), Kanti } \\
\text { Srikanth (PIM), and Jim Zeller (PM) }\end{array}$ & June 17,2013 \\
\hline $\mathrm{I} 10$ & Richmond & Rob Crandol, Sam Hayes (PM), Mark Riblett (PIM) & May 29, 2013 \\
\hline
\end{tabular}

${ }^{a}$ Key: $\mathrm{ACE}=$ Area Construction Engineer, PIM = Planning and Investment Manager, PM = Project Manager

${ }^{\mathbf{b}}$ To understand details in the variability of Preliminary Engineering, interviews were conducted with all 9 VDOT Districts and the Central Office. Throughout this report there are notations in parenthesis such as "(I1)," "(I2)," etc. These notations signify the interview from which the information being discussed was taken.

Several questions from the interviews concerned the VDOT Project Development Process, such as tasks included within PE, the extent to which a project's design changes throughout the PE process, examples of projects that illustrate the role of PE, and how to obtain project information. The initial district interview with Fredericksburg also served to clarify which interview questions were most critical; following that interview, revisions were made and then the same questions, with one exception, were posed in the remaining district interviews. The questions asked during the interviews are shown on page A-2 of Appendix A. 
2. Determine the types of PE expenditure data that are available.

Using the publicly available SYIPs for the period 2004-2012, every UPC within each of the nine VDOT districts was identified. Then, the amount of funds spent for each project on PE, $\mathrm{RW}$, and CN by district and fiscal year was obtained from VDOT Fiscal staff. VDOT district staff were also asked whether certain projects should be excluded from the analysis due to anomalies associated with these projects. (Generally, such anomalies referred to projects that are enhancement, district-wide, study-only, ARRA-funded, or are maintenance/operations projects which are nonetheless funded with construction allocations.). The complete methodology for acquiring these expenditure data is given in Appendix B.

To better interpret these expenditure data, the second half of the VDOT district interview questions addressed how PE expenditure data were tracked. Questions included the availability of expenditure data at the district level, the extent to which district staff monitor these data at the program and project level, and limitations of the data set. These interview questions are also shown on page A-2 of Appendix A. One suggestion that resulted from the interviews was that the authors should consult with VDOT Central Office staff regarding the identification of projects for which financial information is unlikely to change (meaning the project is essentially finished or terminated) versus those projects that may represent ongoing work. Thus an interview was conducted with VDOT Central Office Programming Division and Fiscal Division staff concerning the identification of those projects. The interview also gave an opportunity to learn caveats that Central Office staff recommended be considered when analyzing such data, such as the possibility that a few large projects could skew the analysis, the possibility that estimates of expenditures can later be revised to equal actual expenditures, the length of the project development cycle, and the impact of unexpected changes in forecasted future revenues.

3. At the project level, develop an approach for forecasting PE expenditures as a function of project characteristics identifiable at the time of project inception.

Following a review of the literature of model development in other states, different types of construction projects were identified by district interviewees to explore. An examination of project characteristics recommended by the same interviewees, a sample of 156 projects were identified. These projects had a forecasted PE expenditure, a forecasted $\mathrm{CN}$ expenditure, and an actual PE expenditure. Of the 156 projects 124 were under \$5 million; these smaller projects were then split into a set of training data (97 projects) that were used to develop models and a set of testing data (27 projects) that were used to evaluate model performance. Seven models were identified: the existing model for forecasting PE costs used in Virginia's Project Cost Estimating System (PCES), a second model that had the same functional form as the first but which was recalibrated with the new training data, and five alternative models based on additional project characteristics besides the construction estimate.

The seven new models were evaluated with respect to five criteria: their ability to explain variation in the PE costs in the training data set (e.g., the adjusted $\mathrm{R}^{2}$ ), validation of the model to explain variation in the PE costs in the testing data set (e.g. $\mathrm{R}^{2}$ ), their ability to 
improve forecasting accuracy relative to the first model with the testing data set, their use of variables that are statistically significant in the training data set, and the extent to which they met statistical assumptions in model development: normality, linearity, independence of errors, and homogeneity of variance. A prerequisite for being included in model development is the use of data that are available at project inception and that are easy to acquire.

\section{RESULTS AND DISCUSSION}

The results are organized across three areas, each of which responds to the questions raised in the purpose and scope section:

- Definition of preliminary engineering

- Availability of PE expenditure data and reviews of these data by VDOT staff

- Development of a model to forecast PE expenditures at the project level

\section{Chapter 1: Definition of Preliminary Engineering}

Preliminary engineering has been defined both in the literature and by VDOT district staff. The literature shows considerable variations among these definitions by organization, and the VDOT district interviews show that the preliminary engineering function further varies by project.

\section{Definition of Preliminary Engineering Based on the Literature}

Transportation projects are divided into phases, usually preliminary engineering $(\mathrm{PE})$, right of way acquisition $(\mathrm{RW})$, and construction $(\mathrm{CN})$. This division can help one organize staff resources, understand elements needed to deliver a project, and plan for future expenditures. The PE phase is a complex one that, based on five definitions reviewed (VDOT, 2012; FTA, 2007,undated; Liu et al., 2011; Dowling, 2012; and AECOM et al., 2010) is defined inconsistently by state and federal agencies.

\section{Definition of PE (VDOT, 2012)}

VDOT's Project Development Process defines Preliminary Engineering as five steps: scoping, preliminary design, detailed design, final design \& right of way acquisition, and advertisement. The interactive flowchart (VDOT, 2012) from the Project Management Office (PMO) provides additional information for each of the five steps which are summarized as:

- Scoping outlines the estimate, schedule, management policy, and scope which "establishes the project team and confirms the project purpose and need." The project development approach is determined by a Scoping Kickoff Team Meeting which allows the project team to document all significant information (e.g., environmental data, traffic analyses, sources of 
risk, and evaluations of stakeholder involvement, including coordination with the lead design engineer). The Project Cost Estimating System (PCES) is used to estimate costs across three phases: PE, RW, and CN. Developing the project schedule requires the team members to identify project tasks and assign duration estimates. The schedule is closely monitored and can be changed if circumstances change. The project management policy is the overall structure and organization showing how tasks will be completed and who is responsible for each stage of the project.

- Preliminary design includes the "design of roadways, structures and bridges, traffic control devices/intelligent transportation systems, and landscaping." Each design is then "reviewed by all stakeholders of the project such as affected property owners and local governments." Stakeholders may share their opinions at one (or more) public information hearings and discuss "the location of the roadway and details such as right-of way width, type of intersections and interchanges, and materials needed." Before any major design work or RW acquisition is undertaken, approval of the Commonwealth Transportation Board (CTB) is required.

- Detailed design entails RW acquisition (done early to minimize delays later in the project development process) and field inspections, which help determine "erosion and sedimentation control, perform utility design, inspection, authorizing right of way and perform constructability and work zone reviews." Field inspections also address "issues such as constructability, plan clarity and maintenance aspects as well the project related questions and comments included with the plans." If questions arise that need further review the project manager can seek clarification from the district project development engineer.

- Final design and right-of-way acquisition results in a Pre-Advertisement Conference (PAC) where any plan refinements prior to advertisement are made. This phase consists of a "thorough review of the plans including the proposed sequence of construction and maintenance of traffic, as well as the contract documents, by the entire project team prior to advertisement of the project." Preparing for the PAC is critical as all project details are finalized, making the plans ready for bidding.

- Advertising results in project advertisement and award. Permits, environmental certificates and plans, specifications \& estimates (PS\&E) must all be complete and approved before the bidability review. Projects must also meet the contract time determination guidelines.

In sum, VDOT's definition of PE, as reflected in the VDOT Project Development Process, is quite expansive. Theoretically all of the responsibilities stated in the five steps, except for RW acquisition, are charged to the preliminary engineering phase of a project.

\section{Definition of PE (FTA, 2007, undated)}

The Federal Transit Administration [FTA] (2007) notes the use of varying PE definitions, such as the engineering necessary to complete the environmental requirements stated by the National Environmental Policy Act (NEPA) of 1969 or "30\% of final design." NEPA 
determines the "environmental, transportation, cultural, and social impacts of the proposed project and develops strategies for mitigating them." Final products of the preliminary engineering phase include a final scope, an accurate cost estimate, a project management plan and a financial plan with funding committed to the project. The final scope includes the overall project objectives and clear definitions of what is expected at the end of the project. The guiding principles behind preliminary engineering require the cost estimation "to the level of confidence necessary for the project sponsor to implement its financing strategy." However, the level of confidence necessary for a sponsor to finance a project is not consistent for all projects. Some projects may have funding secured before a cost estimate is complete while other projects may need extensive cost estimates to get any funding.

New Starts (e.g., federal transit capital investments) entail a three-phase project development process (FTA, undated). Phase 1 (Alternatives Analysis) evaluates mode choice for a given corridor and consists of "costs, benefits and impacts of transportation options so that the community can identify a preference." The phase is complete when "local and regional decision makers select a locally preferred alternative, and it is adopted by the metropolitan planning organization (MPO) into the region's long-range transportation plan." Phase 2 (Preliminary Engineering) entails consideration of alternative designs and terminates when NEPA is completed. Throughout this phase leaders "finalize management plans, demonstrate their technical capabilities to develop the project, and commit local funding sources." Phase 3 (Final Design) also entails development of construction plans and details for the bid documents. In sum, FTA (undated) defines PE as not including final design, in contrast with VDOT.

\section{Definition of PE (Liu et al., 2010)}

In reference to North Carolina DOT, Liu et al. (2010), defined preliminary engineering as "the efforts required to plan and design a highway project for construction." This definition is aligned with the VDOT definition in that it includes a broad range of activities; the author writes that

PE begins when a specific highway project first receives funding authorization for planning and/or design activities. The delivery of the construction documents for project letting marks the end of PE.

\section{Definition of PE (Dowling, 2012)}

Dowling (2012) gives preliminary engineering a relatively narrow focus. A general planning and preliminary engineering phase is divided into four categories: Pre-Project Planning, Project Need, Project Initiation, and Project Clearance. The project clearance portion is where the "planning analyses start to intersect and overlap with engineering analyses" and is defined therein as preliminary engineering. In this PE phase, the "project details have still not been finalized but the outcome of this stage will produce the final project details before actual design begins" (Dowling, 2012). Note also that Dowling's (2012) definition of PE overlaps with what VDOT would define as planning, when the author notes that travel demand models are created where system performance measures such as "(PMT, VMT, PHT, and VHT) are useful outputs for use in air quality analyses, including sustainability, climate change, and greenhouse 
gas emission analyses."

Dowling (2012) also notes that users of the Highway Capacity Manual have suggested that a Planning and Preliminary Engineering Applications Guide (PPEAG) should supplement the HCM to "facilitate its use in planning analyses and increase the accuracy and reliability of the traffic performance results predicted by planning studies."

\section{Definition of PE (AECOM et al., 2010)}

AECOM et al. (2010) provides a high-level analysis of how "soft costs" affect transportation projects. In contrast with hard costs (e.g., "construction such as steel, concrete, rail cars and buses, or construction labor," soft costs generally refer to professional services and include "designing the project, obtaining permits, and managing the construction project." A relatively narrow subset of the soft costs category is preliminary engineering, which AECOM et al. (2010) defines (from his review of as "the costs of early design, negotiations for operations and/or maintenance, developing financial plans, and ridership studies." To be clear, this definition of PE excludes certain soft costs (e.g., final design, surveys, and environmental permits) such that although soft costs are estimated as $30 \%$ of construction costs, preliminary engineering is estimated as $2 \%$ of construction costs. AECOM et al. (2010) reports a variety of factors which influence soft costs (e.g., project delivery method) which can hinder accurate forecasting of a project's soft costs.

Summary of Definitions of PE

Table 3. Summary of PE Definitions from the Literature

\begin{tabular}{|c|c|c|c|}
\hline Source & PE Activities & Audience & Breadth of Definition \\
\hline $\begin{array}{l}\text { VDOT } \\
(2012)\end{array}$ & $\begin{array}{l}\text { Scoping, Preliminary Design, Detailed Design, Final } \\
\text { Design \& Right of Way Acquisition Advertising }\end{array}$ & VDOT & \multirow{2}{*}{$\begin{array}{l}\text { Expansive (everything } \\
\text { prior to } \mathrm{CN} \text { except } \mathrm{RW} \\
\text { acquisition) }\end{array}$} \\
\hline $\begin{array}{l}\text { Liu et al. } \\
(2011)\end{array}$ & $\begin{array}{l}\text { Everything between PE funding authorization through } \\
\text { delivery of the construction documents }\end{array}$ & NCDOT & \\
\hline $\begin{array}{l}\text { FTA }(2007 \\
\text { undated })\end{array}$ & $30 \%$ of Design, NEPA & \multirow{2}{*}{$\begin{array}{l}\text { Transit } \\
\text { agencies, } \\
\text { FTA }\end{array}$} & \multirow[t]{2}{*}{$\begin{array}{l}\text { Moderate, excludes final } \\
\text { design }\end{array}$} \\
\hline $\begin{array}{l}\text { AECOM et } \\
\text { al. }(2010)\end{array}$ & $\begin{array}{l}\text { Draft Environmental Impact Statement (DEIS), Early } \\
\text { Design, Negotiations for Operations and/or Maintenance, } \\
\text { Developing Financial Plans, and Ridership Studies. }\end{array}$ & & \\
\hline $\begin{array}{l}\text { (Dowling, } \\
\text { 2012) }\end{array}$ & $\begin{array}{l}\text { Final project details before actual design begins, TDM to } \\
\text { determine performance measures (PMT, VMT, PHT, and } \\
\text { VHT) }\end{array}$ & $\begin{array}{l}\text { Users of the } \\
\text { HCM }\end{array}$ & $\begin{array}{l}\text { Restricted, also overlaps } \\
\text { with planning }\end{array}$ \\
\hline
\end{tabular}

Five different definitions of preliminary engineering were observed in the literature review (FTA, 2007; VDOT, 2012; Liu et al., 2011; Dowling, 2012; AECOM et al., 2010). These definitions ranged from the very precise with specific tasks to general overall percentages of design. For instance, FTA (2007) indicates that during PE, the design must comprise "all major or critical project elements to the level that no significant unknown impacts relative to their costs or schedule will result," but, if PE also terminates at $30 \%$ of final design, clearly does not include final design (which is included in the VDOT PE phase). This also suggests that comparisons of results from PE between these two agencies may be difficult given that their definitions differ. Table 3 summarizes the disparate PE definitions, from the most broad to the most limited. 


\section{Definition of Preliminary Engineering Based on the VDOT District Interviews}

The first four questions from the district interviews help better define preliminary engineering as practiced in VDOT. These questions concerned the alignment between the VDOT project development process and the SYIP (questions 1 and 2), the extent to which preliminary engineering is a linear or recursive process (question 3), and the availability of UPCs that help describe the PE process (question 4).

\section{Alignment Between the VDOT Project Development Process and the SYIP}

The VDOT Project Development Process shows five phases for preliminary engineering: scoping, preliminary design, detailed design, final design \& RW acquisition, and advertisement. These align with the SYIP in terms of funding. However, there is not consistency in terms of scheduling: in practice the RW phase may have some degree of overlap with both the PE and $\mathrm{CN}$ phases. For a hypothetical four-year project, Table 4 shows that the start dates for PE are identical; however, the PE, RW, and CN phases may overlap in project development process whereas in the SYIP they are strictly sequential. PE and RW may overlap and RW and CN may overlap; the only hard and fast rule is that PE ends when CN begins (I1,I3,I7). However, it was also noted that PE may continue after PE has begun (I9). Clearly, of the five definitions of PE noted in Table 3, VDOT's definition of PE aligns most closely with that used by North Carolina as noted by Liu et al. (2010).

Table 4. Alignment of the VDOT Project Development Process and the SYIP

\begin{tabular}{|c|c|c|c|}
\hline \multicolumn{2}{|l|}{ VDOT Project Development Process } & \multicolumn{2}{|c|}{ VDOT Six Year Improvement Program } \\
\hline Phase & Schedule & Phase & Schedule \\
\hline Scoping & \multirow[t]{5}{*}{ Begin Jan. 2013} & \multirow{5}{*}{ Preliminary Engineering } & \multirow[t]{3}{*}{ Begin Jan. 2013} \\
\hline Preliminary Design & & & \\
\hline Detailed Design & & & \\
\hline Final Design \& RW Acquisition & & & \\
\hline Advertise Plans & & & End Dec. 2013 \\
\hline $\begin{array}{l}\text { RW phase is not shown but may begin } \\
\text { while } \mathrm{PE} \text { is underway }\end{array}$ & $\begin{array}{l}\text { Begin Jan. } 2014 \\
\text { End July } 2014\end{array}$ & RW & $\begin{array}{l}\text { Begin Jan. } 2014 \\
\text { End Dec. } 2014\end{array}$ \\
\hline $\begin{array}{l}\text { Construction phase is not shown but } \\
\text { occurs after advertisement. }\end{array}$ & $\begin{array}{l}\text { Begin Jan. } 2016 \\
\text { End Dec. } 2016\end{array}$ & Construction & $\begin{array}{l}\text { Begin Jan. } 2015 \\
\text { End Dec. } 2016\end{array}$ \\
\hline
\end{tabular}

Tables 3 and 4 shows that VDOT's definition of preliminary engineering is quite broad. VDOT PE spans activities that occur from the time from when a charge number for a project is made available until the project is awarded (not just advertised) for construction, thus PE as defined by VDOT spans more activities than that which might be used by other organizations.

\section{Extent to Which PE is a Linear or Recursive Process}

The third question of the survey asked how the end products of three phases within the PE phase - preliminary design, detailed design, and final design \& RW typically changed 
throughout the PE process. The results revealed some typical benchmarks, such as preliminary design being completed at $30 \%$ of PE funding and RW/Detailed Design being at $65 \%$ of PE funding (I2,I7). However, interviewees also pointed out that these benchmarks were not definitive for every project, with one set of interviewees noting that the end products may change "very little, substantially, or somewhere in between" (I4). Perhaps not surprisingly, the scale of the project influences this level of change-one example given was the contrast between paving an unpaved road and constructing a bypass around a metropolitan area, with the latter having more changes relative to the former.

An unanticipated finding was the observation by interviewees that PE can be a recursive process. For instance, one set of interviewees noted one might accomplish 30-40\% of design before realizing a change in the final product was needed, due to changes in land development, unforeseen geotechnical challenges, or public involvement (I7). Five factors tend to increase the likelihood that the PE process will be iterative, where it may be necessary to revisit earlier work as one progresses through project development.

- Duration. As time passes, four key types of events become more likely: design standards or regulations may change (especially if there is a long gap between PE and advertisement, since failure to begin the RW phase within three years of the public meeting means new design standards must be adhered to); the scope may change (perhaps in response to public involvement), available funding may change, or land development may occur (I9). (In this latter instance, it can be the case that new property owners are not satisfied with conditions agreed to by previous property owners.) One example of how the change in funding levels increased the percentage of costs was where the planned addition of a turn lane was replaced with the installation of flashing lights (I6).

- Staff turnover. Such turnover can increase costs because some tasks may need to repeated, especially if late in the PE phase the project moves from an in-house design to a design-build process. This may suggest that the likelihood of such turnover is increased by a longer PE process (I1).

- Size. Although they have numerous design decisions, larger projects (e.g., an interchange) may have some stability in that there is a well-defined solution (e.g., an interchange, a bypass, etc.). By contrast, the purpose and need for a smaller project may not simply be a problem statement (e.g., eliminate flooding) such that numerous designs must be considered (e.g., elevate the roadway versus build a drainage system) (I1). Further, larger projects may also build momentum as the PE process unfolds such that stakeholders do not want to sacrifice the investment that was already made in earlier design steps.

- Responsiveness to public opinion. The visibility of the project and the public involvement process may lead to detailed design changes throughout the process including new design treatments that were not previously anticipated. In particular, it can be the case that PE work is completed at which point the sponsor elects not to have the project move forward or delays its progress. 
- Location in an urban area. One interviewee noted that in an urban area the risk of geotechnical challenges (whether due to buried utilities, rock, results of structural integrity tests based on the CBR [California Bearing Ratio] or other design variables) increases (I7).

While all five of these factors were cited by at least one interviewee as influencing PE costs, many district interviews suggest that duration may be one of the largest influences

\section{Availability of Universal Project Codes (UPC) that Help Describe the PE Process}

Question 4 asked interviewees to recommend a sample of UPCs to help better understand the role of PE and how PE tasks are funded. Interviewees provided projects that illustrated various dimensions of the project development process. For example, Hampton Roads interviewees noted the higher PE costs (on a percentage of total cost basis) associated with smaller scale Highway Safety Improvement Projects (typically under \$1 M); similarly, the Bristol District interview yielded five UPCs that showed Tier 1 versus Tier 2 projects as well as variables that influence cost, such as wetland mitigation $(\mathrm{I} 7, \mathrm{I} 2)$. Other factors that influence PE costs include whether the project is locally administered (as some localities may not have to charge all of their PE staff time to an actual PE phase), whether the project is design-build, and whether the construction project is a "Complete Plan" project (as opposed to minimum-plan projects and no-plan projects which would have lower or no PE costs) (I4).

Interviewees also gave instances where the project development process did proceed as expected; one example was Route 639 in Caroline County which was described as a "best case" scenario due to stakeholders' agreement on the project scope. Similarly, the Lynchburg District noted a passing zone project on Route 501 where first a budget was established and then a design was selected that fit within the constraints of that budget (I6).

However, the interviews also showed at least five scenarios where the work performed during some portion of the PE phase might not ultimately be used in the construction of the project because of a change in scope. These five types are shown in Table 5. For example, one might perform PE for a four mile section of roadway yet only construct a two mile section of that roadway.

Table 5. Types of Scope Changes Within the PE Phase

\begin{tabular}{|c|c|c|}
\hline No. & Type of Scope Change & Example Projects \\
\hline 1 & $\begin{array}{l}\text { PE may be done for a larger } \\
\text { section than what is built. }\end{array}$ & $\begin{array}{l}\text { For Route } 687 \text { in Pulaski County, the PE reflected a } 1.5 \text { mile section but } \\
\text { CN reflects just two spot improvements. (I4) }\end{array}$ \\
\hline \multirow[t]{2}{*}{2} & \multirow{2}{*}{$\begin{array}{l}\text { The scope may change } \\
\text { because, especially for small } \\
\text { projects, the project is not } \\
\text { fully defined or may require } \\
\text { the evaluation of multiple } \\
\text { designs. }\end{array}$} & $\begin{array}{l}\text { For Route } 634 \text { in King \& Queen County, the initial purpose and need was } \\
\text { to raise the roadbed (to eliminate flooding); later the design was to build a } \\
\text { better drainage system. This required multiple pre-scoping efforts to define } \\
\text { a relatively small project. }\end{array}$ \\
\hline & & $\begin{array}{l}\text { For Route } 58 \text { in Scott County, a relatively small project had multiple } \\
\text { designs considered at the Preliminary Field Inspection stage (where a } \\
\text { preliminary set of plans are reviewed. }\end{array}$ \\
\hline 3 & The scope of the project may & A project on Route 668 in the Salem District illustrated the role of elected \\
\hline
\end{tabular}




\begin{tabular}{|l|l|l|}
\hline & $\begin{array}{l}\text { grow as a result of the public } \\
\text { involvement process. }\end{array}$ & officials who can write letters of support. (I4) \\
\hline 4 & $\begin{array}{l}\text { The scope of the project may } \\
\text { shrink as a result of changes } \\
\text { in funding. }\end{array}$ & $\begin{array}{l}\text { A series of widening and intersection improvements were planned for } \\
\text { Route 15 in the Lynchburg District, however, with insufficient funds the } \\
\text { project was scaled back to more modest improvements. (I6) }\end{array}$ \\
\hline 5 & $\begin{array}{l}\text { PE may include other tasks } \\
\text { that are not strictly PE per se. }\end{array}$ & $\begin{array}{l}\text { For an interchange project on I-95 in Stafford County, PE included the cost } \\
\text { of preparing the required Interchange Justification Report (IJR). Other } \\
\text { interviewees noted that the VDOT accounting systems record very specific } \\
\text { tasks within the CN phase, however, this is not the case within the PE } \\
\text { phase. (I1) }\end{array}$ \\
\hline
\end{tabular}

Case 2 can be generalized to mean that for smaller projects, a problem might be presented rather than a project (e.g., a problem might be that "a road is flooding.") Thus, PE will include consideration of diverse alternatives, such as, in this case, building a bypass drainage system or elevating the roadway. (By extension, such projects illustrate the importance of PEin this example, the cost of the different alternatives varied by almost an order of magnitude, from a midpoint estimate of $\$ 700,000$ for the lowest-cost alternative to $\$ 5$ million for the higher cost alternative.) Not surprisingly, VDOT's tool for forecasting the percentage of costs attributed to PE drops as the construction cost rises; one district noted that the percentage of PE costs ranged from $8 \%$ to $35 \%$ depending on the project (I2).

A special case of projects was noted in some interviews: the role of design-build projects. One interview noted that for design-build projects, PE activities are charged to construction, although at the program level, it was suggested that design-build projects were a lesser concern as they are relatively few (on the order of 5 to 10 per year statewide) (I5). That said, one interview noted that certain PE tasks may be repeated (with such repetition increasing costs) if, part way through the PE process, there is a shift from in-house work to consultants (or vice-versa), or a change from a traditional project delivery process to design-build (I3).

\section{Part 2: Availability and VDOT Staff Review of PE Data}

The extent to which PE expenditure data are available to and reviewed by VDOT staff was covered in questions 5 through 9 of the interviews. The interviews showed that although expenditure data are accessible, data limitations influence the types of analyses that are undertaken. District staff review PE percentages for specific projects but not for the entire program. Some interviewees gave a range of appropriate project-level PE percentages but cautioned that they are influenced by several factors. Such factors prevented most interviewees from citing an appropriate program-level PE percentage. Accordingly, this section considers (1) the availability and quality of financial data, (2) the availability and quality of project characteristic data, and (3) the extent to which these data are presently used, or could be used, by staff.

\section{Availability and Quality of PE Financial Information}


A requirement for investigating PE expenditures is the availability of financial data. For information about estimates, and to a limited extent expenditures, the Integrated Six Year Plan (iSYP) provides access to the Project Pool. This database has a Schedule and Estimates section which provides estimates and [cumulative] expenditures for PE, RW, and CN. This information is routinely available and expenditures are updated in the Project Pool every two weeks (I2). Although other databases, with different focus areas, contain project estimates and expenditures, the Project Pool is most likely to have current expenditures (I9). At the beginning of a project, the Project Pool has an approved estimate for each phase. However, after activities are charged to the project, the estimates are changed to reflect current project expenditures.

Estimates that do not change once the project has begun are located in the PCES section of the Project Pool. In that section, estimates are divided into the Pre-Scoping, Scoping, Preliminary Field Inspection (PFI), Preliminary Hearing (PH), Field Inspection (FI), Right-ofWay (RW), Final Submission, Award and actual expenditures. Although these estimates are located in the PCES section, estimates can originate from at least two estimating tools: PCES and TRNS*PORT, a more specific estimating tool. The tolerance for PCES is $\pm 25 \%$, for TRNS*PORT (pronounced "Transport") it is 5\%, and neither includes items such as sidewalks and trails (I1).

The financial data are available for one to compute percentage of expenditures spent on $\mathrm{PE}$ as opposed to RW or CN. However, financial data accessibility is complicated by the need for three different information systems: Cardinal [for expenditures after November 2012]), FMS2 [Financial Management System version 2, for expenditures for roughly the period 2003November, 2012]), and FMS 1 (for projects prior to FMS2). (I4)

Expenditure data from FMS1, which has been ported into FMS 2 from earlier periods, is believed to be accurate. (Further, if a UPC appears in FMS2, the data therein should be complete, although it is acknowledged that some information may be lost generally as financial systems change.) (I5). For current projects [e.g., expenditures since 2012), the Business Objects (BOXI) portal provides financial information by phase; this information comes from the Cardinal Financial System [and a direct query of Cardinal] provides information by activity, account, and entity who is charging to each project (I2, I5).

Interviewees noted that there can be confusion about allocations, estimates and expenditures. The Six Year Improvement Program (SYIP), a publicly available document with planned resources for each project, contains allocations programmed to specific UPCs (I4). There is a difference between what is programmed (e.g. allocated) and what is spent (e.g., expenditures). Expenditures are reported by phase. However, while the Six Year Improvement Program (SYIP) shows estimated amounts by phase, the SYIP formally only programs amounts to specific UPC - e.g., when an SYIP shows a given amount for a particular project, that amount could, in theory, be intended for any of the three phases. That said, one can draw some inferences by comparing the estimated and programmed amounts. [For instance, a project with an estimated PE cost of $\$ 1 \mathrm{M}$, an estimated RW cost of $\$ 2 \mathrm{M}$, and an estimated CN cost of $\$ 3 \mathrm{M}$ that shows an SYIP allocation of \$6 M would be inferred to be fully funded.]

Interviewees noted several reasons why, although the financial data are available, they should be treated with caution. The districts generally agreed that tracking projects by phase and 
activity will not yield the entire amount VDOT spends on PE because of the first two reasons shown - the availability of a pre-scoping UPC and the manner in which maintenance projects are funded. Additionally, some districts noted other exceptions that could affect PE; such as the lack of a PE phase for secondary roads prior to FMS2 (I3). For the nine reasons below, it is possible that reported PE expenditures may not fully represent the PE work required to complete the phase for the project.

\section{The Availability of a Pre-Scoping UPC}

Some PE work may be accounted for in charges made to district-wide project numbers for pre-scoping, and such charges will not be recorded as part of the PE phase (I2,I3) [for a specific project]. For example, UPC 99570 refers to Fredericksburg prescoping; these expenditures are counted as PE but are not attributed to a specific project]. This often occurs when it is difficult to obtain authorization to perform PE work on a specific project; such districtwide numbers will yield a lower PE expenditure since some initial work was charged to a different UPC (I3). Pre-scoping funds are also helpful because a project can begin while waiting for federal funding or getting into the SYIP. High profile projects that begin in the pre-scoping phase may have a lower PE because pre-scoping can take care of some of the early tasks (I8, I9).

Some of these activities in the pre-scoping phase include PE-related charges such as planning costs or administrative costs (I6). However, one district categorized such exceptions as minor if one is concerned about the percentage of PE to CN costs, since these items (e.g., administration) would also affect the RW and CN phases (I6). The amount of pre-scoping funds varies by year: for each district it was $\$ 750,000$ (year 1) and $\$ 1 \mathrm{M}$ (year 2 at the time of the interview); such variation determine the extent to which pre-scoping funds influence the PE percentage (I4).

\section{The Manner in Which Maintenance Projects are Funded}

The number of maintenance projects heavily influences how tracking expenditures by phase and activity yield the entire amount VDOT spends on PE. For maintenance projects, all PE may be charged to a single UPC, such as in the Salem District where there are 28 paving projects whose PE is handled by a single UPC (I4). This use of a single charge number makes it difficult to delineate specific PE tasks from one project to another. However, if maintenance projects are excluded, the limitations may not be significant. A sensitivity analysis could be conducted to determine the importance of such limitations (I3).

\section{Other Sources for Accomplishing PE Work}

Some districts noted that PE tasks can be charged to other sources. In the past, PE work for some projects was done by residencies, and this work may not be captured as PE expenditures but rather would be charged to some other cost center (I4). Presently, staff that charge a significant amount of their time to administration may have charged some time to administration that could also have been instead charged to a given UPC (I10). Some planning staff are $100 \%$ funded by Transportation and Mobility Planning Division (TMPD) but may put 
some time into PE (I10). Further related RW costs (although not RW acquisition) may be charged to PE if RW tasks must be performed when the RW phase is not yet open to charges (I6). Finally, the termini for two projects may intersect such that the environmental portion of one must be done prior to PE on the other being completed. In that case, some of the PE for one project may be linked to the other project (I8). While a best practice is to ensure PE costs are charged to the appropriate UPC, in some cases one UPC has PE for more than one project (I10).

\section{The Use of Multiple UPCs}

There is not necessarily one UPC per project. PE from multiple projects may be bundled into a single UPC; for instance, in the City of Richmond, there is one UPC that contains all the PE for 10 separate CN-only UPCs (I10). Some projects have two UPCs: one for PE/ROW (or PE-only) and one for CN (I2,I7). In such an instance, use of only one UPC to calculate the PE percentage can skew the results toward a higher or lower PE percentage.

\section{The Delineation of PE Activities from CN Activities}

Details that separate the PE, RW, and CN phases may not be immediately apparent. For instance, suppose a project will take existing wetlands. If the mitigation is to purchase wetland credits then that cost is charged to PE, but if the mitigation is to construct a new wetland then that cost is charged to CN. Accordingly, it is difficult to compare Virginia PE with other states.

The use of consultants and the method of project delivery influence interpretation of PE costs. For instance, the loaded rate for consultants is higher than that of in-house staff, but electricity and office space are not included in overhead for the latter (I1). The project delivery type can also influence how PE expenditures are reported in databases. If the project delivery method is "design-build" PE information grouped with other tasks. This category adds a layer of complexity in that in theory one is providing a project that is already at $30 \%$ of design but in practice one is not necessarily at that point [when the project passes from VDOT to the firm doing the design-build work]. (I4)

The duration of the PE phase can implicitly affect how PE activities were defined. Prior to 2001 or 2002, when FMS 2 was relatively new, at least some secondary system projects did not have a PE phase but rather had all PE work charged to $\mathrm{CN}$. For this and other reasons, it is possible that not all PE tasks will show expenditures within the PE phase (I3).

\section{The Need for Additional Details}

The PE budget can change during the scoping phase, where scoping is not tracked to the same degree that RW and CN phases, such that valuable information can be omitted (I1). The inability to track the PE budget at a level of detail useable to managers is a concern. Details such as the amount by which individual disciplines (e.g., environmental versus hydraulics) are charging and is not well documented publicly. While activity codes provide a substantive portion of a project's costs, information about the specific components of an activity are not available. 
Information about a project may not be available to a designer. Most other states leave local road design to localities, in which case more information about the project's need will be available to the local designer than is the case in Virginia.

Accordingly some districts create their own databases to track PE. Although but it requires a lot of management some districts such as the Central Office maintains an Access database only for its Design Services unit (I1).

\section{Dead Projects}

In some cases PE is authorized and a portion of the PE work is completed, but the project is not built. It is difficult to determine how often this occurs, but in one interviewee's experience this happened three times out of 20 recent projects (I2). (This also can skew the analysis to report a higher PE percentage since there is no $\mathrm{CN}$ expenditure information reported.) Accordingly, question 8 raised the subject if there is a credible way to identify a list of projects (including dead projects) - in each district- that will enable determination of the portion of total project cost spent on PE. All district interviews agreed there is a credible way to identify a list of projects in each district. The integrated Project Manager (iPM), an internal VDOT database, has a function to export a spreadsheet of all the projects and their defining characteristics, by district or for the entire state (I2). Similarly, a list of projects can be queried in the SYIP (I3). However, complications may arise. For example, if using iPM to identify dead projects, note that some projects will have a letter uploaded to notify that the project is dead but some cases a letter won't be available. An alternative to using the iPM is contacting VDOT Central Office programming regarding whether a project has been closed out. (I3)

\section{The Presence of Anomalies}

Some projects are atypical such that they have lower-than-expected PE costs. These are (1) maintenance projects, (2) design-build projects (which charge the PE activities to the CN phase),(I3) and (3) "Min" or "No" Plan projects (I7). However, although some ARRA projects may be atypical, some are not. Initially, the researchers thought to remove all ARRA projects as well as projects that did not have expenditure data in all three phases. However, some ARRA projects have normal project development processes, and Northern Virginia—an urban districthas a significant number of projects that do not have a RW phase but are not anomalies (I9).

\section{Some PE Expenditures may occur after CN has begun.}

Some PE expenditures may occur after $\mathrm{CN}$ has begun (I2,I9). The Bristol and Northern Virginia interviews offered examples where PE expenditures can occur after $\mathrm{CN}$ has begun. Unlike other districts, the PE phase does not end when construction begins. This is done to allow for contingencies. Some districts charge additional PE activities to the $\mathrm{CN}$ phase once $\mathrm{CN}$ has begun, however Northern Virginia keeps the PE phase open until the end of the project (I9). 
For example, a VDOT district may use PE funds to answer a question for contractor about traffic control restrictions and revise the plan accordingly (I2).

\section{Availability and Quality of Project Characteristic Information}

Similar to the financial information, the Project Pool also has a General Information section that has project characteristics such as the type of environmental work, functional class, facility type, project length, work flow status, and number of bridges required. This information is routinely available except for some cases where environmental work and functional classification are blank.

The Project Pool and Integrated Project Manager (iPM), two sections within the iSYP, give more detailed information on project characteristics. If it is uploaded to the iPM, a complete Scoping Document will contain characteristics such as, but not limited to as (1) Bicycle/Pedestrian Accommodation, (2) Bio Retention (Water Quality) Basin, (3) Memorandum of Agreements, (4) Recoverable Slope Study, (5) Value Engineering Study, (6) Transportation Management Plan Type, (7) Design Services Provider, (8) Businesses to be taken, (9) Homes to be taken, (10) Railroad Involvement, (11) Utility Relocation (also called Utility Conflicts in some cases), and (12) Alternate Delivery Method. If applicable, documents other than the Scoping Document may show characteristics such as (1) if wetlands are affected, (2) the need for Hazardous Materials (Hazmat) evaluation, and (3) National Historic Preservation Study Evaluations. Generally, project documents are uploaded into the (iPM) about every 3 months, or more frequently if milestones are closer than three months.

As is the case with financial data, there are some limitations of the project characteristic data. One interviewee pointed out that each of these systems (e.g., the Project Pool, iSYP, iPM, CEDAR, RUMS, etc.) was designed to answer a specific question and have since been melded together with various limitations, such as the lack of a strict organizational convention. That said, interviewees collectively suggested four key limitations.

\section{Not all Details are in the Project Pool}

The details that are available on the iPM largely depend on (1) the habits of the project manager (some managers place all information within the iPM; others do not) and (2) when the project was started: for projects initiated prior to the existence of iPM, in 2007 or 2008, some managers may have retroactively updated details to iPM and others may not have (I4). For earlier projects, information on PE could possibly be in a file folder for the specific UPC at the district office (I4) or one may contact the project manager directly (I7, I4).

A scoping document is not required by VDOT for locally administered projects (LAP) nor paving projects, but this district's practice is to complete such documents nonetheless. It was also noted that years ago the district used project folders (e.g., right of way, environmental, and so on) with a consistent naming convention; such folders did help organize the material for each project (I8, I10).

Additionally, while the iPM provides excellent information is not designed to contain every record for a project but rather is expected to have the critical documents and decisions for 
a given project to provide information for people that are higher up access to project documents to make decisions. The iPM relies heavily on the project manager - and in the Hampton Roads District such managers are strongly encouraged to ensure that the critical files are uploaded (I7). 2. The Use of Multiple UPCs

PE information may also limited in the Project Pool if the project UPCs are "co-mingled" where the PE phase and the CN phase are given two separate UPCs yet reflect the same project (I4) This doesn't occur very often however, larger projects with multiple construction phases may have "co-mingled" UPCs. Generally if the project is "co-mingled" there will be a note in the Project Pool Notes Section. However if there is no indication it is nearly impossible to find the UPCs without contacting the project manager. Additionally, some projects can be divided so that PE that reflects a given section of a project [e.g., MP 0 to MP 4]), but the CN reflects only a portion of the project [e.g., construction from MP 2 to MP 4] (I4). This can reflect, in the Project Pool, PE to have a longer length and duration than what was actually built.

\section{Interpretation of Blank Fields}

After reviewing a set of projects for one district, the researchers categorized characteristics as, usually available where the only reason a characteristic is missing such as a data entry error or some unexplained event, sometimes available where the characteristics are often available, such as when the Scoping Document is uploaded, and rarely available where these characteristics were observed less frequently even when extensive documentation was uploaded to the iPM.

Interpretation of blank fields in the Project Pool required judgment from the researchers because it is not always clear that missing characteristic data are not an error. Missing data may be because the project does not require that element. By contrast, a project missing general information would likely constitute an omission of a data element. It was also suggested that when PE duration has zero days, the data element is likely in error because all projects have a PE start and end date (J. Brown, Personal Communication, June 4, 2013). However, projects that are in sequential UPC order and have exactly the same duration are not uncommon and are likely accurate (J. Brown, Personal Communication. June 4, 2013).

\section{Archived Projects}

Project level data are chiefly available from the project pool. Some districts suggested that only those UPCs that had been "closed out" should be used. A VDOT Fiscal Division employee familiar with FMS II noted that although a field exists in FMS II to indicate whether a project has been closed out, this field is not typically updated (Carver, R., Personal Communication, December 10, 2012). However, VDOT Programming staff noted that one may use the projects that have been "archived" for such a purpose.

\section{Staff Review of Project Level and Program Level PE Expenditures}




\section{Staff Review of PE Percentages}

At the project level, district staff track expenditures across all three phases (PE, RW, and $\mathrm{CN})$ to keep the project on budget (I4, I6, I7). Such tracking also helps managers ensure projects are receiving accurate charges and that the Federal Highway Administration (FHWA) is receiving allowable project charges (I7).

At the program level, district staff do not review PE percentages for two reasons: the data have limitations, and it is not clear how such an analysis would be used. Review of such percentages, if performed, would most likely occur within VDOT Central Office Programming (I4). In order to review such percentages, a credible approach would be to obtain projects listed in the SYIP but ensure that maintenance projects were excluded from such a list because maintenance-related projects do not have an explicit PE phase but may have some PE-related tasks (I3). Such a data set would not be perfect but would avoid the problem of mixing construction and maintenance projects (I3).

\section{Appropriate PE Percentages}

One use of PE percentages envisioned by interviewers was using some PE percentage as a desired target. Accordingly, interviewees were asked whether an appropriate PE target could be given at either the project level or program level.

At the project level, interviewees cited a wide range of appropriate percentages to be spent on PE relative to other project phases. The highest and lowest PE percentages for specific projects are around $35 \%$ and $8 \%$, respectively (I2). A rough estimate for a specific project might assume the PE percentage of $\mathrm{CN}$ as $15 \%-20 \%$ for projects between $\$ 5 \mathrm{M}-\$ 10 \mathrm{M}$. This percentage may decrease to $10 \%$ as the projects costs exceed $\$ 20 \mathrm{M}$ and, conversely, may increase to $50 \%$ in some cases, for a $\$ 1 \mathrm{M}$ project $(\mathrm{I} 3, \mathrm{I} 4)$. However, not all projects will fit into the typical project "mold." A recent review of selected projects showed that the percentage of funds spent on PE ranged from $13 \%$ to $58 \%$ (I6).

At the program level, most interviewees (an exception being I4) did not give an appropriate percentage but noted factors that influence this percentage. One factor is the portfolio of projects. For example, a significant number of smaller projects make up the Hampton Roads District program-especially Highway Safety Improvement Project (HSIP) investments which have relatively high ratio of PE to CN. (These are typically in the $\$ 500,000$ to $\$ 750,000$ range) (I7). Similarly, one would suspect that Northern Virginia would spend a lower percentage on PE than Culpeper in part because Northern Virginia tends to pursue a greater proportion of large scale projects than Culpeper (I3). A second factor is district specific costs: RW costs in Northern Virginia are higher than in Culpeper, which would logically increase Culpeper's PE percentage (I3). A third factor is changing agency priorities such that a single percentage may not be appropriate (I5). For example, in the past VDOT almost "ran out of work" because too little money was spent on PE, owing to the large portion of funds dedicated to construction and debt service; more recently, the portion of funds recently focused on PE has been relatively low because of the emphasis on ARRA projects. 
One interviewee noted that for an entire program an appropriate PE percentage might be 15\%. However, consistent with the other interviewees (e.g., I3, I5, and I7) the interviewee noted other factors that influence such a percentage. One is the "non-predictability of funding," where the amount of funds available for investments changes over time. Such changes may occur more quickly than the project development process itself; for example, VDOT has a six year SYIP whereas for some projects the PE phase alone may take eight years. A second factor is the role of politics: state or local officials may influence time and cost for the PE phase of specific projects. Finally, project age-especially older unfinished projects-influence this percentage (I4).

It does not appear that PE percentages are reviewed at the program level, but they are reviewed at the project level. Regarding whether anyone reviews PE percentages the district level on a programmatic basis (e.g., how much has district $x$ spent on PE versus construction for an entire fiscal year with respect to all projects), no interviewees have noted that such programmatic reviews occur. To be clear, interviewees noted that project managers indeed track PE spending for specific projects that are being managed.

\section{Part 3: A Model to Forecast PE Expenditures at the Project Level}

This model uses project-specific characteristics, available at the beginning of the scoping phase, to predict the Preliminary Engineering (PE) cost of a full construction project. The approach consisted of six steps.

1. Review literature to identify methods for forecasting PE costs at the project level

2. Identify candidate project characteristics

3. Establish training and testing data sets

4. Investigate models based on construction cost alone

5. Develop models based on multiple variables

6. Verify model assumptions

\section{Literature Review of Methods for Forecasting PE Costs at the Project Level}

Four methods for forecasting PE costs at the project level were reported: Virginia's existing Project Cost Estimating System (PCES), a workbook for forecasting transit PE costs (FTA, 2011a,b), a sketch method for forecasting transit PE costs (AECOM et al., 2010), and approaches for forecasting bridge PE costs and roadway construction PE costs (Liu et al., 2011; Hollar et al. [undated]).

\section{Virginia's Project Cost Estimating System (PCES)}

The Project Cost Estimating Software (PCES) provides an order of magnitude estimate of PE costs for a specific project. PCES is a series of worksheets that subdivide a project into characteristics that affect its cost such as construction, traffic, bridge, right of way, and utilities. While PCES uses a variety of factors to determine the total construction and right-of-way costs of a project, the approach for determining the amount of funds that should be expended on preliminary engineering is relatively straightforward. Information from Bourne $(2012 a, b, c)$ 
shows that PE cost estimates are initially determined by multiplying a certain percentage by the construction cost estimates. This certain percentage decreases as the construction cost increases, as was shown in Figure 2, where PCES uses three equations depending on the construction cost estimate.

For example, suppose a project has a $\$ 3 \mathrm{M}$ construction cost estimate. Because this estimate is less than $\$ 5 \mathrm{M}$, the percentage assigned to $\mathrm{PE}$ is calculated as 0.203 -

$\$ 3 \mathrm{M}^{*} 0.000000014=0.161$, or $16.1 \%$. Thus PE costs would be forecasted to be $16.1 \%(\$ 3 \mathrm{M})=$ $\$ 0.483 \mathrm{M}$. Note that PCES increases the PE estimate by $50 \%$ if the work is performed by consultants. Thus, if one were informed that consultants were performing one quarter of the PE work in this example, then the PE cost estimate would increase from $\$ 0.483$ to $\$ 0.483(1+$ $0.5(25 \%))=\$ 0.543 \mathrm{M}$. A project manager may then adjust this basic estimate with unusual or additional preliminary engineering costs, based on the manager's experience and knowledge of the project.

As is the case with other methods, (Liu et al., 2011), PCES performs PE estimates for roadway projects separately from bridge projects. Bourne (2012a) explains that there are no PE charges for RW and that the percentage of PE for bridges is computed as $3.145+$ $(12,119,300 /$ bridge construction cost estimate).

\section{Workbook Transit PE Cost Forecasting Method}

FTA (2011a,b) created the Standard Cost Categories (SCC), a new capital estimation format to "establish a consistent format for the reporting, estimating, and managing of capital costs for New Starts projects"(FTA, 2011a). Transit project cost information was gathered from the FTA's Capital Cost Database. The cost estimator helps create a greater understanding of reasonable cost ranges and improve the reliability of cost estimates. The sources of project costs are divided into ten categories as shown in Table 6, with each category's contribution to the total construction cost and total project cost.

Table 6. FTA Standard Cost Categories for Capital Projects (FTA, 2011b)

\begin{tabular}{|l|l|l|l|}
\hline Row No. & Funding Source Category & $\begin{array}{l}\text { \% of CN } \\
\text { Cost }\end{array}$ & $\begin{array}{l}\text { \% of Total } \\
\text { Cost }\end{array}$ \\
\hline 1 & Guideway \& Track Elements & 44 & 28 \\
\hline 2 & Stations, Stops, Terminals, Intermodal & 15 & 9 \\
\hline 3 & Support Facilities & 5 & 3 \\
\hline 4 & Sitework \& Special Conditions & 22 & 14 \\
\hline 5 & Systems & 15 & 10 \\
\hline $\boldsymbol{a}$ & CN Subtotal & $\mathbf{1 0 0 \%}$ & $\mathbf{6 4 \%}$ \\
\hline 6 & RW, Land, Existing Improvements & & 7 \\
\hline 7 & Vehicles & & 6 \\
\hline 8 & Professional Services & & 17 \\
\hline 9 & Unallocated contingency & 5 \\
\hline 10 & Finance Charges & & 1 \\
\hline & TOTAL & $100 \%$ \\
\hline
\end{tabular}

${ }^{a}$ Rows $1-5$ show $100 \%$ of the construction costs such that construction costs are $64 \%$ of total project costs. 
The PE phase falls within the Professional Services category (row 8) and is defined as "early design, negotiations for operations and/or maintenance, developing financial plans, and ridership studies" (AECOM et al., 2010). Other tasks listed in the professional services category include, but are not limited to "Final Design", "Project Management for Design and Construction", "Construction Administration \& Management", "Legal;" and "Surveys and Start Up." (FTA, 2011b). While FTA's definition of PE (e.g., early design) does not contradict VDOT's definition of PE (which also includes early design), note that VDOT's definition of PE is considerably more expansive and includes activities such as final design and surveys which are not included in FTA's definition of PE.

\section{Sketch Transit PE Cost Estimation Method}

In TCRP Report 138 ("Estimating Soft Costs for Major Public Transportation Fixed Guideway Projects"), AECOM et al. (2010) created a four-step process to estimate the "soft costs" for heavy and light rail transit projects, where such soft costs include what VDOT would characterize as preliminary engineering but which may include non-PE activities, such as management of the construction project. Table 7 outlines the four steps of this process.

Table 7. Four-Step Process for Estimating Soft Costs for Transit Projects (AECOM et al., 2010)

\begin{tabular}{|l|l|l|}
\hline Step & Process Name & Description \\
\hline 1 & Begin with Default Averages & Begin with average actual historical soft costs for each component. \\
\hline 2 & $\begin{array}{l}\text { Adjust Based on Mathematical } \\
\text { Relationships }\end{array}$ & $\begin{array}{l}\text { Increase or decrease the soft cost percentages based on how the } \\
\text { project fits into any of several unique situations. }\end{array}$ \\
\hline 3 & $\begin{array}{l}\text { Adjust Based on Categorical } \\
\text { Relationships }\end{array}$ & $\begin{array}{l}\text { Adjust the soft cost estimate following the numerical relationship } \\
\text { between the project's characteristics and historical soft costs. }\end{array}$ \\
\hline 4 & Apply Judgment & $\begin{array}{l}\text { Apply some degree of discretion based on knowledge about the } \\
\text { unique and intangible qualities of the project and its sponsor. }\end{array}$ \\
\hline
\end{tabular}

These steps are summarized as follows, with all quotes from AECOM et al. (2010):

1. Begin with Default Averages. The default averages are "consistent with "average midpoint estimates currently used in the industry, and so provide a safe and wellestablished starting point for estimation purposes." Table 14 shows that the starting point is to assume that soft costs can be estimated as $29.5 \%$ of the construction cost estimate. (Note that Table 8 aligns with the FTA's standard cost categories except that project management and construction administration are combined and that that legal permits, surveys, and startup are combined.)

Table 8. Default Averages (AECOM et al., 2010)

\begin{tabular}{|l|l|}
\hline Cost Type (Abbreviation) & $\begin{array}{l}\text { Percent of CN Cost } \\
\mathbf{\%}\end{array}$ \\
\hline Preliminary Engineering (PE) & $2 \%$ \\
\hline Final Design (FD) & $12 \%$ \\
\hline PM/CA (Project Management/Construction Administration) & $12.5 \%$ \\
\hline Insurance & $2 \%$ \\
\hline Legal permits, surveys, and start up (Other) & $1 \%$ \\
\hline Total & $\mathbf{2 9 . 5 \%}$ \\
\hline
\end{tabular}


2. Adjust Based on Mathematical Relationships. The characteristics that should be evaluated when adjusting the default values are transit alignment length, construction costs, mode, installation conditions, delivery method, and economic conditions. Each of these attributes can increase or decrease the soft costs by implementing a specific formula reported therein.

3. Adjust based on Categorical Relationships. The categorical features are whether the project has an Unusually Long Project Development Phase, Unusual Political Influence, or Agency Tendency to Minimize Capital Charges. These features are more difficult to assess because they cannot always be determined by a "yes" or "no."

4. Apply Judgment. In this phase, the project managers must use experience and "knowledge about the unique and intangible qualities of the project."

The guidelines are intended not only to help estimate costs but also identify possible obstacles early in the process.

\section{Approach for Forecasting Bridge and Roadway PE Costs}

Liu et al. (2011) report that FHWA indicated that state DOTs use three general approaches to estimate overall project costs (not just PE costs), which are (1) "parametric estimating using historical cost figures"; (2) "detailed estimating using quantity takeoff techniques and pricing of labor, equipment, and materials" and (3) a combination of the two, but that states "typically estimate PE costs as a fixed percentage of estimated construction costs disregarding other project-specific parameters." For North Carolina DOT, Liu et al. (2011) calculated the ratio of PE costs to construction costs for bridge projects separately from roadway projects; the former exhibited a considerably higher ratio $(27.8 \%)$ than the latter $(11.7 \%)$. The authors noted, however, that despite the practice of assuming PE costs are $10 \%$ of total project cost, there are many factors that can affect that percentage (Liu et., al 2011).

Accordingly, Liu et al. (2010) developed a models to better forecast this ratio for both bridge projects and roadway projects. The general approach was to acquire project data, select predictive variables, applying regression techniques, and then test the model on data not used to calibrate the model (Hollar et al., undated). For example, for the bridge PE costs, a sample of 505 projects for the period 1999-2008 was chosen. Twenty-eight possible variables were examined and categorized into eight groups (Class, Cost, Date, Design, Dimension, Environmental, Geographic Location). Models for forecasting the ratio of bridge PE costs to construction costs, using between eight and fourteen variables, were developed and yielded $\mathrm{R}^{2}$ values of 0.65 and 0.72 respectively.

Liu et al. (2011) note that for the roadway projects, one particular linear regression model used six statistically significant independent variables with no interactions: (1) whether the project contained an interchange; (2) whether the project was a retrofit (as opposed to a new location); (3) the ratio of the RW cost estimate to the $\mathrm{CN}$ cost estimate; (4) the "roadway percentage of construction cost"; (5) the number of lanes; and (6) whether the project is located in one particular North Carolina division (such divisions are analogous to a VDOT construction 
districts). This model, calibrated from 150 roadway projects, yielded an adjusted $\mathrm{R}^{2}$ of 0.52 ; note that the dependent variable was transformed to be the cubed root of the ratio of PE costs to construction costs.

In terms of assessing performance, Liu et al. (2011) selected an additional 38 roadway projects that were not used to build the models and compared the predicted ratio to the observed ratio. Considering the aforementioned linear regression model, the mean absolute average error for the model was 0.1159 in terms of the dependent variable (e.g., the cubed root of the ratio). Accordingly, the mean absolute error of ratio, without the transformation, would have been somewhat different. For instance, if for a given project the actual ratio of $\mathrm{PE} / \mathrm{CN}=11.7 \%$ and the predicted ratio $=22.14 \%$, then this will correspond to an average error of 0.1159 in the dependent variable (since $0.117^{1 / 3}-0.2214^{1 / 3}=0.1159$ ) but only an error of 0.1044 for the actual ratio (since $0.2214-0.117=0.1044$ ). While these are a substantial improvement over the NCDOT's previous practice of assuming a constant percentage for the ratio of PE to CN costs, Liu et al. (2011) cautioned that their models could not capture the "risk factors" that cause PE costs to rise dramatically for a given project, such as public opposition or environmental impacts, both of which were noted in the early VDOT interviews with Fredericksburg and Bristol District staff $(\mathrm{I} 1, \mathrm{I} 2)$.

\section{Summary of the Literature Review}

At the project level, a best practice reported in the literature review (AECOM et al., 2010) is to develop formal analytical procedures to estimate the funding required for preliminary engineering rather than assuming that preliminary engineering will be a fixed percentage of $\mathrm{CN}$ costs (Liu et al., 2010). Such procedures may also be supported by the availability of planninglevel traffic impacts data (Dowling, 2012) and are necessitated by observations that forecasted preliminary engineering costs lower than actual costs (Liu et al., 2011). The analytical methods reviewed (e.g., AECOM et al. [2010]) require an element of judgment as is the case with Virginia's PCES.

\section{Identification of Candidate Project Characteristics}

The last question in the district interviews asked for project characteristics that should be considered in the development of the model. Suggested characteristics fell into five categories: Magnitude, Infrastructure, External Factors, Funding and Location.

\section{Magnitude}

1. Construction Estimate: Defining the scale of a project such as distinguishing whether the project is either tier 1 (under $\$ 5 \mathrm{M}$ ) or tier 2 (above $\$ 5 \mathrm{M}$, design-build, or located on the interstate system) can impact the PE estimate (I8).

2. Types of stakeholders: Many projects have diverse types of stakeholders with varying motives affecting the PE estimate. Atypical stakeholders that can play a role in the PE 
phase are the National Park Service, the County Board of Supervisors and the military (I7).

3. Management: Projects can either be managed by a VDOT district, more than one VDOT district, Central Office, private consultants and locally. Defining these categories is difficult as many projects have multiple management systems. Some projects use on-call consultants, which gives the consultant an incentive to do this project well in order to be retained for future projects (I10).

\section{Infrastructure Requirements}

1. Type of intersection control: A traffic signal would raise the $\mathrm{CN}$ cost of a project by $\$ 300,000$ or more (I2, I4).

2. Type of materials and earthwork: Various materials and earthwork such as laid back slopes, stabilization, and excavation may be required for a project.

Additional changes may not be evident at the scoping stage (such as rock and or hazardous materials). The possibility of such unexpected findings will influence how much of a contingency should be established (I2, I6)

3. Type of survey: Aerial surveys are more expensive than topographical surveys. (See the revised PM-100 for this.) (I2)

4. Drainage: Revised federal drainage regulations may require more ROW because the method for calculating the amount of land required is now based on total ROW rather than additional ROW acquired for the project (I2).

5. Inclusion of noise abatement: An increase in project costs is attributed to the decision to include noise walls (I3).

6. Construction vehicle access: May require separate contracts for easements (I6).

7. Availability and number of culverts (I8).

\section{Funding}

1. Extent of Funding in the SYIP: Fully-funded might be defined as estimated PE, estimated RW, and a significant portion of the estimated $\mathrm{CN}$ being in the SYIP (I4).

2. State-funded or federally funded (I4).

3. The amount of funding per year (I5).

\section{Location}

1. Urban versus Rural (I4, I7). 
2. Environmentally Sensitive Area: Areas in Virginia such as the tidal region can require additional environmental review and affects the Hampton Roads District (I7).

3. Military Presence: In areas with is a large military presence, Hampton Roads District, many decisions are not made locally but at the Pentagon level. This means that some decisions will take longer-and hence costs will be affected and adds additional stakeholders. (I7).

\section{External Factors}

The external factors referenced in the district interviews such as political environment, PE duration, public involvement and the number of designs required, are largely dependent on one another.

\section{Political Environment}

If there is a fundamental shift in project expectations during the PE phase, then the likelihood of a redesign increases, which would increase the percentage of funds spent on PE. Changes in political environment include an increased emphasis on designing a project within certain funding constraints even if that means certain design practices cannot be followed and a need to revisit PE multiple times in order to yield a design that meets the $\mathrm{CN}$ budget (I1). Elected officials are also involved with public approval can complicate matters (I4, I6).

\section{PE Duration}

The PE duration can be measured as up to three variables: length of time in years, changes in internal stakeholders, and changes in external stakeholders (e.g., number of election cycles). Even projects with short PE durations can reflect a change in will, opinions and desires. While a bridge life cycle may be 75 years, and election life cycle can be 2 to 4 years showing that technical work is evaluated in a political environment (I10). Projects with longer PE phases may require either additional public involvement or duplication of key design tasks, both of which will increase the PE cost) (I3, I4, I7). Although duration was noted early on by the researchers, the Northern Virginia interview pointed out that a better representation of duration is from PE Start to CN Advertisement (I9). The PE duration on the Schedule and Estimates section of the Project Pool has PE, $\mathrm{RW}$ and $\mathrm{CN}$ in a start to finish relationship. Using the PE duration from PE start to $\mathrm{CN}$ Advertisement includes PE tasks that occur during the PE and ROW phase simultaneously.

\section{Public Involvement}

This characteristic was suggested by several of the interviewees but can be hard to quantify (I9). Metrics suggested to estimate the extent of the public involvement 
can measured by the length of the PE duration, number of design iterations and use of the "design approval letter" (I4, I6, I9). The duration can increase as the public involvement becomes more complex. Similarly, if designs are not approved then multiple alternative designs lengthen the project duration. However, the VDOT design approval letter indicates the response to public input and can sometimes be found on the iPM.

\section{Number of Designs}

The number of times a project was designed can double or triple the PE cost. However it is hard to tell the number of designs required other than by looking at PE cost and talking to Project Manager. (I7)

\section{Establishment of Training and Testing Data Sets}

The data collection process included preliminary screening by the authors and expert screening by district personnel, applied to a large list of VDOT projects to gather a sample of representative construction projects. The preliminary screening process removed projects that were anomalies (e.g., projects that were an enhancement, district-wide, a study only, or part of the American Recovery and Reinvestment Act). The expert screening process required district staff to examine specific projects and select any other projects that such staff considered to be anomalies in their district; for example, one interviewee identified maintenance and operations project that nonetheless was funded with a construction (section 603) allocation.

After the projects passed both screening tests, projects were selected if expenditures were reported for all three phases (PE, RW and $\mathrm{CN}$ ) and a scoping construction estimate was uploaded to the Project Pool from PCES. This criterion increased the likelihood that PE expenditures were complete (as most interviewees indicated that once $\mathrm{CN}$ began PE was largely finalized) and that a CN estimate was available. (It was not feasible to rely exclusively on projects that had been archived because those projects were relatively few.) This method produced 157 projects as shown in the second column of Table 15.

Early in the data selection process, district staff suggested that the data set be made of archived projects. This was important because it indicated that the project expenditures would not change. While one interview indicated that if the $\mathrm{CN}$ phase had begun then the PE phase was complete, making the use of only archived projects unnecessary (I5), one interview showed that the PE phase can remain open to charges after $\mathrm{CN}$ begins (I9). Therefore, in most cases the $\mathrm{PE}$ does not change after $\mathrm{CN}$ has begun but there are instances where PE can change after $\mathrm{CN}$ has begun. Ultimately, after the preliminary and expert screening, there were only 23 archived projects, and thus to enlarge the data set the criterion of using a project with $\mathrm{CN}$ expenditures was adopted. 
Table 9. Projects by District

\begin{tabular}{|l|l|l|l|}
\hline District & $\begin{array}{l}\text { Number of Projects with } \\
\text { PE/RW/CN }\end{array}$ & $\begin{array}{l}\text { Number of Projects with } \\
\text { PE/CN and NO RW }\end{array}$ & Total \\
\hline Bristol & 9 & 37 & 46 \\
\hline Culpeper & 4 & 3 & 7 \\
\hline Fredericksburg & 7 & 2 & 9 \\
\hline Hampton & 7 & 18 & 25 \\
\hline Lynchburg & 17 & 1 & 18 \\
\hline NOVA & 36 & 7 & 43 \\
\hline Richmond & 39 & 93 & 132 \\
\hline Salem & 11 & 14 & 25 \\
\hline Staunton & 27 & 35 & 62 \\
\hline Total & 157 & 210 & 367 \\
\hline
\end{tabular}

During the Northern Virginia District interview (which occurred while this data collection process was underway), it was noted that there are a significant number of projects that do not have a RW phase, but are still "typical" construction projects. The third column of Table 9 shows the additional projects for each district that have PE and CN but no dollars spent on RW.

A concern was that the projects without RW are fundamentally different from those with RW. One way to verify this concern is to determine if the construction estimates, and the preliminary engineering expenditures, between the projects with $\mathrm{PE} / \mathrm{RW} / \mathrm{CN}$ and projects with $\mathrm{PE} / \mathrm{CN}$ and NO RW were significantly different. The t-test, where unequal variances are assumed, indeed shows that both the CN Estimate and the PE Expenditures are significantly different $(p<0.001)$ between these two groups. Since the two data sets were significantly different, it was important to keep them separate, therefore the initial model only used projects that had expenditures for PE, RW and CN.

\section{Initial Data Set}

The data set had 157 projects that passed the preliminary and expert screening. These projects were split up into $80 \%$ training and $20 \%$ testing data sets. The training data set had 125 projects which were used to develop various models to forecast PE costs (see Table 10). The testing data set had 32 projects, which enables a comparison between the predicted PE costs (from the model) and the actual PE costs (from expenditures). The projects were divided into projects that had a scoping construction estimate under $\$ 5$ million, between $\$ 5$ and $\$ 18$ million, and over $\$ 18$ million. Since most of the projects were under $\$ 5$ million, the following models are entirely based on projects in that category.

Table 10. Projects with PE, RW, and CN Expenditures, by CN Scoping Estimate

\begin{tabular}{|l|l|l|l|l|}
\hline \multirow{2}{*}{ Data Type } & \multicolumn{2}{|l|}{ CN Scoping Estimate } & \multirow{2}{*}{ Total } \\
\cline { 2 - 5 } & Under \$5 Million & Between \$5-\$18 million & Over \$18 million & \\
\hline Training & 107 & 13 & 5 & 125 \\
\hline Testing & 26 & 5 & 1 & 32 \\
\hline
\end{tabular}


The first set of results showed a smaller nominal average error for the existing PCES model than the developed model. However the differences between the errors (based on PCES) and the errors (based on the developed models) were not significant. A contributing factor appears to be that the initial data set included projects with Minimum Plan (known as "M") and No Plan (known as "N") projects. Initially, rather than remove the $\mathrm{M}$ and $\mathrm{N}$ plan projects, the plan type was a fundamental characteristic included in the model as an independent variable. However, these models continued to have large error rates.

Recognizing that several district interviews had suggested excluding $\mathrm{M}$ and $\mathrm{N}$ projects from the data set, all $\mathrm{M}$ and $\mathrm{N}$ projects were removed from the data set as anomalies, which yielded only 88 projects (all of which had PE, RW and $\mathrm{CN}$ expenditures.) In order to increase the number of projects, those construction plan ("C") projects that had PE/ CN but no RW, which were shown in the third column of Table 15, were added back into the data set. This increased the data set to 156 projects and was the basis for further testing.

\section{Revised Data Set}

The revised data set has 156 projects, 69 of which had PE and $\mathrm{CN}$ expenditures but no RW, while 87 projects had PE, RW and CN expenditures. These projects again were split into $80 \%$ training and $20 \%$ testing data sets. The training data had 124 projects while the testing had 32 (see Table 11). The projects were then divided into projects that had a Scoping Construction Estimates under \$5 Million, between \$5 and \$18 million, and over \$18 million. Since most of the projects construction estimates were under $\$ 5$ million, the following models are entirely based on those projects.

Table 11. Revised Data Set for the Project Level Analysis

\begin{tabular}{|l|l|l|l|l|}
\hline Data Type & Under \$5 Million & $\mathbf{\$ 5 - \$ 1 8 ~ m i l l i o n}$ & Over \$18 million & Total \\
\hline Training & 97 & 19 & 8 & 124 \\
\hline Testing & 27 & 4 & 1 & 32 \\
\hline
\end{tabular}

Again two t-Tests were conducted to determine if the construction estimates and the preliminary engineering expenditures, between the projects with $\mathrm{PE} / \mathrm{RW} / \mathrm{CN}$ and projects with $\mathrm{PE} / \mathrm{CN}$ and NO RW were significantly different (but this test removed all $\mathrm{M}$ and $\mathrm{N}$ projects). The data sets were significantly different $(p=0.001$ for construction estimate and $\mathrm{p}<0.001$ for the PE expenditure). Accordingly, although both types of projects were retained in the data set, the model building process included a variable reflecting whether a project had RW expenditures was considered.

As discussed in the sections that follow, all models were calibrated with the training data set (except for the existing PCES which has already been calibrated). All models were evaluated with the testing data set of 27 projects. 


\section{Investigation of Models Based on Construction Cost Alone}

Two single-variable project-level models were considered.

- Model 1. Project Cost Estimating System (PCES)

- Model 2. PCES with New Parameters

\section{Model 1. Project Cost Estimating System (PCES)}

The existing PCES model is what VDOT uses at present to predict the PE estimate. This model was applied to the testing data and compared to the actual PE expenditures as a base case against which to judge the accuracy of any future models.

Equation 1 is used to determine the PE estimate from PCES is for projects under \$5 M:

$$
\text { PE Estimate }=(C N \text { Estimate }) *[0.203-(C N \text { Estimate }) * 0.000000014] \quad(\text { Eq. } 1)
$$

Based on the 27 projects in the testing data set that are under \$5 M, the PCES model has an average percentage error of $135 \%$, with the error, computed as the absolute difference between the actual PE expenditure the modeled expenditure, being about $\$ 200,000$. (For example, suppose the testing data set contained just two projects, where project 1 had actual expenditures of $\$ 100,000$ (but the model forecasted $\$ 130,000$ ) and project 2 had actual expenditures of $\$ 1$ million (which the model forecasted as $\$ 0.9$ million). The average absolute percent error is $20 \%$ and the average absolute error is $\$ 65,000$. Note further that the average percent error - if absolute values are not used-is $10 \%$ because the underprediction for project 2 partially cancels the overprediction for project 1 .

\section{Model 2. PCES with New Parameters}

The second approach used the training data to calibrate new coefficients for the same PCES equation as shown in Equations 2 and 3.

$$
\begin{aligned}
& \text { PE Estimate }=a * C N+b * C N^{2} \\
& \text { PE Estimate }=(0.3197 * C N)-\left(0.0000000294 * C N^{2}\right)
\end{aligned}
$$

Based on the testing data, Table 12 shows the average percent error and average absolute error for PCES and PCES with new parameters. PCES has a lower average absolute percent error while PCES with new parameters has a lower average absolute error. However, the paired t-test shows there is not a significant difference between PCES and PCES with new parameters for the average absolute percent error $(p=0.09)$ and average absolute error $(p=0.07)$.

Table 12. PCES and PCES (with new parameters) Average Error

\begin{tabular}{|l|l|l|l|l|}
\hline $\begin{array}{l}\text { Model } \\
\text { No }\end{array}$ & Model & $\begin{array}{l}\text { Average Absolute } \\
\text { Percent Error }\end{array}$ & $\begin{array}{l}\text { Average Percent } \\
\text { Error (absolute }\end{array}$ & $\begin{array}{l}\text { Average Absolute } \\
\text { Error }\end{array}$ \\
\hline
\end{tabular}




\begin{tabular}{|l|l|c|c|c|}
\hline & & & values not used $)$ & \\
\hline 1 & PCES & 133.6 & 77.1 & $\$ 194,648.89$ \\
\hline 2 & $\begin{array}{l}\text { PCES with new } \\
\text { parameters }\end{array}$ & $\begin{array}{c}202.1 \\
(\mathrm{p}=0.09)\end{array}$ & $\begin{array}{c}172.1 \\
(\mathrm{p}=0.01)\end{array}$ & $\begin{array}{c}\$ 153,972.08 \\
(\mathrm{p}=0.07)\end{array}$ \\
\hline
\end{tabular}

Figure 1 shows the actual preliminary engineering expenditures, PCES estimates and PCES with new parameter estimates. The PCES model with new parameters predicts a slightly higher estimate than the existing PCES model, and also shows substantial variation in the PE expenditures. The projects are listed in order of increasing $\mathrm{CN}$ cost from left to right, and the oscillation of the PE expenditures line suggests that other factors, besides $\mathrm{CN}$ cost, likely contribute to this oscillation. The desire to use other characteristics besides the CN estimate to reduce this variation is the motivation for models 3-7.

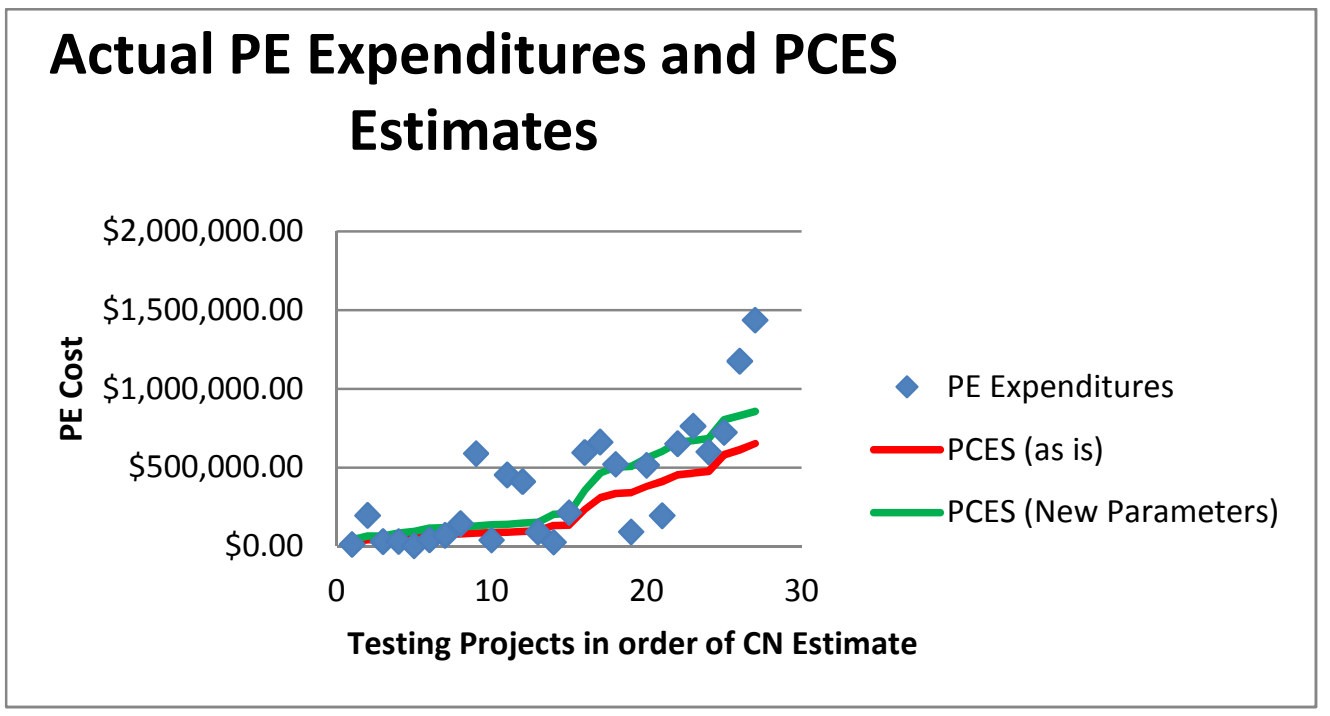

Figure 1 Actual PE Expenditures and PCES Estimates

\section{Development of Models with Additional Variables}

\section{Characteristic Selection}

Project characteristics, such as environmental factors (e.g., were wetlands required), order of magnitude factors (e.g., how many homes will be taken or how long is the project), and the delivery method (e.g., design-build project) were collected to better understand factors for forecasting the cost of preliminary engineering, as shown in Table 13.

Some of the characteristics were ultimately eliminated from consideration because the data were not available for all of the projects. The remaining characteristics that were available for every project in the data set were tested for statistical significance in terms of whether they explained the variation in preliminary engineering costs. Variables that were not significant 
were not used in the model; such variables were functional classification, facility type, district, and plan type).

Table 13. Project Level Model Characteristics

\begin{tabular}{|c|c|c|}
\hline All Characteristics & $\begin{array}{l}\text { Characteristics Tested } \\
\text { in the Model }\end{array}$ & $\begin{array}{l}\text { Characteristics Used } \\
\text { in the Model }\end{array}$ \\
\hline \multicolumn{3}{|l|}{ Environmental } \\
\hline Environmental Work & $\mathrm{X}$ & $\mathrm{X}$ \\
\hline \multicolumn{3}{|l|}{ Wetlands Mitigation } \\
\hline \multicolumn{3}{|l|}{ Bio Retention (water quality) basins considered? } \\
\hline \multicolumn{3}{|l|}{ Cost } \\
\hline \multicolumn{3}{|l|}{ PE Pre-Scoping Estimate } \\
\hline PE Expenditure & $\mathrm{X}$ & $\mathrm{X}$ \\
\hline \multicolumn{3}{|l|}{ Magnitude of Total Cost } \\
\hline \multicolumn{3}{|l|}{ Pre-Scoping RW Estimate } \\
\hline \multicolumn{3}{|l|}{ Ratio of RW to CN } \\
\hline CN Estimate & $\mathrm{X}$ & $\mathrm{X}$ \\
\hline \multicolumn{3}{|l|}{ Order of Magnitude } \\
\hline Functional Classification & $\mathrm{X}$ & \\
\hline Facility type & $\mathrm{X}$ & \\
\hline \multicolumn{3}{|l|}{ Design Services Provider } \\
\hline \multicolumn{3}{|l|}{ Transportation Management Plan Class } \\
\hline \multicolumn{3}{|l|}{ \# of Bridges } \\
\hline PE Phase Duration & $\mathrm{X}$ & $\mathrm{X}$ \\
\hline \multicolumn{3}{|l|}{ Businesses to be taken } \\
\hline \multicolumn{3}{|l|}{ Homes to be taken } \\
\hline \multicolumn{3}{|l|}{ Railroad involvement } \\
\hline \multicolumn{3}{|l|}{ Bike Ped Accommodations } \\
\hline District & $\mathrm{X}$ & \\
\hline VDOT or LAP & $\mathrm{X}$ & $\mathrm{X}$ \\
\hline Length & $\mathrm{X}$ & $\mathrm{X}$ \\
\hline $\mathrm{C}, \mathrm{M}$ or N Plan & $\mathrm{X}$ & \\
\hline \multicolumn{3}{|l|}{ Agreements } \\
\hline \multicolumn{3}{|l|}{ Required National Historic Preservation Act } \\
\hline \multicolumn{3}{|l|}{ HazMat Evaluation } \\
\hline \multicolumn{3}{|l|}{ Utility Relocation } \\
\hline \multicolumn{3}{|l|}{ IJR or IMR } \\
\hline \multicolumn{3}{|l|}{$\begin{array}{l}\text { Memorandum of Agreement, between public } \\
\text { agencies }\end{array}$} \\
\hline \multicolumn{3}{|l|}{ Recoverable Slope Study } \\
\hline \multicolumn{3}{|l|}{ Value Engineering Study } \\
\hline \multicolumn{3}{|l|}{ Delivery Method } \\
\hline \multicolumn{3}{|l|}{ Alternate Delivery Method? } \\
\hline Alternate Designs Considered (when in process) & & \\
\hline
\end{tabular}

The use of these characteristics led to the development of five additional models:

- Model 3. Non Linear with a Single Environmental Variable

- Model 4. Non Linear with Multiple Environmental Variables 
- Model 5. Exponential with a Single Environmental Variable

- Model 6. Exponential with Multiple Environmental Variables

- Model 7 Non Linear with ROW and no Environmental Variables

Note: Transformations of the dependent and independent variables were explored early on in the model development process to identify a linear relationship, help with correlation issues and distribution of residuals.

\section{Model 3. Non Linear with a Single Environmental Variable}

Non-linear equations (models 3, 4 and 7) and exponential equations (models 5 and 6) were considered. These models used descriptive project characteristics to predict the preliminary engineering cost. Model 3 used the construction estimate at the scoping phase, project duration, whether or not the project was administered by VDOT or Locally, project length and whether or not the project required a Categorical Exclusion environmental document. This nonlinear model may be made linear with a logarithmic transformation, and the parameters that are estimated based on the training data set are shown in Table 14 and Equations 4, 5, and 6. All parameters, except the intercept, were statistically significant. The VDOT and CE are binary independent variables thus their coefficient requires a transformation. Similarly, although the length independent variable is not binary there are projects that do require $0 \mathrm{mi}$ of length, thus the coefficient requires a transformation as well. Models 5-6 do not require transformations for length.

Table 14. Model 3 Coefficients and p-values

\begin{tabular}{|l|c|c|c|}
\hline \multicolumn{1}{|c|}{ Variable } & P value & Coefficient & Transformed \\
\hline Intercept & 0.6527 & 2.2285 & 2.2285 \\
\hline CN Estimate & $<.0001$ & 0.73010 & 0.73010 \\
\hline Duration & 0.0001 & 0.32275 & 0.32275 \\
\hline VDOT & $<.0001$ & 2.8634 & 2.8634 \\
\hline Length & 0.0025 & 0.64695 & 0.64695 \\
\hline CE & 0.0499 & 1.70796 & 1.70796 \\
\hline
\end{tabular}

$$
\begin{array}{rl}
\ln (P E)=\ln (a) & +b * \ln (C N \text { Estimate })+c * \ln (\text { Duration })+\text { VDOT } * \ln (d)+\text { Length } \\
& * \ln (f)+C E * \ln (g) \\
P E=e^{0.80137} & * C N \text { Estimate } 0.73010 * \text { Duration }^{0.32275} *\left(e^{1.05201^{\text {VDOT }}} * e^{-0.43548^{\text {Lenth }}}\right. \\
& * e^{0.53530^{C E}} \\
P E=2.2285 & * C N \text { Estimate } \\
& * 1.70796^{C E}
\end{array}
$$

(Eqs. 4-6)

Model 4. Non Linear with Multiple Environmental Variables

Model 4 (Table 15, Equations 7-9) is comparable to model 3 but separated the environmental variable into more specific categories by adding in whether the project required a 
categorical exclusion (CE), programmatic categorical exclusion (PCE), environmental assessment (EA), or no environmental work. While this added more variables into the model, it clarifies the specific type of environmental document needed for the project. The programmatic categorical exclusion and EA variables are not significant $(p>0.05)$ and thus may be removed.

Table 15. Model 4 Coefficients and p-values

\begin{tabular}{|l|l|l|c|}
\hline Variable & P value & Coefficient & Transformed \\
\hline Intercept & 0.9440 & 1.139911 & 1.139911 \\
\hline CN Estimate & $<.0001$ & 0.75025 & 0.75025 \\
\hline Duration & 0.0003 & 0.30267 & 0.30267 \\
\hline VDOT & $<.0001$ & 2.844621 & 2.844621 \\
\hline Length & 0.0036 & 0.657099 & 0.657099 \\
\hline Categorical exclusion & 0.0204 & 2.525477 & 2.525477 \\
\hline $\begin{array}{l}\text { Programmatic categorical } \\
\text { exclusion }\end{array}$ & 0.1638 & 1.641204 & 1.641204 \\
\hline Environmental assessment & 0.9173 & 0.889683 & 0.889683 \\
\hline
\end{tabular}

$$
\begin{gathered}
\ln (P E)=\ln (a)+b * \ln (C N \text { Estimate })+c * \ln (\text { Duration })+V D O T * \ln (d)+\text { Length } * \\
\ln (f)+C E * \ln (g)+P C E * \ln (h)+E A * \ln (\mathrm{j}) \\
P E=e^{0.13095} * C N \text { Estimate } e^{0.75025} * \text { Duration }^{0.30267} * e^{1.04543^{V D O T}} * e^{-0.41992^{\text {Lenth }}} \\
* e^{0.92643^{C E}} * e^{0.49543^{P C E}} e^{*-0.11689^{E A}} \\
P E=1.139911 * \text { CN Estimate } \text { Estimg }^{0.75025} * \text { Duration }^{0.30267} * 2.844621^{\text {VDOT }} * 0.657099^{\text {Length }} \\
* 2.525477^{C E} * 1.641204^{P C E} * 0.889683^{E A}
\end{gathered}
$$

(Eqs. 7-9)

Model 5. Exponential with a Single Environmental Variable

The exponential format used the same characteristics: duration, whether or not the project was administered by VDOT or locally, project length and whether or not the project required a Categorical Exclusion environmental document (see Table 16, Equations 10-11).

Table 16. Model 5 Coefficients and p-values

\begin{tabular}{|l|c|c|c|}
\hline \multicolumn{1}{|c|}{ Variable } & P value & Coefficient & Transformed \\
\hline Intercept & 0.8918 & 0.26092 & 1.2981 \\
\hline CN Estimate & $<.0001$ & 0.77742 & 0.77742 \\
\hline Duration & 0.0646 & 0.05091 & 0.05091 \\
\hline VDOT & 0.0003 & 1.00212 & 1.00212 \\
\hline Length & 0.0031 & -0.45843 & -0.45843 \\
\hline Categorical exclusion & 0.0243 & 0.65853 & 0.65853 \\
\hline
\end{tabular}

$$
\ln (P E)=\ln (a)+b * \ln (C N \text { Estimate })+c * \text { Duration }+d * V D O T+f * \text { Length }+g * C E
$$$$
P E=1.2981 * C N \text { Estimate } e^{0.77742} * e^{(0.05091 * \text { Duration }+1.00212 * V D O T-0.45843 * \text { Length }+0.65853 * C E)}
$$

(Eqs. 10-11) 
Model 6. Exponential with Multiple Environmental Variables

Similar to the nonlinear function when the specific types of environmental documents were added to the model the PCE and EA variables were insignificant as shown in Table 17 and Equations 12-13.

Table 17. Model 6 Coefficients and p-values

\begin{tabular}{|l|c|c|c|}
\hline \multicolumn{1}{|c|}{ Variable } & P value & Coefficient & Transformed \\
\hline Intercept & 0.7325 & 0.508810 & 1.66331 \\
\hline CN Estimate & $<.0001$ & 0.80475 & 0.80475 \\
\hline Duration & 0.0864 & 0.04692 & 0.04692 \\
\hline VDOT & 0.0003 & 0.98595 & 0.98595 \\
\hline Length & 0.0047 & -0.43504 & -0.43504 \\
\hline Categorical exclusion & 0.0041 & 1.20153 & 1.20153 \\
\hline $\begin{array}{l}\text { Programmatic } \\
\text { categorical exclusion }\end{array}$ & 0.0628 & 0.69339 & 0.69339 \\
\hline $\begin{array}{l}\text { Environmental } \\
\text { assessment }\end{array}$ & 0.8565 & 0.21509 & 0.21509 \\
\hline
\end{tabular}

$$
\begin{aligned}
& \ln (P E)=\ln (a)+b * \ln (C N \text { Estimate })+c * \text { Duration }+d * V D O T+f * \text { Length }+g * C E \\
& +h * P C E+j * E A \\
& P E=0.5088 * C N \text { Estimate } e^{0.80475} \\
& * e^{(0.04692 * \text { Duration }+0.98595 * V D O T-0.43504 * \text { Length }+1.20153 * C E+0.69339 * P C E+0.21509 * E A)}
\end{aligned}
$$

(Eqs. 12-13)

Model 7. Non Linear- Duration, VDOT, Length, ROW

Similar to model 3 and 4, this model 7 (Table 18, Equation 14) uses a non linear format, but does not include the environmental independent variable of $\mathrm{CE}$. Instead the model includes whether or not the project required ROW.

Table 18. Model 7 Coefficients and p-values

\begin{tabular}{|l|c|c|c|}
\hline \multicolumn{1}{|c|}{ Variable } & P value & Coefficient & Transformed \\
\hline Intercept & 0.6790 & 0.70330 & 2.02041 \\
\hline CN Estimate & $<.0001$ & 0.73033 & 0.73010 \\
\hline Duration & 0.0001 & 0.31147 & 0.32275 \\
\hline VDOT & 0.0021 & 0.82842 & 2.89696 \\
\hline Length & 0.0080 & -0.37764 & 0.68547 \\
\hline ROW & 0.0048 & 0.72754 & 2.06998 \\
\hline
\end{tabular}

$$
\begin{gathered}
\ln (P E)=\ln (a)+b * \ln (C N \text { Estimate })+c * \ln (\text { Duration })+V D O T * \ln (d)+\text { Length } \\
* \ln (f)+R O W * \ln (g)
\end{gathered}
$$

(Eq. 14) 
Summary of Performance for Program Level Models 3-7

In terms of performance with the training data set, Table 19 shows project level models 3-7 tested with the $\mathrm{R}^{2}$ and adjusted $\mathrm{R}^{2}$ values. The non linear models (models 3, 4 and 7) have a higher adjusted $\mathrm{R}^{2}$ value compared to the exponential models (models 5 and 6 ).

Table 19. Project Level Model Characteristics with the Training Data Set

\begin{tabular}{|c|c|c|c|c|c|c|}
\hline No. & Model & Characteristic & p-value & Coefficient & $\mathbf{R}^{2}$ & Adjusted $\mathbf{R}^{2}$ \\
\hline \multirow[t]{6}{*}{3} & \multirow{6}{*}{$\begin{array}{l}\text { Non Linear- Duration, } \\
\text { Length, VDOT, CE }\end{array}$} & Intercept & 0.6527 & 2.2285 & \multirow[t]{6}{*}{0.6025} & \multirow[t]{6}{*}{0.5806} \\
\hline & & CN Est & $<.0001$ & 0.73010 & & \\
\hline & & Duration & 0.0001 & 0.32275 & & \\
\hline & & VDOT & $<.0001$ & 2.8634 & & \\
\hline & & Length & 0.0025 & 0.64695 & & \\
\hline & & $\mathrm{CE}$ & 0.0499 & 1.70796 & & \\
\hline \multirow[t]{8}{*}{4} & \multirow{8}{*}{$\begin{array}{l}\text { Non Linear- Duration, } \\
\text { VDOT, Length, CE, } \\
\text { PCE, EA }\end{array}$} & Intercept & 0.9440 & 1.139911 & \multirow[t]{8}{*}{0.6123} & \multirow[t]{8}{*}{0.5818} \\
\hline & & CN Estimate & $<.0001$ & 0.75025 & & \\
\hline & & Duration & 0.0003 & 0.30267 & & \\
\hline & & VDOT & $<.0001$ & 2.844621 & & \\
\hline & & Length & 0.0036 & 0.657099 & & \\
\hline & & $\mathrm{CE}$ & 0.0204 & 2.525477 & & \\
\hline & & PCE & 0.1638 & 1.641204 & & \\
\hline & & EA & 0.9173 & 0.889683 & & \\
\hline \multirow[t]{6}{*}{5} & \multirow{6}{*}{$\begin{array}{l}\text { Exponential- Duration, } \\
\text { Length, VDOT, CE }\end{array}$} & Intercept & 0.8918 & 0.26092 & \multirow[t]{6}{*}{0.5477} & \multirow[t]{6}{*}{0.5229} \\
\hline & & CN Est & $<.0001$ & 0.77742 & & \\
\hline & & Duration & 0.0646 & 0.05091 & & \\
\hline & & VDOT & 0.0003 & 1.00212 & & \\
\hline & & Length & 0.0031 & -0.45843 & & \\
\hline & & $\mathrm{CE}$ & 0.0243 & 0.65853 & & \\
\hline \multirow[t]{8}{*}{6} & \multirow{8}{*}{$\begin{array}{l}\text { Exponential- Duration, } \\
\text { Length, VDOT, CE, } \\
\text { PCE, EA }\end{array}$} & Intercept & 0.7325 & 0.508810 & \multirow[t]{8}{*}{0.5657} & \multirow[t]{8}{*}{0.5315} \\
\hline & & CN Estimate & $<.0001$ & 0.80475 & & \\
\hline & & Duration & 0.0864 & 0.04692 & & \\
\hline & & VDOT & 0.0003 & 0.98595 & & \\
\hline & & Length & 0.0047 & -0.43504 & & \\
\hline & & $\mathrm{CE}$ & 0.0041 & 1.20153 & & \\
\hline & & PCE & 0.0628 & 0.69339 & & \\
\hline & & EA & 0.8565 & 0.21509 & & \\
\hline \multirow[t]{6}{*}{7} & \multirow{6}{*}{$\begin{array}{l}\text { Non Linear- Duration, } \\
\text { VDOT, Length, ROW }\end{array}$} & Intercept & 0.6790 & 0.70330 & \multirow[t]{6}{*}{0.62} & \multirow[t]{6}{*}{0.60} \\
\hline & & CN Est & $<.0001$ & 0.73033 & & \\
\hline & & Duration & 0.0001 & 0.31147 & & \\
\hline & & VDOT & 0.0021 & 0.82842 & & \\
\hline & & Length & 0.0080 & -0.37764 & & \\
\hline & & ROW & 0.0048 & 0.72754 & & \\
\hline
\end{tabular}

$\mathrm{CE}=$ Categorical exclusion, $\mathrm{PCE}=$ Programmatic categorical exclusion, $\mathrm{EA}=$ Environmental assessment

Table 20 shows the average percent error (with and without absolute value) and the average absolute error of each of the models based on the testing data set. The error in the PCES model is the base for comparison. These columns have a slightly different nuance: percent error weights each project equally, regardless of size, whereas absolute error weights errors associated 
with larger projects more heavily. The PCES model with new parameters has a much higher average percent error than PCES but has a lower absolute error. All five of the models using project characteristics have lower nominal errors than PCES. The values in parentheses indicate whether there is a substantial difference between the model and model 1 based on the paired ttest.

Table 20. Average Percent Error and Absolute Error for All Project Level Models

\begin{tabular}{|l|l|l|l|l|}
\hline Model No. & Model Name & $\begin{array}{l}\text { Average Absolute } \\
\text { Percent Error }\end{array}$ & $\begin{array}{l}\text { Average Percent } \\
\text { Error (absolute } \\
\text { values not used) }\end{array}$ & Average Absolute Error \\
\hline 1 & PCES & $133.6(\mathrm{~N} / \mathrm{A})$ & $77.1(\mathrm{~N} / \mathrm{A})$ & $\$ 194,648.89(\mathrm{~N} / \mathrm{A})$ \\
\hline 2 & PCES with new parameters & $202.1(p=0.09)$ & $172.1(p=0.01)$ & $\$ 153,972.08(p=0.07)$ \\
\hline 3 & $\begin{array}{l}\text { Non Linear- Duration, } \\
\text { Length, VDOT, CE }\end{array}$ & $43.9(p=0.08)$ & $-4.1(p=0.013)$ & $\$ 109,040.12(p=0.02)$ \\
\hline 5 & $\begin{array}{l}\text { Non Linear- Duration, } \\
\text { VDOT, Length, CE, PCE } \\
\text { EA }\end{array}$ & $45.8(p=0.08)$ & $-1.63(p=0.12)$ & $\$ 105,598.54(p=0.02)$ \\
\hline 6 & $\begin{array}{l}\text { Exponential- Duration, } \\
\text { Length, VDOT, CE }\end{array}$ & $54.9(p=0.06)$ & $2.78(p=0.09)$ & $\$ 108,951.09(p=0.02)$ \\
\hline 7 & $\begin{array}{l}\text { Exponential- Duration, } \\
\text { Length, VDOT, CE, PCE, } \\
\text { EA }\end{array}$ & $56.5(p=0.06)$ & $7.34(p=0.09)$ & $\$ 103,316.41(p=0.02)$ \\
\hline & $\begin{array}{l}\text { Non Linear- Duration, } \\
\text { VDOT, Length, ROW }\end{array}$ & $45.2(p=0.09)$ & $-5.0(p=0.09)$ & $\$ 129,232,19(p=0.005)$ \\
\hline
\end{tabular}

Note that there is not a significant difference, based on the paired t-test, for the average absolute percent error. The reason for this may be the relatively high probability of a type 2 error - that is, the probability of failing to detect a significant difference even though such a difference exists - for this particular data set. An operating characteristic curve for the paired ttest based on the sample size $n=27$ and the sample standard deviation of $\sigma=259 \%$ suggests that if the difference in the average absolute paired error is $60 \%$, there is only a $23 \%$ probability of detecting that error. 


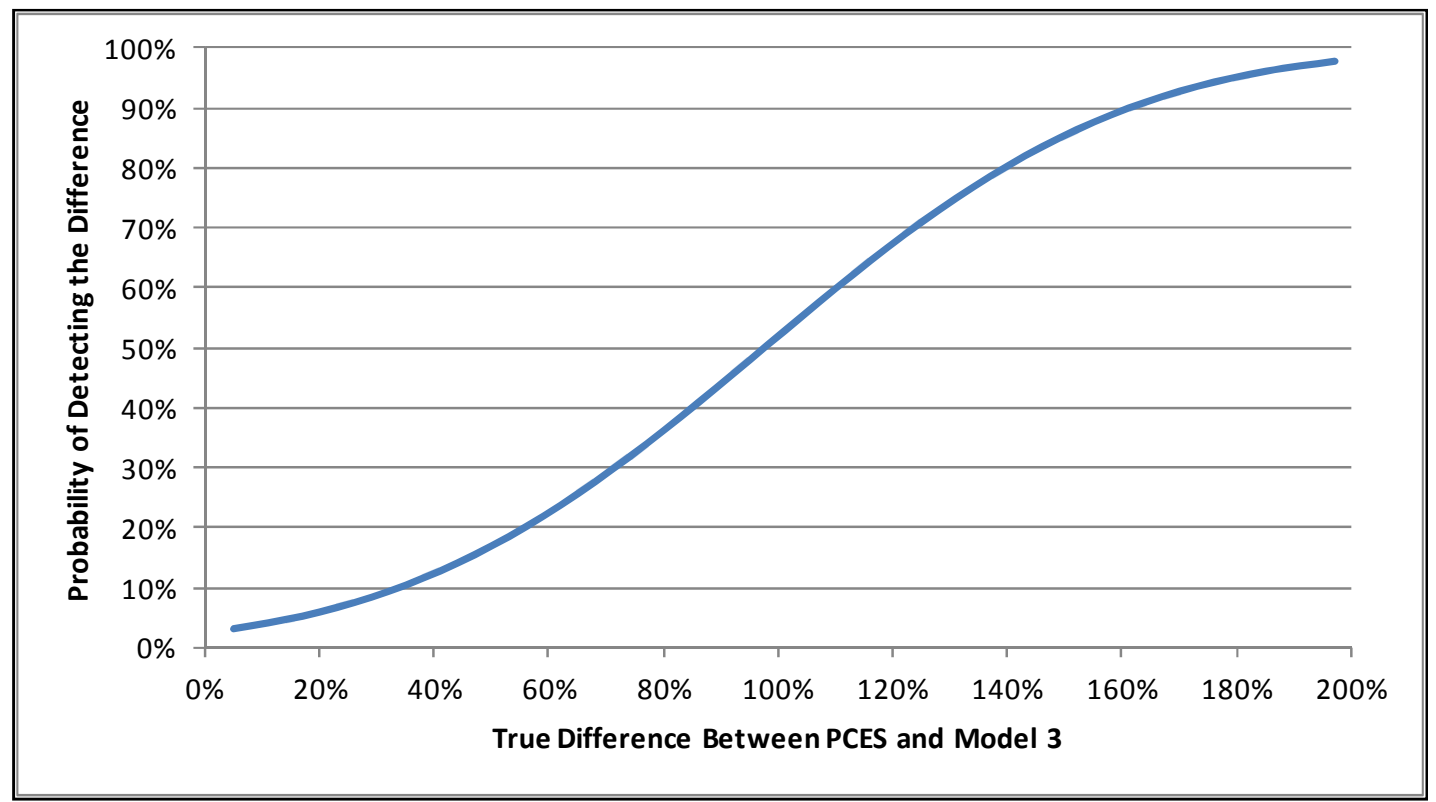

Figure 2. Power Curve for the Paired T-Test Results in Table 20 (Model 3). The values on the vertical axis are plotted based on this relationship in Eq. 15, where $\Phi$ is the standard normal cumulative distribution.

$$
\Phi\left[\sqrt{\frac{(\mathrm{n}=27)(\text { true difference })^{2}}{(\sigma=258 \%)^{2}}}-\left(Z_{\alpha}=1.96\right)\right]
$$

For this particular data set, Figure 2 is instructive because the probability of detecting a true difference between model performance is relatively low (below 40\%) if the true difference between the models is below $\$ 60,000$. Two factors explain why it is hard to detect such differences. One is the relatively small n, with just 27 testing samples. The other factor is a large $\sigma$ owing to scatter in the data set: when one compares how close PCES came to the true PE cost and how close Model 3 came to the true PE cost, the difference between these two quantities ranged from $\$ 1,129$ (the models were very close) to $\$ 748,098$ (one model performed much better than the other). Thus, it is probable that while the authors have minimized the likelihood of type 1 error with a value of 0.05 , the fact that some models show nominal average differences of under $\$ 100,000$ leads one to suspect that the probability of Type 2 error is larger. In short, the authors are more confident that the models which are cited as being different in terms of performance truly are different, but the authors are less confident that they have detected all of the significant differences between the models.

\section{Goodness of Fit Measurement of the Testing Data Set}

The goodness of fit measurement $\left(\mathrm{R}^{2}\right)$ is an important indication of how well the independent variables explain the data in the training data set. However, a goodness of fit measurement of the testing data will also show how well the testing data is explained by the model and the accuracy of the model. Table 21 shows the $\mathrm{R}^{2}$ values for models $3-7$. In all 5 models the adjusted $\mathrm{R}^{2}$ values on the testing data were higher than the training data set, suggesting that the independent variables explain the variation in the testing set better than the training data set. Additional validation data may change these results. 
Table $21 \mathbf{R}^{2}$ Measurement for Testing Data

\begin{tabular}{|l|l|l|l|l|c|c|}
\hline $\begin{array}{l}\text { Model } \\
\text { No. }\end{array}$ & Model Name & SSE & SSR & SST & $\begin{array}{l}\text { Adjusted R } \\
\text { (Testing) }\end{array}$ & $\begin{array}{l}\text { Adjusted R }^{2} \\
\text { (Training) }\end{array}$ \\
\hline 3 & $\begin{array}{l}\text { Non Linear- Duration, } \\
\text { Length, VDOT, CE }\end{array}$ & $7.24 \mathrm{E}+11$ & $3.75 \mathrm{E}+12$ & $4.48 \mathrm{E}+12$ & 0.81 & 0.58 \\
\hline 4 & $\begin{array}{l}\text { Non Linear- Duration, } \\
\text { VDOT, Length, CE, } \\
\text { PCE EA }\end{array}$ & $7.22 \mathrm{E}+11$ & $3.72 \mathrm{E}+12$ & $4.44 \mathrm{E}+12$ & 0.79 & 0.58 \\
\hline 5 & $\begin{array}{l}\text { Exponential- Duration, } \\
\text { Length, VDOT, CE }\end{array}$ & $7.03 \mathrm{E}+11$ & $3.84 \mathrm{E}+12$ & $4.54 \mathrm{E}+12$ & 0.82 & 0.52 \\
\hline 6 & $\begin{array}{l}\text { Exponential- Duration, } \\
\text { Length, VDOT, CE, } \\
\text { PCE, EA }\end{array}$ & $7.04 \mathrm{E}+11$ & $3.80 \mathrm{E}+12$ & $4.51 \mathrm{E}+12$ & 0.80 & 0.53 \\
\hline 7 & $\begin{array}{l}\text { Non Linear- Duration, } \\
\text { VDOT, Length, ROW }\end{array}$ & $1.30 \mathrm{E}+12$ & $2.42 \mathrm{E}+12$ & $3.72 \mathrm{E}+12$ & 0.59 & 0.60 \\
\hline
\end{tabular}

\section{Characteristic Selection}

A criticism brought up in the November 2013 Transportation Planning Research Advisory Committee meeting was that the models were developed using characteristic data from projects that were already complete. This adds a complication because if these models are implemented for planning purposes then one would not have the exact information required at the early stages of the project. For example, all of the models have duration as an independent variable. If a model were to use duration for planning purposes, the forecasting model will not be able to make use of the actual duration. This suggests that a proxy for duration may be necessary.

Various methods to account for the unknown duration at the inception of a project were considered. The accuracy was computed for model 3 using three scenarios.

1. No duration information is available therefore the project duration is unknown (average project duration)

2. The user of the model has basic a understanding of the forecasted project duration; therefore a high or low value for duration will be used in the model.

3. The user makes a poor estimate of duration and the opposite (high or low) will be used in the model.

The average duration was 3.75 years, the high duration was 6.1 years and the low was 1.8 years. Table 22 shows the results using the post project duration and the three duration scenarios. Surprisingly, when less information is known about the project, the average absolute error is lower than when the exact project duration is used. The average duration produced an average absolute error of $\$ 104,035$ and the High/Low duration yielded an average absolute error of $\$ 107,728$. However, when a poor estimate is used in the model, where the user either over or under estimates the duration, the absolute error is higher than that produced using the exact 
duration by about $\$ 28,000$. Note that there is a significant difference, based on the paired t-test, between each of these models and the actual PE expenditures.

Table 22 Accuracy Using Various Duration Knowledge

\begin{tabular}{|l|c|}
\hline Model Name & $\begin{array}{l}\text { Average Absolute } \\
\text { Error }\end{array}$ \\
\hline $\begin{array}{l}\text { Post Project } \\
\text { Duration }\end{array}$ & $\begin{array}{c}\$ 109,040.12 \\
(p=0.02)\end{array}$ \\
\hline $\begin{array}{l}\text { Average Duration } \\
(3.75 \text { year })\end{array}$ & $\begin{array}{c}\$ 104,035.03 \\
(p=0.01)\end{array}$ \\
\hline $\begin{array}{l}\text { Correct High and } \\
\text { Low Duration }\end{array}$ & $\begin{array}{c}\$ 107,728.17 \\
(p=0.01)\end{array}$ \\
\hline $\begin{array}{l}\text { Incorrect Hi and } \\
\text { Low Duration }\end{array}$ & $\begin{array}{c}\$ 137,099.44 \\
(p=0.04)\end{array}$ \\
\hline
\end{tabular}

\section{Verification of Assumptions}

While a variety of assumptions are inherent in any linear regression model, there are five principal assumptions that affect the use of linear regression models for the purposes of prediction. They are: (1) linearity of the relationship between dependent and independent variables, (2) independence of the errors, (3) homoscedasticity (constant variance), (4) normality of the error distribution and (5) verification that coefficients are reasonable. If the first four assumptions are violated then the forecasts, confidence intervals, and insights yielded by a regression model may be inefficient, biased or misleading. If the fifth assumption is violated then the model may not be applied in practice. The assumptions were tested for all models but are highlighted for Model 3, 5 and 7 because those three models appeared promising based on the results shown in Table 20.

\section{Assumption 1. Linearity}

To understand the relationship between dependent and independent variables it is important to look at the plots of the observed versus predicted values and the plot of residuals versus predicted values. For the observed versus predicted value plots the data should be should be symmetrically distributed around a diagonal line while the data should be symmetrically distributed around the horizontal line in the plot of residuals versus predicted values. 

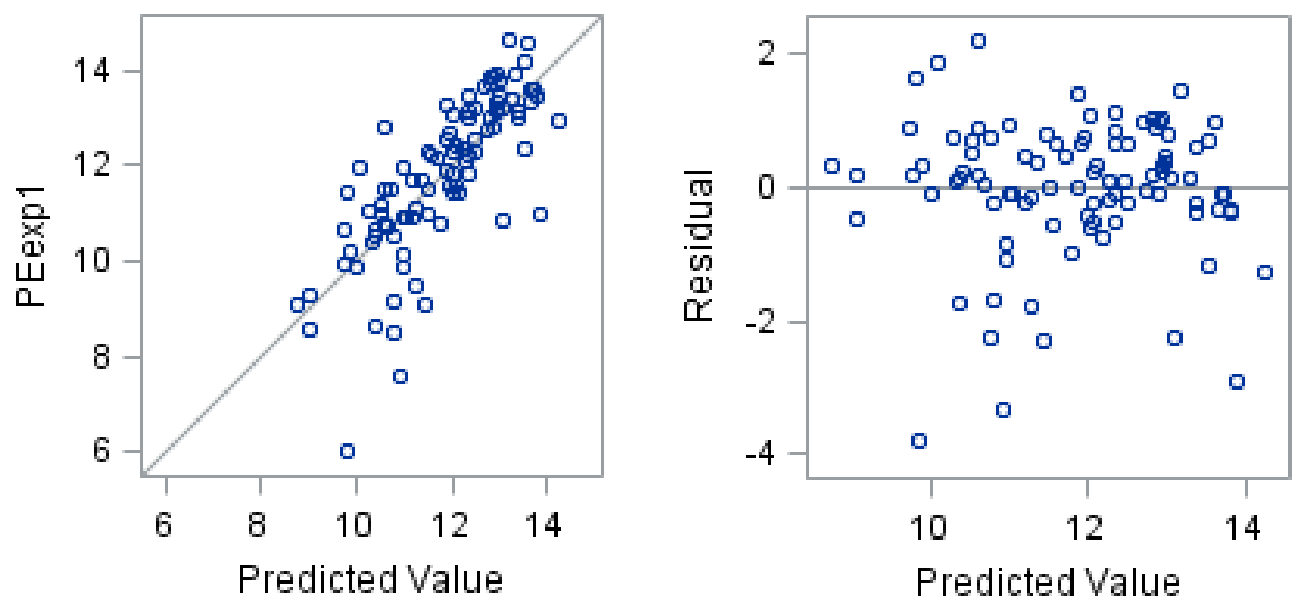

Figure 3 (a) Observed vs. Predicted Values and (b) Residuals vs. Predicted Values

Figure 3 a shows the observed vs. predicted values. The data are generally balanced around the regression line. Figure $3 b$ shows the residuals vs. the predicted values. In this plot, the data is symmetrically distributed around the horizontal line proving that there is a linear relationship between dependent and independent variables. The results were analyzed for Model 5 and 7 are very similar suggesting that there is a linear relationship between dependent and independent variables.

\section{Assumption 2. Independence of the Errors}

The correlation coefficient quantifies the degree of linear association among two variables. Table 23 shows that the highest correlation is between the dependent variable of PE expenditures and an independent variable - the construction estimate (0.61). Such a correlation is not problematic and is in fact expected given the use of the construction estimate to forecast PE expenditures. The correlations of interest are those between the pairs of independent variables — and the highest such correlation was between ROW and VDOT (0.50). (The correlations between the binary variables $\mathrm{CE}, \mathrm{PCE}$, and EA are not a concern because these jointly define the environmental factor).

Table 23. Correlation Between Variables in the Project Level Models

\begin{tabular}{|l|r|r|r|r|r|r|r|r|r|}
\hline & \multicolumn{1}{|l|}{ PE } & \multicolumn{1}{l|}{ CN } & \multicolumn{1}{l|}{ Duration } & \multicolumn{1}{l|}{ VDOT } & \multicolumn{1}{l|}{ Length } & \multicolumn{1}{l|}{ ROW } & \multicolumn{1}{l|}{ CE } & \multicolumn{1}{l|}{ PCE } & \multicolumn{1}{l|}{ EA } \\
\hline PE & 1.00 & 0.61 & 0.46 & 0.50 & 0.08 & 0.53 & 0.45 & -0.26 & -0.05 \\
\hline CN & 0.61 & 1.00 & 0.31 & 0.35 & 0.39 & 0.33 & 0.39 & -0.35 & -0.08 \\
\hline Duration & 0.46 & 0.31 & 1.00 & 0.13 & 0.14 & 0.19 & 0.19 & -0.05 & -0.01 \\
\hline VDOT & 0.50 & 0.35 & 0.13 & 1.00 & 0.22 & 0.50 & 0.34 & -0.26 & 0.08 \\
\hline Length & 0.08 & 0.39 & 0.14 & 0.22 & 1.00 & 0.02 & 0.12 & -0.15 & -0.02 \\
\hline ROW & 0.53 & 0.33 & 0.19 & 0.50 & 0.02 & 1.00 & 0.33 & -0.34 & 0.10 \\
\hline CE & 0.45 & 0.39 & 0.19 & 0.34 & 0.12 & 0.33 & 1.00 & -0.74 & -0.06 \\
\hline PCE & -0.26 & -0.35 & -0.05 & -0.26 & -0.15 & -0.34 & -0.74 & 1.00 & -0.13 \\
\hline EA & -0.05 & -0.08 & -0.01 & 0.08 & -0.02 & 0.10 & -0.06 & -0.13 & 1.00 \\
\hline
\end{tabular}


A second method, to check for multicolinearity is to calculate the Variance Inflation Factor (VIF). The approach detailed above shows that no one characteristic is correlated with another. However, the VIF measures how much the variance of coefficients is inflated as compared to when factors are not linearly related (Neter 1996). The VIF is equal to 1 when the independent variable is not linearly related to the other variables (Neter 1996). Neter (1996) also suggests that when the VIF exceeds 10, multi-collinearity is problematic and the model structure needs to be examined. Table 24 shows that with VIF values close to the ideal value of 1.0, multicollinearity is not a concern for models 3 and 7.

Table 24 Variance Inflation Factors for Models 3 and 7

\begin{tabular}{|l|l|l|l|}
\hline No. & \multicolumn{1}{|c|}{ Model } & Characteristic & VIF \\
\hline 3 & $\begin{array}{l}\text { Non Linear- Duration, } \\
\text { Length, VDOT, CE }\end{array}$ & CN Estimate & 1.15 \\
\cline { 3 - 4 } & & Duration & 1.11 \\
\cline { 3 - 4 } & & VDOT & 1.21 \\
\cline { 3 - 4 } & & Length & 1.20 \\
\cline { 3 - 4 } & \multirow{2}{*}{$\begin{array}{l}\text { Exponential- Duration, } \\
\text { Length, VDOT, CE }\end{array}$} & CE & 1.26 \\
\cline { 3 - 4 } & & Duration & 1.45 \\
\cline { 3 - 4 } & & VDOT & 1.11 \\
\cline { 3 - 4 } & & Length & 1.44 \\
\cline { 3 - 4 } & & ROW & 1.43 \\
\hline
\end{tabular}

A third method to show independence of the errors begins with a model that has only one independent variable, where one tracks how the $p$ values and adjusted $\mathrm{R}^{2}$ values change as additional variables are included. Table 25 shows how the adjusted $\mathrm{R}^{2}$ value changed as additional variables are added to model 3 and 5. The $p$ values did not increase, therefore, there is not a high correlation between the variables. The adjusted $\mathrm{R}^{2}$ did increase with the smallest increment of about $2 \%$ between iteration 2 and 3. For Model 5, the $p$ value for duration decreased between the second and third iteration, but slightly increased between the third and fourth iteration. In the fifth and final iteration the $p$ value for duration was 0.0646 . The adjusted $\mathrm{R}^{2}$ increased the most between the third and fourth iteration when a variable indicating whether or not the project was administered by VDOT was added to the model.

Table 25. Model 3 Progression Based on the Addition of Independent Variables

\begin{tabular}{|c|c|c|c|c|c|c|}
\hline Iteration & $\begin{array}{l}\text { Model } 3 \text { (Non } \\
\text { Linear) }\end{array}$ & p value & Adjusted $R^{2}$ & $\begin{array}{l}\text { Model } 5 \text { (Non } \\
\text { Linear) }\end{array}$ & p value & Adjusted $\mathbf{R}^{2}$ \\
\hline 1 & CN Est & $<.0001$ & 0.36 & CN Est & $<.0001$ & 0.36 \\
\hline 2 & $\begin{array}{l}\text { CN Est } \\
\text { Duration }\end{array}$ & $\begin{array}{l}<.0001 \\
0.0004\end{array}$ & 0.44 & $\begin{array}{l}\text { CN Est } \\
\text { Duration }\end{array}$ & $\begin{array}{l}<.0001 \\
0.1366\end{array}$ & 0.37 \\
\hline 3 & $\begin{array}{l}\text { CN Est } \\
\text { Duration } \\
\text { Length }\end{array}$ & $\begin{array}{l}<.0001 \\
0.0002 \\
0.0156\end{array}$ & 0.46 & $\begin{array}{l}\text { CN Est } \\
\text { Duration } \\
\text { Length }\end{array}$ & $\begin{array}{l}<.0001 \\
0.0140 \\
0.0606\end{array}$ & 0.40 \\
\hline 4 & $\begin{array}{l}\text { CN Est } \\
\text { Duration } \\
\text { Length } \\
\text { VDOT }\end{array}$ & $\begin{array}{l}<.0001 \\
<.0001 \\
0.0019 \\
<.0001\end{array}$ & 0.57 & $\begin{array}{l}\text { CN Est } \\
\text { Duration } \\
\text { Length } \\
\text { VDOT }\end{array}$ & $\begin{array}{l}<.0001 \\
0.1012 \\
0.0026 \\
<.0001\end{array}$ & 0.50 \\
\hline 5 & $\begin{array}{l}\text { CN Est } \\
\text { Duration } \\
\text { Length }\end{array}$ & $\begin{array}{l}<.0001 \\
0.0001 \\
0.0025\end{array}$ & 0.58 & $\begin{array}{l}\text { CN Est } \\
\text { Duration } \\
\text { Length, }\end{array}$ & $\begin{array}{l}<.0001 \\
0.0646 \\
0.0031\end{array}$ & 0.52 \\
\hline
\end{tabular}




\begin{tabular}{|c|l|l|l|l|l|l|}
\hline Iteration & $\begin{array}{c}\text { Model 3 (Non } \\
\text { Linear) }\end{array}$ & p value & Adjusted R & $\begin{array}{c}\text { Model 5 (Non } \\
\text { Linear) }\end{array}$ & p value & Adjusted R $^{2}$ \\
\hline & VDOT & $<.0001$ & & VDOT & 0.0003 & \\
& CE & 0.0499 & & CE & 0.0243 & \\
\hline
\end{tabular}

Assumption 3. Homoscedasticity

Common graphical methods for detecting heteroscedacticity are the plots of the residuals versus independent variables. Heteroscedactic plots will have the magnitude of the errors increase showing that the errors are not constant. Homoscedatic plots will have no systematic relationship between the residuals and independent (or dependent) variables.

The residuals should cluster near the horizontal line with some above and some below in a random pattern seen in Figure 4. The construction estimate residual plot (CN1) is the most random and shows a heteroscedactic relationship. The other independent variable plots are not as random and may suggest that there is some heteroscedacticity, where the error terms do not all have the same variance.

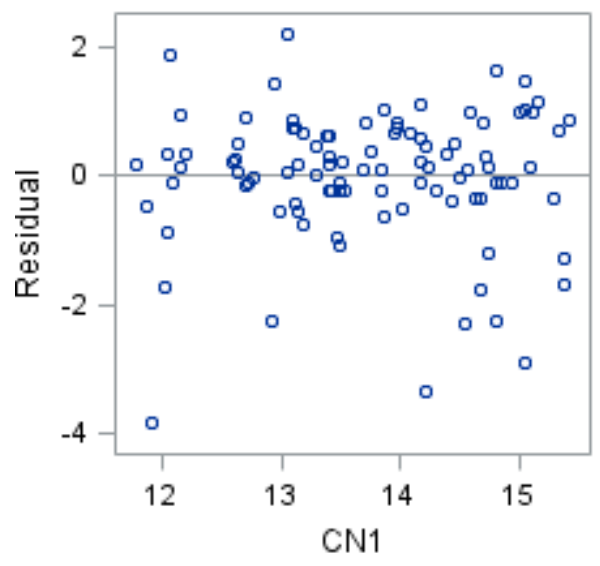

Figure 4. Residual vs. CN Estimate

To check for nonconstant variance of the residuals (heteroscedasticity), aside from the graphs, a test suggested by Newbold (1988) was performed, where, using the square of the residual as the dependent variable and the predicted value as the independent variable, a new regression is performed and the quantity $n R^{2}$ is estimated, which for Model 3 was $(n=97)\left(R^{2}=\right.$ $0.02)=1.95$. The test is that if this value does not exceed the appropriate Chi-square variable (which is 2.71 given a $10 \%$ level test and 1 degree of freedom), then the data are not heteroscedatic with respect to the dependent variable. Models 5 and 7 were similarly not heteroscedatic with $\mathrm{nR}^{2}$ quantities of 0.75 and 0.48 .

\section{Assumption 4. Normality of the Error Distribution}

Another regression assumption is that the errors are normally distributed; e.g., a Q-Q plot would ideally show a straight line for the residuals plotted against their standard normal quantiles; such a plot for model 3 is shown in Figure 5. Different patterns suggest residuals have excessive skewness or kurtosis. A test suggested by Johnson and Wichern (2002) is to compute 
the correlation coefficient for the standard normal quantiles (e.g., where the residuals would lie if they were perfectly normally distributed) and the actual points where the residuals lie. The correlation coefficient for both model 3 and 5 is 0.95 while for model 7 it is 0.96 The critical value point for the Q-Q plot correlation coefficient test for normality, (for $n=97$ and $a=0.05$ ) is 0.9873. This test suggests that the residuals for all three models are not normal. This places greater importance on using the results of the models' performance with the testing data set to determine the model's performance.

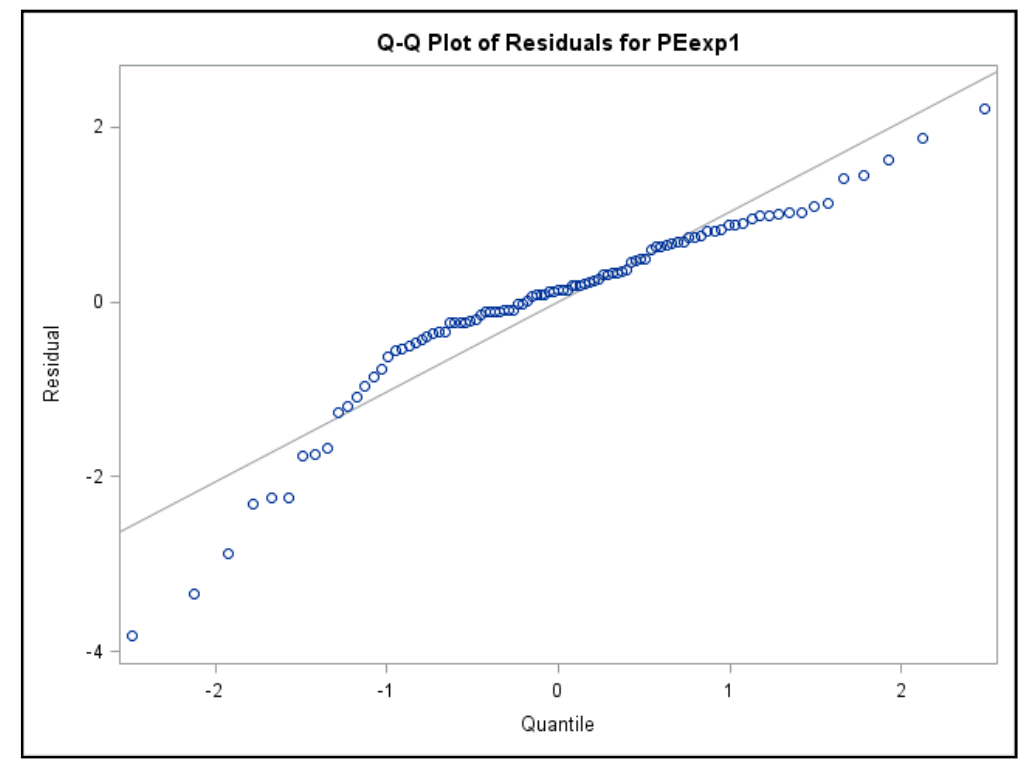

Figure 5 Q-Q Plot of Residuals for Model 3

\section{Assumption 5. Reasonableness of the Coefficients}

Model 3 was used to examine the reasonableness of the coefficients. The environmental coefficient is surprising, the VDOT coefficient is plausible, and the duration coefficient is logical.

The project with the median CN estimate $(\$ 691,240)$ was used to examine these first two coefficients. Model 3 predicted the PE estimate to be $\$ 296,475$, for a project that was 4.6 years long, $0.233 \mathrm{mi}$ long, required a CE environmental document, and administered by VDOT. By changing the environmental work from being eligible for $\mathrm{CE}$ to not being eligible for $\mathrm{CE}$, the $\mathrm{PE}$ estimate decreases by $40 \%$ to $\$ 173,584$. This is surprising because the CE is generally not considered as expensive as other environmental requirements such as an EIS or EA.

For the same project and also for model 3, changing the VDOT variable to suggest the project was not administered by VDOT decreased the PE estimate by $65 \%$ from $\$ 296,475$ to $\$ 103,540$. The fact that non-VDOT administered projects would have lower PE costs was consistent with the interviews (I7, I9). 
Unlike the environmental and VDOT variables which are binary, the duration variable is continuous and thus can take many values besides 0 or 1 . One approach to understand this coefficient is to increase duration by $10 \%$ and then examine how the PE estimate changes. For model 3, if the duration is set to the mean of 3.75 years then the PE estimate will be $\$ 397,867.50$. A $10 \%$ increase in duration to 4.12 years increases the PE estimate by $3 \%$ to $\$ 410,296.60$.

Because the duration variable can take a range of values, a second approach is to examine how changing duration from its maximum to minimum observed value influences the PE estimate. For example, for projects under $\$ 5 \mathrm{M}$, the longest duration is 11.25 years. The actual PE Expenditure and CN Estimate were $\$ 454,229.46$ and $\$ 1,245,000$ respectively. This particular project was 0.386 miles in length, managed by VDOT and required a CE environmental review. Thus its PE cost is forecasted to be approximately $\$ 567,000$. When the duration is changed to the lowest duration in the testing data set, 0.30 years, the PE estimate will is reduced by $69 \%$ to approximately $\$ 177,000$. Table 25 shows duration's influence on the Model 3, and for comparison purposes shows how duration influences the PE estimate for Models 5 and 7.

For model 5, when the duration was changed to the lowest duration in the testing data set, the PE estimate was $\$ 318,396.35$, about a $40 \%$ decrease. For model 7 , when the duration was changed to the lowest duration in the set, the PE estimate was $\$ 162,014.30$, about a $47 \%$ decrease.

With a $10 \%$ increase in duration for model 5 , the PE estimate will be $\$ 386,711$ yielding an overall $2 \%$ increase. Model 7 predicts the PE estimate to be $\$ 363,816.90$, yielding an overall $3 \%$ increase.

Table 26 Duration Influence on Project Level Models 3, 5, and 7

\begin{tabular}{|c|c|c|c|c|c|c|}
\hline Duration & $\begin{array}{l}\text { Model } 3 \text { PE } \\
\text { Estimate }\end{array}$ & $\begin{array}{l}\text { Percent } \\
\text { Difference }\end{array}$ & $\begin{array}{l}\text { Model } 5 \text { PE } \\
\text { Estimate }\end{array}$ & $\begin{array}{l}\text { Percent } \\
\text { Difference }\end{array}$ & $\begin{array}{l}\text { Model } 7 \text { PE } \\
\text { Estimate }\end{array}$ & $\begin{array}{l}\text { Percent } \\
\text { Difference }\end{array}$ \\
\hline $\begin{array}{l}\text { High } \\
\text { (11.25 years) }\end{array}$ & $\$ 567,225.70$ & \multirow{2}{*}{$-69 \%$} & $\$ 555,861$ & \multirow{2}{*}{$-40 \%$} & $\$ 497,494$ & \multirow{2}{*}{$-67 \%$} \\
\hline $\begin{array}{l}\text { Low } \\
(0.30 \text { years })\end{array}$ & $\$ 177,368.3$ & & $\$ 318,396$ & & $\$ 162,014$ & \\
\hline $\begin{array}{l}\text { Average } \\
\text { (3.75 years) }\end{array}$ & $\$ 397,867.50$ & \multirow{2}{*}{$3 \%$} & $\$ 379,398$ & \multirow[b]{2}{*}{$2 \%$} & $\$ 353,308$ & \multirow{2}{*}{$3 \%$} \\
\hline $\begin{array}{l}10 \% \text { increase } \\
(4.12 \text { years) }\end{array}$ & $\$ 410,296.60$ & & $\$ 386,711$ & & $\$ 363,816$ & \\
\hline
\end{tabular}




\section{CONCLUSIONS}

Reconsidering the three questions posed in the project's purpose, the first finding is that the district interviews and the literature indicate that VDOT's definition of PE is a recursive process that prepares projects for construction, spanning activities that occur from the time a project charge number is made available until the date the project is awarded for construction. Such PE activities are diverse and, especially for smaller projects, may include developing a fundamental definition of the project (e.g., raising the entire road bed versus designing a new drainage system). The second finding is that the financial data are available to determine the percentage of funds spent on PE by district, fiscal year, and project but are subject to several limitations. While these data are reviewed at the project level, they are not reviewed at the program level. The third finding is that at the project level, factors that influence PE variability for specific projects include construction cost (as was known prior to this project), but also project duration, project length, whether the project is locally administered, and an indication of the level of environmental work required such as a categorical exclusion or an environmental assessment.

Two specific conclusions may be drawn based on the findings:

\section{Preliminary engineering expenditure data are available but their interpretation is subject to} caveats noted by interviewees.

These caveats include the availability of a district-wide pre-scoping UPC, the fact that a single project may use multiple UPCs, and the sharing of PE for some projects. To be clear, such caveats do not inhibit the calculation of PE expenditures at the program level but may have an impact at the project level. Other caveats that complicate any project-level or program-level PE analysis are the fact that there are other sources for accomplishing PE work (such as maintenance projects), an ability for some activities to be placed in different phases (e.g., wetland banking is PE cost but wetland replacement is a $\mathrm{CN}$ cost), and as noted in the third conclusion, the presence of anomalous projects such as those that are enhancements.

2. The use of significant variables to forecast PE costs at the project level improved improve forecast accuracy in the testing data set.

Currently, forecasts of PE costs are based solely on the construction estimate, and the percentage of total project costs devoted to PE is inversely proportional to this estimate. Accordingly, forecasting PE costs for smaller projects, i.e., under $\$ 5$ million, merits attention. Based on a training data set of 97 projects, a new model for forecasting PE costs as a function of additional characteristics typically known at the project's inception are length, duration, level of required environmental review and locally administered status was developed. Based on an additional 27 projects used to test the model that were not included in the training data set, the new model reduced the mean absolute error from about $\$ 200,000$ to $\$ 110,000$, and this reduction was statically significant $(p=0.02)$. Further, compared to the original approach, the new approach nominally reduced the mean percentage error from $135 \%$ to $47 \%$. 


\section{RECOMMENDATIONS}

\section{Standardize smaller activities that may be charged to the PE phase.}

A large part of PE is interpretation, thus when many smaller activities are charged to a different phase it can skew the PE expenditure data. For example, some PE work may be accounted for in charges made to district-wide project numbers for pre-scoping, and such charges will not be recorded as part of the PE phase. This often occurs when it is difficult to obtain authorization to perform PE work on a project; such district-wide numbers will yield a lower PE expenditure since some initial work was charged to a different UPC.

\section{Consider applying project level model 3 on a pilot basis in the Fredericksburg District.}

For projects with a $\mathrm{CN}$ estimate that is under $\$ 5$ million, apply both model 3 and PCES over time and compare the accuracy of the results. The 27 projects in this testing data set suggest that model 3 may be able to improve project accuracy. If the new approach continues to offer improvements in accuracy, then this model may be incorporated into the PE estimation portion of PCES.

\section{Consider the implication of bad estimate.}

Further study should evaluate the implication of a bad estimate both statistically and practically. In a least squares regression analysis there are normally distributed residuals with a mean of zero, suggesting the over predictions equal the under predictions. Statistically, more validation data may be necessary to reach this benchmark. Practically, for planning purposes at the program and project level, an analysis or correction for systematically over or under predicting PE costs should be reviewed in the pilot program. This pilot program can nominally assess the accuracy of the estimates as well as the consequence of an over or underprediction. 


\section{ACKNOWLEDGMENTS}

This project could not have been completed without Dr. John Miller. The information gathered for this report is also used in the VDOT Report "Determinants of Preliminary Engineering Funding Variability." Three groups of staff were largely involved in both projects. The project was guided by a technical review panel, comprised of Jeff Kessler (chair, and Lynchburg District), Rob Case (Hampton Roads TPO), Tommy DiGiulian (Salem District), and Abdul Hammadi (Fredericksburg District). Financial data were provided by Rob Carver, assistance with various aspects of data interpretation was provided by Corey Borne, Amy Frye, Gene Holley, and Alan Saunders, and editing help with the references was provided by Linda Evans. Insights from the interviews were a fundamental piece of this work, and interviewees included, in addition to the Panel members, Jay Brown, Dic Burke, Chase Buchanan, Brian Casto, Rob Crandol, Matt Dana, Bruce Duvall, Mike Fulcher, Randy Hamilton, Sam Hayes, Jane-Ellen Hess, John Giometti, Claudia Llana, Kevin Northridge, Alex Price, Margit Ray, Mark Riblett, Steve Rowan, Terry Short, Bud Siegel, Brent Sprinkel, Kanti Srikanth, Wendy Thomas, Rob Walters, Zack Weddle, Jason Williams, and Jim Zeller.

\section{REFEFENCES}

AECOM, Schneck, D., Touran, A., Raul V. Bravo + Associates, Inc., and Sharp \& Company. Estimating Soft Costs for Major Public Transportation Fixed Guideway Projects. Report 138. Transit Cooperative Research Program. Washington, D.C. 2010. http://www.trb.org/Main/Blurbs/163381.aspx. Accessed November 30, 2012.

Bourne, C. Email to J.S. Miller, November 30, 2012a.

Bourne, C. Email to J.S. Miller, December 3, 2012b.

Bourne, C. Email to B. Turner, December 6, 2012c.

Carver, R. Email to J.S. Miller, October 17, 2012.

Cherry, Bekaert \& Holland. Performance Audit of Significant Operations of the Virginia Department of Transportation, Richmond, 2010.

Dowling, R. and Elias, A. National Cooperative Highway Research Program (NCHRP) Report Synthesis 427. The Extent of Highway Capacity Manual Use in Planning, Transportation Research Board, National Research Council, Washington, D.C. 2012. http://onlinepubs.trb.org/onlinepubs/nchrp/nchrp_syn_427.pdf. Accessed October 10, 2012.

Federal Highway Administration. A Guide to Reporting Highway Statistics, Office of Highway Policy Information, Washington, D.C., undated, a. http://www.fhwa.dot.gov/policyinformation/hss/guide/guide.pdf. Accessed March 15, 2013. 
Federal Highway Administration. Highway Statistics Series, Office of Highway Policy Information, Washington, D.C., undated, b. http://www.fhwa.dot.gov/policyinformation/statistics.cfm. Accessed March 15, 2013.

Federal Transit Administration. Major Capital Transit Investment Fact Sheet. US Department of Transportation, Washington, D.C. 2007. http://www.fta.dot.gov/documents/PE_Fact_Sheet_9-18-07_doc. Accessed September $12,2012$.

Federal Transit Administration. New Starts Fact Sheet. U.S. Department of Transportation, Washington, D.C. http://www.fta.dot.gov/12304_2607.html. Undated. Accessed December 7, 2012.

Federal Transit Administration. Standard Cost Categories Workbook. U.S. Department of Transportation. 2011a. http://www.fta.dot.gov/13070_2580.html. Accessed November 30, 2012.

Federal Transit Administration. Standard Cost Categories (SCC) for Capital Projects. U.S. Department of Transportation. 2011b. http://www.fta.dot.gov/13070_2580.html. Accessed November 30, 2012.

Johnson, R.A. and Wichern, D.W. Applied Multivariate Statistical Analysis, $5^{\text {th }}$ Edition, Prentice Hall, Upper Saddle River, NJ, 2002.

Hollar, D., Arocho, I., Hummer, J., Liu, M., Rasdorf, W. Development of a Regression Model to Predict Preliminary Engineering Costs. North Carolina State University, Raleigh, undated.

http://repository.lib.ncsu.edu/publications/bitstream/1840.2/2343/1/216+Development+of $+\mathrm{a}+$ Regression+Model+to+Predict+Preliminary+Engineering+Costs.pdf. Accessed September 9, 2012. (Note: source may be 2010 based on ppt; we will verify date.)

Liu, M., Hummer, J.E., Rasdorf, W.J., Hollar, D.A., Parikh, S.C., Lee, J., and Gopinath, S. Preliminary Engineering Cost Trends for Highway Projects, Report No. FHWA/NC/2010-10, North Carolina State University, Raleigh, 2011. http://www.ncdot.gov/doh/preconstruct/tpb/research/download/2010-10finalreport.pdf. Accessed December 5, 2012.

Neter, J., Kutner, M., Nachtsheim, C., Wasserman, W., “Applied Linear Statistical Models”, $4^{\text {th }}$ Edition. McGraw Hill. Boston, Massachusetts, 1996.

Newbold, P. "Statistics For Business Economics.” $2^{\text {nd }}$ Edition. Prentice Hall. New Jersey. 1988.

O’Leary, A.A. Beyond the Byrd Road Act: VDOT's Relationship with Virginia's Urban Counties, Report No. VTRC 98-R29, Virginia Transportation Research Council, Charlottesville, 1998. 
Oman, A.E. Funding and Responsibilities for Virginia's Local Roadways, Richmond, 2006. http://hac.state.va.us/aarchives/2006/committee/files/09-18-06/Transportation--09-1806.pdf. Accessed April 19, 2013.

Savin, N.E. and White, K.J. The Durbin-Watson Test for Serial Correlation with Extreme Sample Sizes or Many Regressors, Econometrica, Vol. 45, No. 8, pp. 1989-1996, The Econometric Society, NY, November 1977.

Transportation Planning Research Advisory Committee. Results of Research Needs: Fall 2010. VCTIR. Charlottesville, 2011. http://www.vtrc.net/tprac/pdf/ResearchNeedsResults.pdf.

Virginia Department of Transportation. Project Development Process Flow Chart. Richmond. August 2012. http://www.virginiadot.org/projects/concureng-default.asp. Accessed September 12, 2012.

Virginia Department of Transportation. Business Plan for FY13 - FY14, Richmond. http://www.virginiadot.org/about/resources/2013_VDOT_Business_Plan.pdf. Accessed December 7, 2012. 


\section{APPENDIX A. INTERVIEW QUESTIONS AND RESPONSES}

Although nine district interviews were conducted for the research, only one interview, Salem, is presented in Appendix A. The interviews questions are shown on page A-2 and the interview responses are given on the pages that follow.

A separate set of questions were posed to Central Office staff representing the VDOT Programming and Fiscal Divisions but are not included in this report. 


\section{DISTRICT INTERVIEW QUESTIONS}

At this meeting we hope to identify closed-out UPCs and to better understand Preliminary Engineering within the VDOT Project Development Process. Potential questions are:

Questions about the VDOT Project Development Process

1) Do all 5 phases of the VDOT Project Development Process fall within the Preliminary Engineering phase in terms of SYIP allocations? Our understanding of this alignment is shown below.

\begin{tabular}{|c|c|}
\hline VDOT Project Development Process Tasks & SYIP Phases \\
\cline { 1 - 2 } Scoping Phase & \\
\cline { 1 - 2 } Preliminary Design Phase & \multirow{2}{*}{ Preliminary Engineering } \\
\cline { 1 - 2 } Detailed Design Phase & \\
\cline { 1 - 2 } Final Design \& ROW Acquisition Phase & \\
\cline { 1 - 2 } Advertise Plans & ROW \\
\hline [Not shown, Occurs after advertisement] & Construction \\
\hline
\end{tabular}

2) FTA defines PE as "the engineering necessary to complete NEPA...or $30 \%$ of final design"

a. Are we correct that VDOT's PE definition differs (e.g., PE includes all of final design)?

b. Is there consistency between PE in the Project Development Process and PE in the SYIP?

3) To what extent do the end products of the Preliminary Design Phase, the Detailed Design Phase and the Final Design \& ROW Phase typically change in terms of money spent and the design product?

4) Can you recommend a sample of (preferably closed-out) UPCs that help us better understand both

a. the role of PE and

b. how PE tasks are funded?

5) Where can we find details for specific projects besides the project Pool (http://isyp)?

a. How often is information uploaded to the iPM and how is it determined what is uploaded? (Some projects have a scoping document 57044,78621 , while others do not)

Questions About How Project Expenditures are Tracked

6) At the district level, for a given fiscal year,

a. Are the data available to determine what percentage of funds are spent on PE (versus RW or CN)?

b. Are VDOT staff reviewing percentages, and if so, for what purpose?

c. What is a range of appropriate percentages to be spent on PE relative to other project phases?

7) Will tracking expenditures by phase (e.g., PE vs. RW) and by activity (e.g., 616 for road plans or 613 for location surveys) yield the entire amount VDOT spends on preliminary engineering activities?

8) Is there a credible way to identify a list of projects (including dead projects)- in each district- that will enable us to determine the portion of total project cost spend on PE?

9) Are there any characteristics you would add or remove from the taxonomy list? (see next page.) Note: Variations in these questions were asked in the pilot interview in Fredericksburg). 


\section{Characteristics that May (Or May Not) Influence the Ratio of PE to Total Project Costs}

\section{(Draft Taxonomy, May be Revised)}

\begin{tabular}{|c|c|c|c|c|}
\hline Characteristic & UPC 57044 & UPC 75915 & UPC 78621 & UPC 13558 \\
\hline \multicolumn{5}{|l|}{ Environmental } \\
\hline Environmental Work & EA & $\mathrm{CE}$ & $\mathrm{CE}$ & EA \\
\hline Wetlands Mitigation & Yes & Yes & Yes & Yes \\
\hline $\begin{array}{l}\text { Bio Retention (water quality) } \\
\text { basins considered? }\end{array}$ & Yes & & Yes & Yes \\
\hline \multicolumn{5}{|l|}{ Cost } \\
\hline PE Pre-Scoping Estimate & $\$ 2,417,729$ & $\$ 506,512$ & $\$ 454,142$ & $\$ 11,474,054$ \\
\hline PE Expenditure & $\$ 1,534,898$ & $\$ 224,141$ & $\$ 409.042$ & $\$ 4,210,417$ \\
\hline Magnitude of Total Cost & $\$ 24,528,934$ & $\$ 5,168,340$ & $\$ 3,528,048$ & $\$ 168,205,449$ \\
\hline Pre-Scoping RW Estimate & $\$ 12,797,756$ & $\$ 559,015$ & $\$ 840,906$ & $\$ 29,200,000$ \\
\hline Ratio of RW to CN & 1.37 & 0.136 & 0.377 & 0.229 \\
\hline \multicolumn{5}{|l|}{ Order of Magnitude } \\
\hline Functional Classification & Urban Minor Arterial & $\begin{array}{l}\text { Rural Major } \\
\text { Collector }\end{array}$ & $\begin{array}{l}\text { Rural Major } \\
\text { Collector }\end{array}$ & Rural Interstate \\
\hline Facility type & Intersection & Secondary & Roadway & Interchange \\
\hline Design Services Provider & District & District & District & Consultant \\
\hline $\begin{array}{c}\text { Transportation Management } \\
\text { Plan Class }\end{array}$ & C (3) & A (1) & B (2) & B (2) \\
\hline$\#$ of Bridges & 0 & 0 & 0 & 3 \\
\hline PE Phase Duration & $\begin{array}{c}\text { Start- } 12 / 1 / 2000 \\
\text { End- } 9 / 9 / 2011 \\
10.9 \text { years } \\
\end{array}$ & $\begin{array}{c}\text { Start- } 7 / 6 / 2007 \\
\text { End-10/21/2013 } \\
6.3 \text { years } \\
\end{array}$ & $\begin{array}{c}\text { Start- } 5 / 8 / 2010 \\
\text { End- } 2 / 27 / 2010 \\
2.9 \text { years } \\
\end{array}$ & $\begin{array}{c}\text { Start- } 5 / 9 / 1994 \\
\text { End- } 11 / 13 / 2013 \\
19.5 \text { years } \\
\end{array}$ \\
\hline Businesses to be taken & 8 & & 0 & \\
\hline Homes to be taken & 8 & & 0 & \\
\hline Railroad involvement & No & No & No & No \\
\hline Bike Ped Accommodations & $\begin{array}{c}\text { Widening sidewalk by } \\
1 \text { in, Paved shoulder, } \\
\text { Pedestrian signals and } \\
\text { Curb Ramps } \\
\end{array}$ & $\begin{array}{c}\text { Yes, proposed } \\
\text { pavement wider to } \\
\text { accommodate } \\
\text { bicycles }\end{array}$ & $\begin{array}{l}\text { Yes, Sidewalk } \\
\text { and 4' bike lane }\end{array}$ & \\
\hline \multicolumn{5}{|l|}{ Agreements } \\
\hline $\begin{array}{c}\text { Required National Historic } \\
\text { Preservation Act }\end{array}$ & Yes & No & & \\
\hline HazMat Evaluation & Yes & & & \\
\hline Utility Relocation & Yes & No & No & \\
\hline IJR or IMR & IJR & & & IMR \\
\hline $\begin{array}{l}\text { Memorandum of Agreement, } \\
\text { between public agencies }\end{array}$ & $\begin{array}{c}\text { Yes, due to historic } \\
\text { district }\end{array}$ & & No & No \\
\hline Recoverable Slope Study & No & No & No & \\
\hline Value Engineering Study & Yes & No & No & Yes \\
\hline \multicolumn{5}{|l|}{ Delivery Method } \\
\hline Alternate Delivery Method? & No, DBB & No, DBB & No, DBB & \\
\hline $\begin{array}{c}\text { Alternate Designs Considered } \\
\text { (when in process) }\end{array}$ & $\begin{array}{l}\text { Project budget more } \\
\text { than doubled with the } \\
\text { bypass/ single point } \\
\text { urban interchange } \\
\text { options considered. }\end{array}$ & & & Yes \\
\hline
\end{tabular}




\section{Salem District Meeting on January 28, 2013 - I4}

\section{Meeting with Tommy DiGiulian, Jane-Ellen Hess, Alex Price, John Miller, and Beth Turner Verified Notes by Phone on April 15-16, 2013}

1. Generally, the answer to question 1 is yes: the 5 phases of the VDOT Project Development Process (e.g., scoping, preliminary design, detailed design, final design \& ROW acquisition, and advertisement) fall within the Preliminary Engineering phase in terms of expenditures, but do note that allocations in the SYIP are formally designated to a specific UPC but not necessarily a specific phase (although one can infer which phases are funded in the SYIP by comparing the estimated costs in the SYIP for each phase with the total amount that has been formally programmed.)

2. Yes, VDOT's definition of PE differs from that of FTA, and yes, generally, there is agreement between the SYIP and the project development process in terms of how PE is defined. (However, recognize that the SYIP contains allocations, not expenditures, and as noted in question 1 funds are programmed to specific UPCs but not specific phases.)

3. The end products of the Preliminary Design Phase, the Detailed Design Phase and the Final Design \& ROW Phase may change very little, substantially, or somewhere in between. For instance, paving an unpaved road in Craig County may have a very short scoping phase with a signed waiver indicating no public involvement process is needed and a relatively quick final design. By contrast, projects such as the Charlottesville Bypass or the Springfield Interchange may have had 3, 4, or a dozen public meetings with detailed design changes throughout the process. That said, as noted in question $6 \mathrm{c}$, factors that influence the extent to which these product change also include responsiveness to public opinion and the role of delegates [or other elected officials].

(This question also prompted discussion of whether the percentage of cost each of the different subphases of the PE phase would vary by project; the consensus was that while the ratio of PE/CN will decrease for larger projects, one would expect the ratios of scoping/PE, preliminary design/PE, detailed design/PE, final design/PE, and advertise plans/PE to remain consistent across different types of projects.)

4. A sample of UPCs for the Salem District based on the FY2004-FY2012 SYIPs is shown on an attached excel spreadsheet. Salem District staff review of these projects would be especially helpful to account for the following anomalies:

- There may be "co-mingled" UPCs where the PE phase and the CN phase are given two separate UPCs yet reflect the same project.

- There may be projects where the PE reflects a given section [e.g., MP 0 to MP 4]), but the $\mathrm{CN}$ reflects only a portion of the project [e.g., construction from MP 2 to MP 4].

- The "design-build" category adds a layer of complexity in that in theory one is providing a project that is already at $30 \%$ of design but in practice one is not necessarily at that point [when the project passes from VDOT to the firm doing the design-build work].

- Ideally one would want only the "C" (meaning "Complete Plan" projects and one would want to exclude the "no plan" projects (which have minimal design) and the maintenance projects. These projects can be identified in the "jobs" section of the project pool, where for 
$\mathrm{PE} / \mathrm{RW} / \mathrm{CN}$, a code will show ("N501" for no plan, "M501" for minimum plan, "P501" for paving, or "C501" for construct. The projects with "N" or "M" should be excluded.) For example, for UPC 71586 as shown below, this project would included because the job\# indicates "C501."

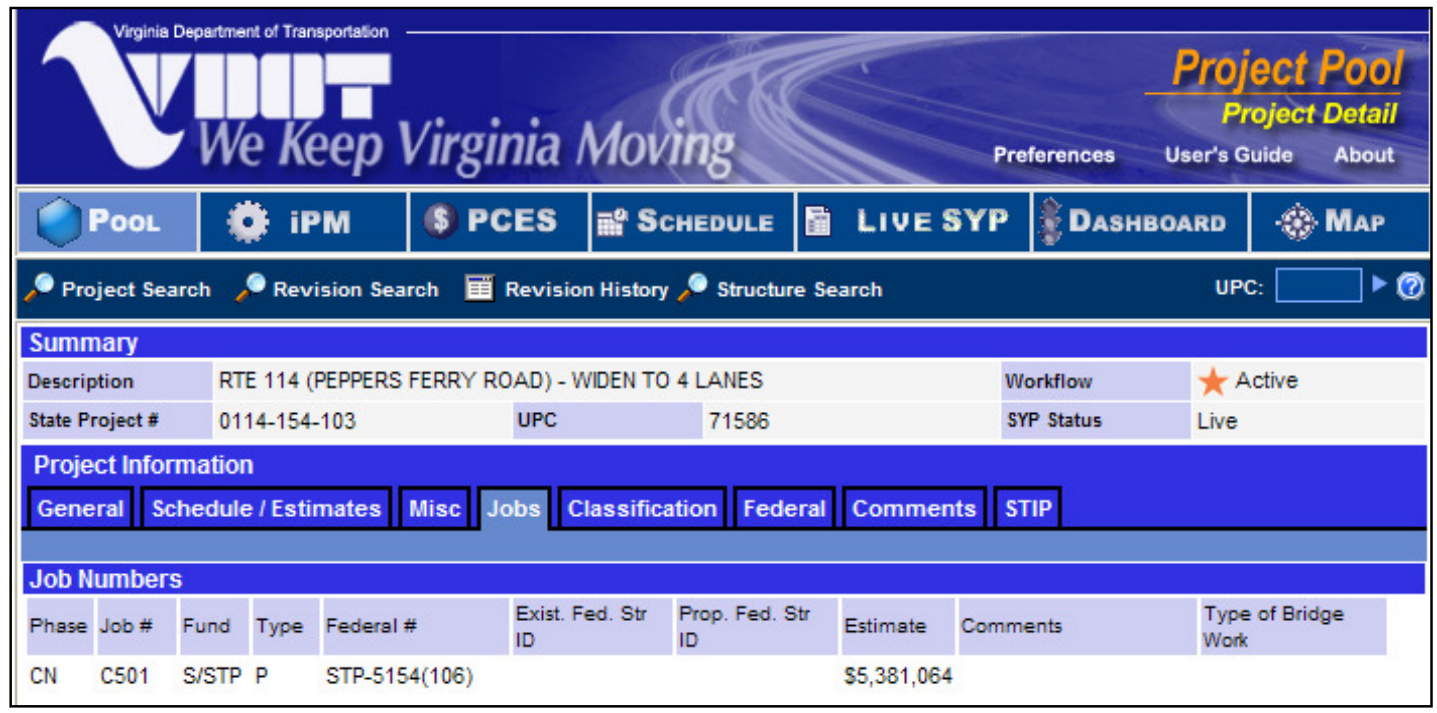

- There are several projects that might merit special attention because they convey some historical lesson:

i. Route 687 in Pulaski County (PE reflected a 1.5 mile section but $\mathrm{CN}$ reflects just two spot improvements.)

ii. Route 668 (illustrates the role of elected officials who can write letters of support.)

iii. Route 460 near the police headquarters

iv. Route 220 in Northern Botetourt (illustrates a project that was the victim of changes in funding and scope creep.)

v. Route 8746 which was built under UPC 71586 (illustrates a project that was prepared when the funding outlook was considerably better than at present)

vi. Route 58 project (illustrates a case where homes were condemned yet the project remained unbuilt for a substantial amount of time; at the same time there were homeless persons in the area who needed housing.)

While closed-out projects may be complete, recognize that district staff likely have stronger familiarity with more recent or ongoing projects.

5. Details for specific projects can be found in the Project Pool or, for earlier projects, possibly in a file folder for the specific UPC at the district office. The details that are available on iPM depend on the following:

- The habits of the project manager: some managers place everything on iPM and some do not.

- When the project was started: for projects initiated prior to the existence of iPM (which was roughly 2007 or 2008), some managers may have retroactively updated details to iPM and others may not have. 
6. As noted in the free response section, keep in mind that when looking at expenditures it may make more sense to examine the ratio of PE to total costs or $\mathrm{CN}$ costs over a long period of time that encompasses multiple projects being completed rather than only on an annual basis.

a. At the district level, for a given fiscal year, the data are available to determine the percentage of expenditures spent on PE/RW/CN. However, this is not a simple task as three different information systems are needed: Cardinal [for expenditures after 2012]), FMS2 [for expenditures for roughly the period 2003-2012]), and FMS 1 (for projects prior to FMS2).

b. VDOT district staff are generally not reviewing overall percentages of funds spent on $\mathrm{PE} / \mathrm{RW} / \mathrm{CN}$ for the entire program, which is more of a Central Office Programming function. However, District staff do track expenditures for individual projects across all three phases (PE, RW, and $\mathrm{CN}$ ) to keep the project on budget.

c. When considering an entire program — not just an individual project—an appropriate percentage to be spent on PE relative to other project phases might be $15 \%$, however, such a percentage is driven by at least four other factors:

i. The "non-predictability of funding" where the amount of funds available for investments changes over time, and in fact changes more quickly in some cases than the project development process (e.g., a funding outlook can radically shift during a four year period, VDOT has only a six year SYIP, and for some projects the PE phase alone may take 8 years.) A key example is the City of Roanoke's urban program, where one particular project has had 16 managers and was designed many years ago when funding was more plentiful.

ii. The role of politics: some projects involve state or local elected officials [which influences the time, and hence cost, for the PE phase of specific projects and hence the PE program as a whole]

iii. The age of projects that are included in such a program's analysis (e.g., it would make sense to exclude projects with three and four digit UPCs as those were started some time ago.)

iv. Characteristics of individual projects such as the use of "no plan" projects (where $10 \%$ might be a good PE estimate), the use of consultants (where hourly costs are higher for consultants based on the manner in which hourly costs are tracked in VDOT systems), and the cost of individual projects. (Some general rules of thumb for individual projects are that $\mathrm{PE} / \mathrm{CN}$ is typically in the range of $15 \%$ to $20 \%$ for projects between $\$ 5 \mathrm{M}$ and $\$ 10 \mathrm{M}$, with a $10 \%$ figure for larger projects and concerns being raised if the $\mathrm{PE} / \mathrm{CN}$ ratio exceeds $20 \%$.)

7. Tracking expenditures by phase (e.g., PE vs. RW) and by activity (e.g., 616 for road plans or 613 for location surveys) will yield the entire amount VDOT spends on preliminary engineering activities except for the three following exceptions:

- In the past, PE work for some projects was done by residencies, and this work may not be captured as PE expenditures but rather would be charged to some other cost center.

- Each district has prescoping funds that may be used prior to PE being authorized. The amount of funding by district for prescoping was $\$ 750,000$ (year 1) and $\$ 1 \mathrm{M}$ (year 2 at present). 
- For maintenance projects, all PE may be charged to a single UPC: e.g., there are 28 paving projects in Salem whose PE is handled by a single UPC.

8. Regarding a credible way to identify a list of projects (including dead projects)- in each district- that enable us to determine the portion of total project cost spend on PE, see question 5 where district staff need to help review the list of UPCs to ensure that anomalies for individual projects have been addressed. In addition, consider the following which would guide the interpretation of such a list:

- Many projects have long time frames such that one must account for the projects that have not been built (see comments following question 9).

- The funding outlook changes over time such that large-scale construction projects previously thought to be realistic may no longer be feasible (see question 6c).

9. There are several characteristics that may be added to the taxonomy list.

- Whether the project was fully funded in the SYIP. (Fully-funded might be defined as estimated PE, estimated RW, and a significant portion of the estimated $\mathrm{CN}$ being in the SYIP). For instance the Orange Avenue project is now that the PFI [Preliminary Field Inspection] stage but it will not progress to the public hearing stage unless it becomes clear that funding will be available —otherwise it could be 15 years—or never-when the project is built.

- The project duration. A project that sits for 5 years may need to have portions, or all of, PE redone. Salem District still has projects in the PE phase that have 3 digit UPCs.

- Clarity of project purpose.

- Clear public support and/or changes resulting from public input.

i. One way to capture this might be to review the formal "design approval letter" indicating VDOT's response to public input. To be clear, it is the response to input that influences costs (e.g., if the Department made no changes in design, that would presumably lower PE costs.) This letter, if not available in the Project Pool (iPM), might be available in the project file at the district office (see question 5).

ii. A different way to capture this information might be to examine the length of time between the public hearing and the design approval steps, which is the difference between steps 49 and 52 as reflected in the scheduler section of iPM. (These steps are not immediately evident in the project scheduler unless one hits "print" in which case a screen shot such as that shown in the figure on the next page appears.) 


\begin{tabular}{|c|c|c|c|c|c|}
\hline \multirow{4}{*}{$\begin{array}{l}\text { UPC } \\
\text { Description } \\
\text { PPMS Code }\end{array}$} & \multicolumn{4}{|c|}{ Schedule Report } & \multirow[b]{4}{*}{ Actual Finish } \\
\hline & Project \# & 0114-154-103 & & & \\
\hline & \multicolumn{4}{|c|}{ RTE 114 (PEPPERS FERRY ROAD) - WIDEN TO 4 LANES } & \\
\hline & Task & Planned Start & Actual Start & Planned Finish & \\
\hline 18 & $\begin{array}{l}\text { SERP-NOTICE TO STATE } \\
\text { AGENCIES }\end{array}$ & $9 / 1 / 2004$ & $8 / 31 / 2004$ & $12 / 31 / 2004$ & $11 / 10 / 2004$ \\
\hline 22 & SCOPE PROJECT & $10 / 1 / 2004$ & $9 / 1 / 1989$ & $3 / 31 / 2005$ & $10 / 13 / 1995$ \\
\hline 24 & ENVIRONMENTAL PERMITS & $1 / 3 / 2005$ & $9 / 13 / 2004$ & $1 / 31 / 2005$ & $9 / 14 / 2004$ \\
\hline $34 \mathrm{~F}$ & FINAL SOILS SURVEY & $4 / 1 / 2005$ & $4 / 1 / 2005$ & $7 / 29 / 2005$ & $6 / 21 / 2005$ \\
\hline $35 \mathrm{C}$ & $\begin{array}{l}\text { TRAFFIC CONTROL DEVICE } \\
\text { PLANS CO }\end{array}$ & $10 / 29 / 2004$ & $10 / 21 / 2004$ & $10 / 3 / 2005$ & $9 / 30 / 2005$ \\
\hline 40 & MINOR STRUCTURES DATA & $3 / 22 / 2005$ & $3 / 22 / 2005$ & $3 / 31 / 2005$ & $3 / 31 / 2005$ \\
\hline $43 \mathrm{H}$ & HYDRAULIC PLAN DESIGN/F.I. & $2 / 1 / 2005$ & $8 / 2 / 2004$ & $5 / 31 / 2005$ & $3 / 23 / 2005$ \\
\hline 45 & MINOR STRUCTURE REPORT & $4 / 1 / 2005$ & $4 / 1 / 2005$ & $7 / 29 / 2005$ & $6 / 21 / 2005$ \\
\hline $51 \mathrm{H}$ & HYDRAULIC REVIEW FOR PAC & $9 / 1 / 2005$ & $7 / 11 / 2005$ & $4 / 18 / 2008$ & $6 / 24 / 2008$ \\
\hline $53 \mathrm{~F}$ & FINAL LANDSCAPING PLANS & $10 / 3 / 2005$ & $10 / 3 / 2005$ & $3 / 23 / 2006$ & $3 / 23 / 2006$ \\
\hline
\end{tabular}

iii. Be aware that elected officials' involvement with public approval can complicate matters.

iv. Scope creep. Some projects start with a clear purpose and others do not. [There is no easy way to identify this but it may be possible to review changes in the project scope as reported in iPM, with the caveat that, as noted in question 5, some project managers place all details in iPM and others do not.]

- State-funded versus federal funded.

- Inclusion of a traffic signal (as this would raise the $\mathrm{CN}$ cost of a project by $\$ 250,000$ in the past and $\$ 300,000$ or more at present).

- Urban versus rural.

- Support was expressed for developing a model that predicted the ratio of actual PE expenditures to forecasted construction costs, as was performed with a study done in North Carolina. (It was suggested that it may be preferable to use the TRNS*PORT forecasts rather than the PCES forecasts, and the TRNS*PORT forecasts may be available either in the Project Pool or on the PCES page as shown in the screen shot on page A-26).

\section{Other Comments}

- While many people have asked "are we programming too much on PE" another question needs to be "are we programming enough for PE?" The reason is that lately the Federal stimulus projects and the state's Governor's package have emphasized having shovel-ready projects that can use these fundsbut now VDOT does not have those types of projects in the pipeline.

- A fundamental challenge is that VDOT now has large-scale projects designed when the funding outlook was better. How does VDOT mover forward given this large backlog of projects where, for the foreseeable future, funds are not available?

- Note some districts have separate Assistant Division Administrator (ADA) functions which split the programming-related tasks and the project-management (e.g., Location and Design) tasks. In the Salem District, however, both programming and project management are included within the PIM [Planning and Investment Manager] function. 
- As was noted in the project kickoff meeting, there is a difference in the interpretation of the ratio of annual $\mathrm{PE} / \mathrm{CN}$ and $\mathrm{PE} / \mathrm{CN}$ over multiple years. The reason is that projects have relatively long lifetimes spanning multiple years.

- There is a difference between what is programmed (e.g. allocated) and what is spent (e.g., expenditures). Expenditures are of course reported by phase. By contrast, while the SYIP shows estimated amounts by phase, the SYIP formally programs amounts only to a specific UPC-e.g., when an SYIP shows a given amount for a particular project, that amount could, in theory, be intended for any of the three phases. That said, one can draw some inferences by comparing the estimated and programmed amounts. [For instance, a project with an estimated PE cost of $\$ 1 \mathrm{M}$, an estimated RW cost of \$2 M, and an estimated CN cost of \$3 M that shows an SYIP allocation of \$6 $\mathrm{M}$ would be inferred to be fully funded.]

- It would be interesting to compare the results of PCES to the results of TRNS*PORT after a project had been constructed, to evaluate the tradeoffs in accuracy (favoring the latter) and time required (favoring the former).

- Funding is unpredictable, it takes an average project 8 years to complete the Project Development Process, which is 2 beyond longer the SYIP and there can be a lot of fluctuation between the beginning and end.

- VDOT's outlook on projects is very different than it used to be. There are fewer large projects because maintenance of existing infrastructure is taking priority. 


\section{APPENDIX B \\ DETAILED METHODOLOGY FOR DATA COLLECTION}

Appendix B describes how the three main sets of project-level data were obtained:

1. financial data

2. engineering data

3. frequency of projects.

Financial data refers to expenditures for preliminary engineering (PE), Right-of-Way $(\mathrm{RW})$, and Construction $(\mathrm{CN})$. Engineering data refers to the characteristics that describe each project, such as environmental work and design complexity. Frequency of projects data includes the types of projects found statewide and by VDOT district.

\section{How Financial Data Were Obtained}

Financial data were obtained by VDOT staff from the older Financial Management System II (FMS II) database used by VDOT from approximately 1990 through part of 2011 and the newer Cardinal financial system database (via a Business Objects user interface) used by VDOT since 2011. During year 2011, VDOT transitioned from FMS II to Cardinal such that FMS II was active in the earlier part of the year and Cardinal in the latter part of the year. districts.

Six steps were performed to collect financial data for each of VDOT's nine construction

1. Identify Universal Project Codes (UPCs).

2. Remove anomalies from the dataset.

3. Obtain expert screening from each district.

4. Compile UPCs that pass initial and expert screening.

5. Obtain expenditures for each UPC.

6. Identify Candidate UPCs for the Preliminary Engineering Estimation Model.

\section{Step 1. Identify UPCs.}

All UPCs for one district were obtained from VDOT's Six-Year Improvement Program (SYIP) database (VDOT, 2008) for FY04 through FY13 inclusive. As may be seen, for FY09 and FY10, there were two "final" SYIPs (i.e., the first "final" and later "revised final") and for those 2 years the data for both SYIPs were examined. For example, to obtain projects for the Culpeper District, the first step was to select FY04 FINAL in the Program drop-down menu and then select Culpeper in the District drop-down menu as the one to be analyzed. The next step was to export the project list for that fiscal year (2004), which yielded an Excel document with 
all the UPCs for that fiscal year and for that district (i.e., the Culpeper District). This process was repeated for the remaining fiscal years and compiled into one master list with UPC data for FY05, FY06, FY07, FY08, FY09, FY09 Revised, FY10, FY10 Revised, FY11, FY12, and FY13. The next step removed the duplicate UPCs for projects that spanned over more than one fiscal year, such that the UPC descriptive information appeared only once. At the conclusion of Step 1, this Excel document contained for each UPC the project description, route, district, road system, jurisdiction, and planned allocations over the next 6 years. Then, UPCs with a "T" were excluded from the list as these designated projects for which no data were available within VDOT's system (Carver, 2012). (The researchers later noted that many of these were public transportation projects.)

\section{Step 2. Remove Anomalies From Dataset.}

Sprinkel (2013a) suggested that certain "special funded" projects, even though they are found in the SYIP, should be excluded from the dataset. Examples of such projects are projects funded through the federal Transportation Enhancement Program; district-wide projects (e.g., funded through the federal Highway Safety Improvement Program); studies; and projects funded through the American Recovery and Reinvestment Act (ARRA). The reason for the exclusion of these projects is that each represented an anomaly that could adversely affect the ratio of PE to construction costs. For example, ARRA projects were included in the SYIP because they were shovel-ready and would presumably have lower-than-expected PE costs compared to an average construction project. Accordingly, any projects that fulfilled any of these four criteria (i.e., funded with enhancement funds, district-wide, study only, and ARRA projects) were excluded.

\section{Step 3. Obtain Expert Screening From Each District.}

The first four categories of anomalies were identified by the researchers using the UPC description. A fifth category of projects that Sprinkel (2013a) suggested be excluded was maintenance/operations projects, which are nonetheless funded with construction allocations. An example of such a project was UPC 84707, which was a bridge maintenance repairs project that used SYIP construction funds (Sprinkel, 2013b). Such anomalies, however, can be identified only with the help of an expert. Thus, for each district, an expert was asked to identify from the UPCs any maintenance/operations projects that remained after the four criteria were applied. For example, for the Culpeper District, of a total of 103 projects, application of the four criteria correctly classified 90 projects. (Note also that a manual review was required because 1 of the 90 projects had initially been excluded incorrectly since the street name "Barracks" contained the acronym ARRA.) The remaining 13 projects were noted by the expert as meriting exclusion but were not captured by these criteria. These results varied by district; for example, in the Salem District, the four criteria identified 74 projects but the expert identified an additional 149 projects that should be excluded. (Experts thus had the opportunity to identify any anomalous projects.) The results of applying the criteria are shown in the spreadsheet titled "ScreenedUPCs" used by the researchers. 


\section{Step 4. Compile UPCs That Pass Initial and Expert Screening.}

In a separate Excel spreadsheet, the UPCs that passed the initial (Step 2) and expert screening (Step 3) were compiled.

\section{Step 5. Obtain Expenditures for Each UPC.}

Expenditures were obtained from VDOT (R. Carver, unpublished data) for the UPCs given in Step 4. As discussed preciously, these expenditures reflected two sources: FMS II and Cardinal. The expenditures showed the total amount spent by phase (e.g., PE, RW, or CN) for each UPC for each fiscal year. The financial data were also stratified by activity. These expenditures served two purposes: to determine the percentage of funds spent on PE at the program level and to develop a model to forecast PE expenditures at the project level.

\section{Step 6. Identify Candidate UPCs for the Preliminary Engineering Estimation Model.}

The financial data were compiled to show the total amount of money spent on a project by phase. Candidate UPCs were those that met 3 minimum criteria; (1) the project had a CN estimate at the scoping phase uploaded to the PCES section of the Project Pool (2) the project job type was a construction plan and (3) the PE phase was considered complete because the project had $\mathrm{CN}$ expenditures.

\section{How Engineering Data Were Obtained}

\section{Overview}

Each project has a unique set of project characteristics that influence how much money is spent on PE. VDOT's Project Pool, created in 2003 is a database that contains fundamental project characteristics. Some projects have more specific information uploaded into the Project Documents section of the Project Pool, such as data related to scoping, preliminary field inspections, public hearings, pre-advertising, and construction.

The difficulty of gathering the data for each project varied. For projects that were initiated relatively recently, the broad project characteristics that can be found in the Project Pool are consistently available for each project. Most projects that have an "active" status on the Project Pool have more documents uploaded and therefore more data available to determine project characteristics. Older projects generally do not have documents uploaded to the Project Pool; therefore, gathering specific data about the project is more difficult. Some of the older projects created prior to the creation of the Project Pool have little data uploaded into the Project Pool. Unique project characteristics can be found in the scoping document, environmental records, and records of field inspections.

Before the determination of which project characteristics were most important and thus considered for the model, a literature review was conducted to ascertain how certain 
characteristics influenced project development. Characteristics such as geographic location (e.g., coast, mountainous, piedmont); environmental review (e.g., categorical exclusion [CE], environmental assessment [EA], environmental impact statement [EIS]); party responsible for the planning document (e.g., department of transportation, private engineering firm); and the scope of the project construction had a considerable impact in a study of cost estimation regarding PE in North Carolina (Liu et al., 2011).

Similar to the findings of Min et al. (2011), the VDOT district interviews suggested related characteristics such as the role of environmental regulation, project duration, type of design services provider, type of wetlands mitigation, and project delivery method. The importance of environmental regulation may vary by location. For example, the interviewees in the Hampton Roads District noted that the amount of environmental work needed for projects in that district is substantial because of its proximity to the Chesapeake Bay watershed.

Additional characteristics were identified by using a sample set of projects provided in the Fredericksburg District interview. Interviewees explained that the sample set had projects that followed the VDOT Project Development Process (VDOT, 2012) and projects that did not follow this process. Through analysis of both types of projects, various characteristics were found in the scoping document available in the Project Pool. Some characteristics, mostly originating from the standard projects, were expected by the researchers, such as the functional classification of the facility. However, the existence of certain characteristics for a subset of the projects, such as requiring a National Historic Preservation Study or requiring a HazMat (i.e., Hazardous Materials) Evaluation, showed the breadth of characteristics that were conceivable.

\section{Types of Project Characteristics}

Five types of project characteristics were identified: environmental, approved estimates, order of magnitude, agreements, and delivery method. An additional characteristic that would have been desirable to include is public approval. This term was mentioned during the Bristol District interview: if the public does not approve a design, the PE process can return to the beginning, repeating the cycle. If project managers are not available, reviewing documents uploaded to the Project Pool that show attendance forms at the public hearings might be one way to gather these data. Ultimately, however, the researchers did not find a cost-effective way to gather this characteristic.

\section{Environmental Characteristics}

Environmental Work. The various types of environmental work required for projects

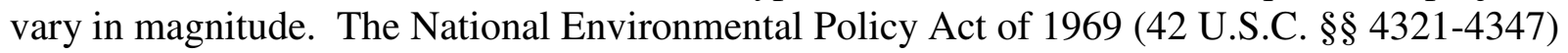
states that agencies "are required to systematically assess the environmental impacts of their proposed actions and consider alternative ways of accomplishing their missions in ways which are less damaging to the environment." Projects are classified into three groups based on the amount of environmental work necessary, CE, EA, or EIS. Thus, the type of environmental work directly impacts the overall PE costs. 
Wetlands Mitigation. After the Fredericksburg District interview, wetlands mitigation developed into an important topic because if the mitigation is to purchase wetland credits, the cost is charged to PE, but if the mitigation is to construct a new wetland, the cost is charged to $\mathrm{CN}$. Thus, the manner in which wetlands are mitigated is key to the total percentage of funds spent on PE. .

Bioretention Basin Consideration. A bioretention basin is a specific type of best management practice (BMP) used in stormwater management.

\section{“Approved Estimate” Characteristics}

"Approved Estimate"- The project estimates and expenditures for PE, RW, CN and their sum can define the magnitude of the overall project. This section of the Project Pool, although is labeled "Approved Estimate," contains current project expenditures. More reliable estimates are found in the PCES section of the Project Pool.

\section{Order of Magnitude Characteristics}

Functional Classification. The functional class of a project helps define the type of area in which the project is located. Some of the possible functional classes examined were rural major collectors, rural principal arterials, urban collectors, and rural interstates.

Facility Type. Facility type defines the type of project.

Design Services Provider. In most of the district interviews, VDOT staff suggested that the design services provider played a large role in the overall PE costs. According to the Fredericksburg District interview, projects designed by VDOT staff were less expensive than those designed by consultants.

Transportation Management Class. This classification defines the projects complexity based on how the transportation network will be affected.

- Type A (Project Management Project Category I \& II): No-Plan, Minimum Plan, Single Phase Construction, Maintenance Projects, Utility and Permitted Work. Project types include simple projects such as widening pavement or adding turn lanes or entrances,

- Type B (Project Management Project Categories III \& IV): Typical Projects: Moderate level of construction activity with the primary traffic impact limited to the roadway containing the work zone. Project types include moderately complex projects such as pavement or bridge widening for additional through lanes and pavement rehabilitation.

- Type C (Significant Project-Project Management Category V): These types of projects are anticipated to cause sustained and substantial work zone impacts greater 
than what is considered tolerable based on policy or engineering judgment. They should be identified early in the design process in cooperation with the Federal Highway Administration (FHWA). Typical projects are long duration construction or maintenance projects on interstate and freeway projects that occupy a location for more than 3 days with intermittent or continuous lane closures (VDOT, 2011).

Number of Bridges. The number of bridges on a project plays a large role in the overall scale of a project.

PE Phase Duration. The Bristol District interview made it clear that the overall PE phase duration has a large effect on PE cost. One of the factors that either accelerated or delayed the PE phase duration was the position of the public, whether in favor of the design or against the project. If the public hearings were unsuccessful in persuading citizens, the PE phase often took longer for alternate design consideration.

Interchange Justification Reports / Interchange Modification Reports. Often these reports suggest a large scale project with multiple components.

Businesses/Homes to Be Taken. If a project needs to purchase right of way that takes a number of business or homes, the PE estimate will likely be affected.

Length of Time. The longer the project's duration, in general the higher the PE estimate.

Railroad Involvement. Projects located near a railroad require coordination with multiple agencies and often entail more complex design features to avoid distress on the existing railroad crossings or system.

Job \#. The Salem District interview clarified that the "job \#" should be included as a characteristic. Such projects can be identified in the Jobs section of the Project Pool (see Figure B1) and are designated by the letter associated with the $\mathrm{CN}$ phase. For example, for the UPC shown in Figure B1, the letter is C. The significance of this characteristic is that interviewees suggested only C projects (meaning "Complete Plan" according to the interview) would be wanted and that the "no plan" projects (designated with an $\mathrm{N}$ ) and the minimal design projects (designated with an $\mathrm{M}$ ) would not be wanted. 


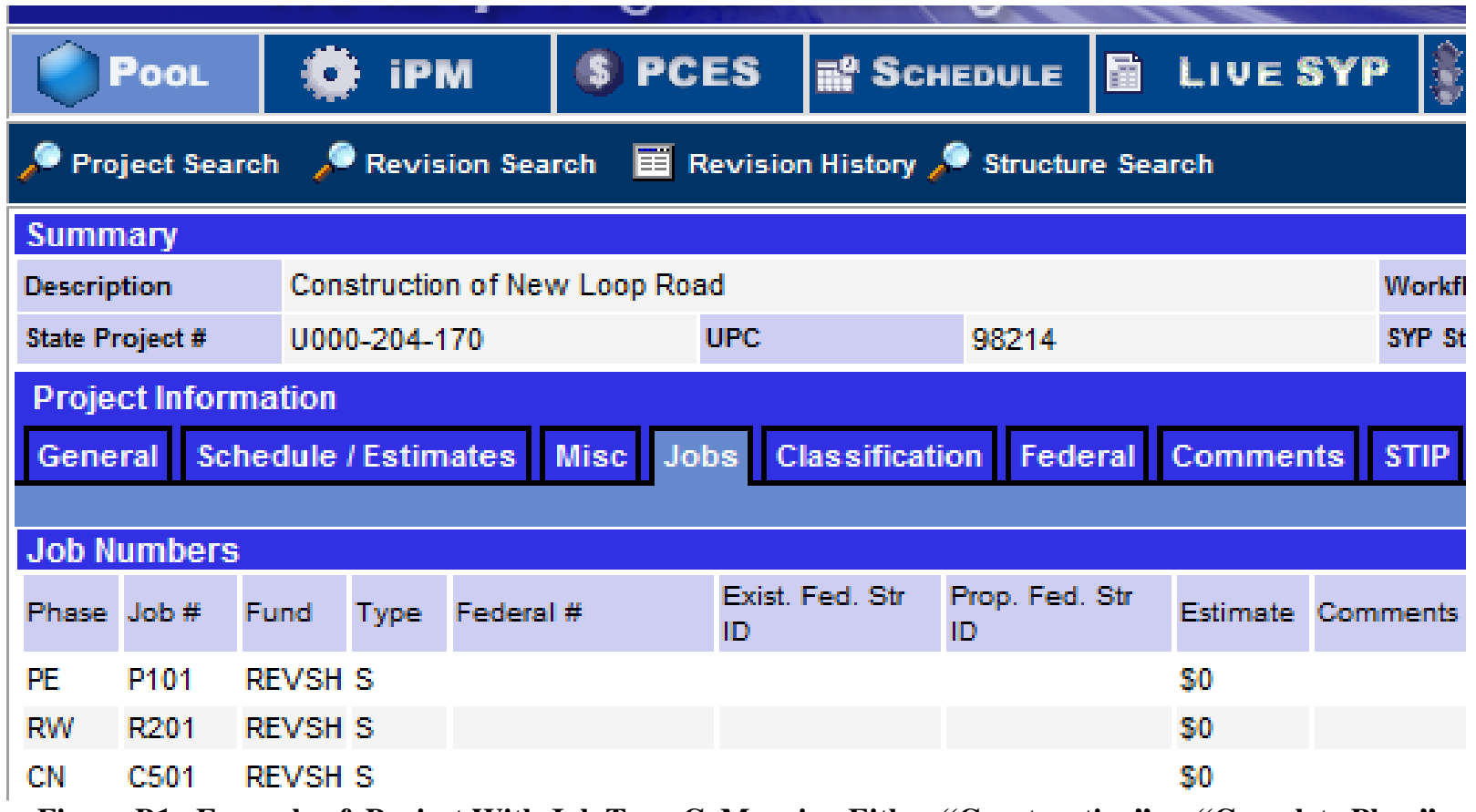

Figure B1. Example of Project With Job Type C, Meaning Either "Construction" or "Complete Plan." Screen shot of Jobs Section, UPC 98214, as it appears in the Project Pool

VDOT (2007) clarified that there are many job types other than the C, N, and M types, and these job types did not arise in the interviews. The job types are B (Bridge), D (Drainage), G (Grading), P (Paving), FS (Flashing Signals), L (Landscaping), and SG (Signing). VDOT (2007) also refers to the $\mathrm{C}$ designation as Construction.

\section{Agreements Characteristics}

Required National Historic Preservation Study. Projects that are located in historic districts must undergo a National Historic Preservation Study. The National Historic Preservation Act of 1966 (16 U.S.C. 470 et seq.) states that "the historical and cultural foundations of the Nation should be preserved as a living part of our community life and development in order to give a sense of orientation to the American people."

Hazardous Materials Evaluation. Various projects located near warehouses or manufacturing facility may require a hazardous materials evaluation to determine whether the area of the proposed project is not contaminated.

Utility Conflicts or Relocation. This is a broad characteristic that can vary extensively and also play a major role in how PE is estimated. Projects that span two municipalities can have major utility conflicts whereas other projects may have a simple issue.

Bicycle and Pedestrian Accommodations. Projects that require additional design work for bicycle and pedestrian infrastructure can affect PE estimate.

Memorandum of Agreement (MOA). The scoping document that VDOT uses for its projects asks whether the project involves any MOAs with any state, federal, or private agency 
regarding special treatment for consideration for aesthetics or scenic quality for a corridor, bridge structure, view shed, or historic property, thus requiring mitigation of aesthetic impacts.

Recoverable Slope Study. Recoverable slope studies are performed to evaluate whether the terrain adjacent to a roadway complies with VDOT's slope threshold. as follows:

Value Engineering (VE) Study. According to the FHWA (2012), a VE study is defined

A systematic process of review and analysis of a project, during the concept and design phases, by a multidiscipline team of persons not involved in the project that is conducted to provide recommendations for:

- providing the needed functions safely, reliably and efficiently and at the lowest overall cost

- improving the value and quality of the project; and

- reducing the time to complete the project.

FHWA (2012) also stated that the following projects are required to conduct a VE Study (VE Policy):

[those that] utilize Federal-aid highway funding with an estimated total cost of $\$ 25$ million or more that are located on the National Highway System (NHS), and all bridge projects with an estimated cost of \$20 million or more that are located on or off of the NHS that utilize Federal-aid highway funding (as specified in 23 U.S.C. 106(e)).

\section{Delivery Method Characteristics}

Alternate Delivery Method. A majority of projects use the Design-Bid-Build Project Delivery Method. Other methods such as Design-Build are somewhat common and tend to have higher PE costs.

Alternate Designs Considered. In the scoping document that VDOT uses for its projects there is a section to describe whether alternate designs were considered. In the early stages of all projects, various designs are considered; however, when designs change late in the project development process (such as after a preliminary public hearing), it can influence the PE cost greatly.

Workflow Status. As a result of the meeting with Programming at VDOT's Central Office, the Workflow Status developed into an important characteristic in order to determine which projects were complete in that no more money would be spent on the project in any phase. Projects can be Active, Inactive, or Archived. For projects that are active or inactive, expenditures are likely to change. For projects that are archived, all three phases have been completed and do not require any more money. Projects that are inactive or archived tend to have less documentation, and active projects generally have up-to-date information. However, the VDOT Central Office interview indicated that only archived projects should be used, and these tend to have fewer characteristics available. 


\section{Availability of Project Characteristic Data}

The Project Pool contains the characteristics for each UPC. The Project Pool has broad information located in the General Information Tab and the Schedule and Estimates Tab. More specific information, in the form of project documents, is located in the integrated Project Manager (iPM) which is accessible from the Project Pool for a specific UPC.

- The General Information Tab has characteristics such as the type of environmental work, functional class, facility type, project length, work flow status, and number of bridges required. This information is routinely available except for some cases where environmental work and functional classification are blank.

- The Schedule and Estimates Tab provides characteristics such as estimates for PE, $\mathrm{RW}$, and $\mathrm{CN}$ and the programming schedule (which gives the PE Phase Duration). This information is routinely available, except in some cases where no information was recorded for the duration.

- The Project Pool gives more detailed information. If it is uploaded, a complete Scoping Document will contain characteristics such as (1) Bicycle/Pedestrian Accommodation, (2) Bio Retention (Water Quality) Basin, (3) Memorandum of Agreements, (4) Recoverable Slope Study, (5) Value Engineering Study, (6) Transportation Management Plan Type, (7) Design Services Provider, (8) Businesses to be taken, (9) Homes to be taken, (10) Railroad Involvement, (11) Utility Relocation (also called Utility Conflicts in some cases), and (12) Alternate Delivery Method. If applicable, documents other than the Scoping Document may show characteristics such as (1) if wetlands are affected, (2) the need for Hazardous Materials (Hazmat) evaluation, and (3) National Historic Preservation Study Evaluations. Whether this information is available depends on the project manager. Salem District interviewees noted that when documents are not uploaded to the Project Pool, it is nearly impossible to get any detailed information about a project without contacting the project manager directly.

Table B1 summarizes the availability of these project characteristics by UPCs for each district. The characteristics fall into three categories:

1. Usually available. The only reason a characteristic would be missing is a data entry error or some unexplained event. For example, in the Bristol District, 25 of the 29 projects had environmental characteristic data.

2. Sometimes available. These characteristics are often available when the Scoping Document is uploaded. For example, in the Bristol District, 6 of the 29 projects indicated the design services provider.

3. Rarely available. These characteristics were observed less frequently even when extensive documentation was uploaded to the Project Pool. For example, in the Bristol District, 3 of the 29 projects indicated wetlands mitigation data. 
Judgment was required by the researchers to interpret blank data fields. . It is not always clear that missing characteristic data are not an error. For example, a project not on the interstate system would not have an Interchange Justification Report — thus a blank IJR field would not be an error. Similarly, if the number of bridges is not recorded, it is likely that the project does not require a bridge. By contrast, a project without a functional classification would likely constitute an omission of a data element. It was also suggested by Programming that when PE duration has zero days, the data element is likely in error because all projects have a PE start and end date (J. Brown, Personal Communication). However, projects that are in sequential UPC order and have exactly the same duration are not uncommon and are likely accurate (J. Brown, Personal Communication). 
Table B1. Summary of Available Characteristics by Project

\begin{tabular}{|c|c|c|c|c|c|c|c|}
\hline Availability & Characteristic & Bristol & Hampton Roads & Culpeper & Salem & Lynchburg & Fredericksburg \\
\hline \multirow[t]{10}{*}{ Usually } & Environmental Work & $25 / 29$ & $52 / 63$ & $20 / 24$ & $21 / 28$ & $40 / 43$ & $11 / 12$ \\
\hline & PE Cost & $29 / 29$ & $63 / 63$ & $24 / 24$ & $28 / 28$ & $43 / 43$ & $12 / 12$ \\
\hline & Magnitude of Total Cost & $29 / 29$ & $63 / 63$ & $24 / 24$ & $28 / 28$ & $43 / 43$ & $12 / 12$ \\
\hline & Amount of RW & $29 / 29$ & $63 / 63$ & $24 / 24$ & $28 / 28$ & $43 / 43$ & $12 / 12$ \\
\hline & Ratio of RW to $\mathrm{CN}$ & $29 / 29$ & $63 / 63$ & $24 / 24$ & $28 / 28$ & $43 / 43$ & $12 / 12$ \\
\hline & Duration & $29 / 29$ & $63 / 63$ & $23 / 24$ & $28 / 28$ & $40 / 43$ & $12 / 12$ \\
\hline & Functional Class & $29 / 29$ & $63 / 63$ & $24 / 24$ & $28 / 28$ & $42 / 43$ & $12 / 12$ \\
\hline & Length & $29 / 29$ & $63 / 63$ & $24 / 24$ & $28 / 28$ & $42 / 43$ & $12 / 12$ \\
\hline & Workflow Status & $29 / 29$ & $63 / 63$ & $24 / 24$ & $28 / 28$ & $43 / 43$ & $12 / 12$ \\
\hline & Facility Type & $29 / 29$ & $63 / 63$ & $24 / 24$ & $28 / 28$ & $43 / 43$ & $12 / 12$ \\
\hline \multirow[t]{10}{*}{ Sometimes $^{\mathrm{a}}$} & Design Services Provider & $6 / 29$ & $7 / 63$ & $2 / 24$ & $7 / 28$ & $9 / 43$ & $1 / 12$ \\
\hline & Transportation Management Class & $4 / 29$ & $2 / 63$ & $3 / 24$ & $6 / 28$ & $8 / 43$ & $0 / 12$ \\
\hline & Business/Homes to Be taken & $10 / 29$ & $11 / 63$ & $4 / 24$ & $11 / 28$ & $11 / 43$ & $7 / 12$ \\
\hline & Railroad Involvement & $8 / 29$ & $11 / 63$ & $6 / 24$ & $11 / 28$ & $12 / 43$ & $7 / 12$ \\
\hline & Number of Bridges & $14 / 29$ & $43 / 63$ & $13 / 24$ & $18 / 28$ & $38 / 43$ & $7 / 12$ \\
\hline & Utility Conflicts or Relocations & $9 / 29$ & $11 / 63$ & $6 / 24$ & $11 / 28$ & $12 / 43$ & $5 / 12$ \\
\hline & Bike and Ped Accommodations & $5 / 29$ & $10 / 63$ & $4 / 24$ & $7 / 28$ & $14 / 43$ & $4 / 12$ \\
\hline & Recoverable Slope Study & $9 / 29$ & $10 / 63$ & $5 / 24$ & $11 / 28$ & $13 / 43$ & $4 / 12$ \\
\hline & Value Engineering Study & $9 / 29$ & $10 / 63$ & $5 / 24$ & $10 / 28$ & $14 / 43$ & $4 / 12$ \\
\hline & Alternate Delivery Method & $5 / 29$ & $3 / 63$ & $3 / 24$ & $3 / 28$ & $7 / 43$ & $1 / 12$ \\
\hline \multirow[t]{7}{*}{ Rarely $^{\mathrm{a}}$} & Wetlands Mitigation & $3 / 29$ & $7 / 63$ & $1 / 24$ & $3 / 28$ & $2 / 43$ & $1 / 12$ \\
\hline & Memorandum of Agreement & $2 / 29$ & $0 / 63$ & $0 / 24$ & $3 / 28$ & $8 / 43$ & $2 / 12$ \\
\hline & $\begin{array}{l}\text { Bio Retention (Water Quality } \\
\text { Basin) Consideration }\end{array}$ & $2 / 29$ & $3 / 63$ & $2 / 24$ & $5 / 28$ & $9 / 43$ & $2 / 12$ \\
\hline & National History Preservation Study & $0 / 29$ & $1 / 63$ & $0 / 24$ & $0 / 28$ & $1 / 43$ & $2 / 12$ \\
\hline & Hazmat Evaluation & $0 / 29$ & $3 / 63$ & $0 / 24$ & $3 / 28$ & $1 / 43$ & $2 / 12$ \\
\hline & Alternate Designs Considered & $0 / 29$ & $1 / 63$ & $1 / 24$ & $1 / 28$ & $1 / 43$ & $0 / 12$ \\
\hline & IJR and or IMR & $0 / 29$ & $0 / 63$ & $0 / 24$ & $1 / 28$ & $0 / 43$ & $1 / 12$ \\
\hline
\end{tabular}

$\mathrm{PE}=$ Preliminary Engineering RW =Right-of-Way ; CN = Construction ; Ped =Pedestrian ; IJR =Interchange Justification Report ; IMR $=$ Interchange Modification Report .

a-The division between "sometimes available" and "rarely available" is arbitrary, except that the characteristics in the former category could be obtained more often than characteristics in the latter category. 


\section{How Frequency of Projects Was Determined}

Tables B2, B3, and B4 summarize the types of projects across three categories:

environmental work, workflow status, and construction cost. Table B5 provides Bristol specific information on availability of characteristic data.

Table B2. Projects with Environmental Characteristics by VDOT District

\begin{tabular}{|l|r|r|r|r|r|r|}
\hline Characteristic & Bristol & Hampton Roads & Culpeper & Salem & Lynchburg & Fredericksburg \\
\hline CE & 11 & 29 & 18 & 9 & 7 & 8 \\
\hline EA & 5 & 15 & 0 & 0 & 1 & 1 \\
\hline PCE & 9 & 6 & 2 & 9 & 20 & 2 \\
\hline EIS & 0 & 2 & 0 & 1 & 12 & 0 \\
\hline N/A & 4 & 11 & 4 & 4 & 3 & 1 \\
\hline TBD & 0 & 0 & 0 & 5 & 0 & 0 \\
\hline Total & 29 & 63 & 24 & 28 & 43 & 12 \\
\hline
\end{tabular}

$\mathrm{CE}=$ Categorical Exclusion; $\mathrm{EA}=$ Environmental Assessment PCE $=$ Programmatic Categorical Exclusion; EIS = Environmental Impact Statement; N/A = Not Applicable; TBD = To Be Determined.

Table B3. Workflow Status of Projects by VDOT District

\begin{tabular}{|l|r|r|r|r|r|r|}
\hline \multicolumn{1}{|c|}{ Status } & Bristol & Hampton Roads & Culpeper & Salem & Lynchburg & Fredericksburg \\
\hline Active & 16 & 43 & 17 & 15 & 35 & 8 \\
\hline Inactive & 7 & 15 & 5 & 7 & 6 & 4 \\
\hline Archived & 6 & 5 & 2 & 6 & 2 & 0 \\
\hline Total & 29 & 63 & 24 & 28 & 43 & 12 \\
\hline
\end{tabular}

Table B4. Magnitude of Construction Estimate by VDOT District

\begin{tabular}{|l|r|r|r|r|r|r|}
\hline $\begin{array}{c}\text { CN Estimate from Project } \\
\text { Cost Estimating System } \\
\text { (PCES) }\end{array}$ & Bristol & $\begin{array}{c}\text { Hampton } \\
\text { Roads }\end{array}$ & Culpeper & Salem & Lynchburg & Fredericksburg \\
\hline CN under \$5 million & 22 & 34 & 19 & 19 & 30 & 10 \\
\hline $\begin{array}{l}\text { CN between \$5 and \$18 } \\
\text { million inclusive }\end{array}$ & 5 & 18 & 5 & 6 & 6 & \\
\hline CN over \$18 million & 2 & 11 & 0 & 3 & & 7 \\
\hline Total & 29 & 63 & 24 & 28 & & 43 \\
\hline
\end{tabular}

$\mathrm{CN}=$ Construction.

a - This row includes projects with a cost of exactly 5million or exactly 18 million dollars 
Table B5. Summary of Available Characteristics by Project (Bristol District)

\begin{tabular}{|c|c|}
\hline Availability & Characteristic \\
\hline Usually Available & 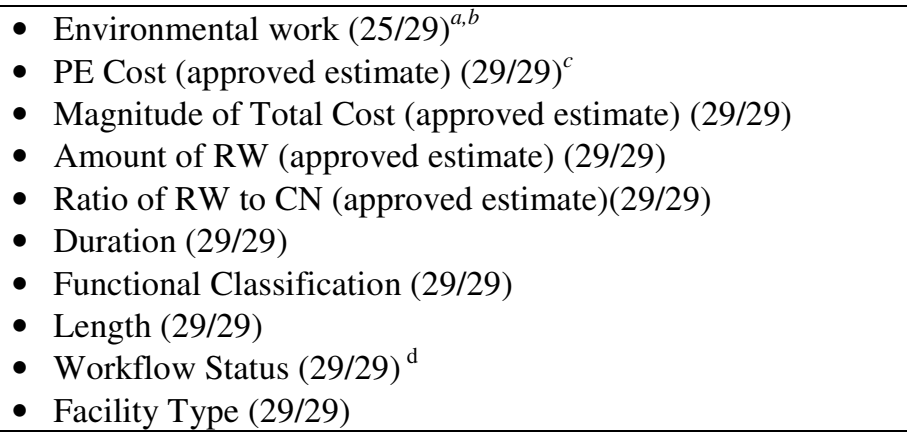 \\
\hline Sometimes Available & $\begin{array}{l}\text { - Design Services Provider (District, Consultant, Other) }(6 / 29) \\
\text { - Transportation Management Class }(4 / 29) \\
\text { - Businesses/Homes to be taken }(10 / 29) \\
\text { - Railroad Involvement }(8 / 29) \\
\text { - Number of Bridges }(14 / 29) \\
\text { - Utility Conflicts or Relocation }(9 / 29) \\
\text { - Bike and Pedestrian Accommodations }(5 / 29) \\
\text { - Recoverable Slope Study }(9 / 29) \\
\text { - Value Engineering Study }(9 / 29) \\
\text { - Alternate Delivery Method }(5 / 29) \\
\end{array}$ \\
\hline Rarely Available & $\begin{array}{ll}\text { - } & \text { Wetlands Mitigation (3/29) } \\
\text { - } & \text { Memorandum of Agreement }(2 / 29) \\
\text { - } & \text { Bio Retention (water quality basins consideration) }(2 / 29) \\
\text { - } & \text { Required National History Preservation Study }(0 / 29) \\
\text { - } & \text { Hazmat Evaluation }(0 / 29) \\
\text { - } & \text { Alternate Designs Considered }(0 / 29) \\
\text { - } & \text { IRJ and or IMR }(0 / 29)\end{array}$ \\
\hline
\end{tabular}

$\mathrm{PE}=$ Preliminary Engineering RW =Right-of-Way ; CN = Construction ; IJR =Interchange Justification Report ; IMR =Interchange Modification Report .

a- Numbers in parentheses indicate the number of projects with the characteristic and total number of projects respectively; 25/29 projects had environmental work noted, 4 had N/A recorded.

b - Of the 29 projects evaluated, 25 had a specific type of environmental work in the Project Pool. Five had an EA, 11 a CE, 9 a Programmatic CE, and 4 N/A.

${ }^{c}$-PE estimates were mostly below \$1 million; however, the PE estimates for three were over \$1 million. PE phases were mostly around 4 years but for one case was 12 years.

d -Of the selected projects, the Bristol District had 16 active; 7 inactive, and 6 archived. For 11 projects, nothing had been uploaded to the Project Pool; therefore, only the general information was recorded. 